\title{
WestVirginiaUniversity
}

THE RESEARCH REPOSITORY @ WVU

Graduate Theses, Dissertations, and Problem Reports

2021

\section{Asymmetry Risk And Asset Pricing}

Jiahao Gu

West Virginia University

Follow this and additional works at: https://researchrepository.wvu.edu/etd

Part of the Finance and Financial Management Commons

\section{Recommended Citation}

Gu, Jiahao, "Asymmetry Risk And Asset Pricing" (2021). Graduate Theses, Dissertations, and Problem Reports. 10292.

https://researchrepository.wvu.edu/etd/10292

This Dissertation is protected by copyright and/or related rights. It has been brought to you by the The Research Repository @ WVU with permission from the rights-holder(s). You are free to use this Dissertation in any way that is permitted by the copyright and related rights legislation that applies to your use. For other uses you must obtain permission from the rights-holder(s) directly, unless additional rights are indicated by a Creative Commons license in the record and/ or on the work itself. This Dissertation has been accepted for inclusion in WVU Graduate Theses, Dissertations, and Problem Reports collection by an authorized administrator of The Research Repository @ WVU.

For more information, please contact researchrepository@mail.wvu.edu. 


\title{
Asymmetry Risk and Asset Pricing
}

\author{
Jiahao Gu \\ Dissertation submitted \\ to the John Chambers College of Business and Economics \\ at West Virginia University \\ in partial fulfillment of the requirements for the degree of \\ Doctor of Philosophy in Business Administration \\ Concentration in Finance \\ K. Victor Chow, Ph.D., Chair \\ Naomi Boyd, Ph.D. \\ Alexander Kurov, Ph.D. \\ Ann Marie Hibbert, Ph.D. \\ Feng Yao, Ph.D. \\ Department of Finance
}

Morgantown, West Virginia

2021

Keywords: Asymmetry risk, Asymmetry beta, AVIX, Implied Beta, Implied Equity Premium, Risk Indifference Curve, SVIX, Tail Risk, VIX, Volatility-asymmetries

Copyright 2021 Jiahao Gu 


\section{ABSTRACT \\ Asymmetry Risk and Asset Pricing}

\section{Jiahao Gu}

The dissertation primarily focuses on asymmetry risk and its role in asset pricing. Asymmetry risk is a crucial component of systematic risk. However, it does not attract much attention, probably because of the misconception that it is similar to other asymmetry measures (e.g., skewness). Chapter 1 defines the asymmetry risk. The risk indifference curve (RIC) predicts two asymmetry premiums in the return distribution rather than one in the downside. I also derive the risk-neutral measure of asymmetry risk.

Chapter 2 empirically investigates the asymmetry beta's return predictability and tail risk hedging ability. Consistent with the risk indifference curve, the asymmetry beta exhibits significant explanation and prediction power for equity risk premiums of US stocks. In addition, low asymmetry beta stocks provide a more effective hedge against crashing markets.

Chapter 3 develops the implied market beta based on the risk-neutral measure of the asymmetry risk. The implied market beta is a superior measure of ex-ante beta in that it possesses significant return predictability and hedging ability. The investible option-implied market portfolio built on the implied market beta outperforms the value-weighted market portfolio with better risk-adjusted performance and less downside risk.

Overall, the asymmetry risk is a non-negligible systematic risk factor for the market index and individual stocks in physical probability and risk-neutral spaces: the asymmetry beta and $\mathrm{AVIX}^{2}$ own strong return predictability and powerful hedging ability in crashing markets. These results are robust to the risk factors documented in the previous literature. 


\section{DEDICATION}

To my wife and son, Miaomiao Sun and Hardy $\mathrm{Gu}$, for their support and understanding throughout my study at West Virginia University. I would also like to thank my parents, Yilin $\mathrm{Gu}$ and Youhua Zhou, for raising me and my parents-in-law, Jianning Sun and Ruidi Shi, for their care and help. 


\section{ACKNOWLEDGMENTS}

I am greatly indebted to my advisor Dr. K. Victor Chow, for his patience and support throughout my studies at John Chambers College of Business and Economics at West Virginia University. I would like to especially thank Dr. Naomi Boyd, Dr. Alexander Kurov, Dr. Ann Marie Hibbert, Dr. Feng Yao, Dr. Bingxin Li, Dr. Gulnara Zaynutdinova, and Dr. Jonathan Fluharty for their comments and suggestions. I also thank my colleagues for many helpful discussions and suggestions. 


\section{Table of Contents}

Chapter 1 The Economic Theory of Asymmetry risk ........................................................... 1

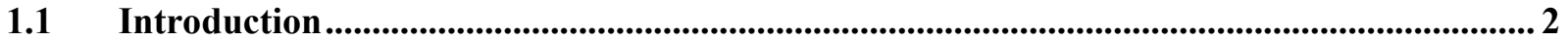

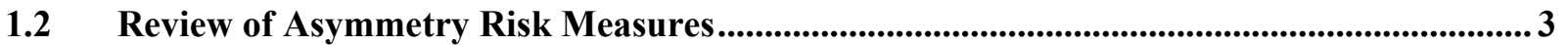

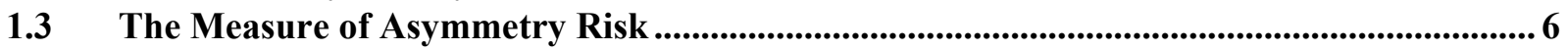

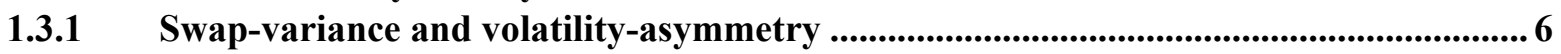

1.3.2 The expected utility with volatility-asymmetry ..................................................................... 7

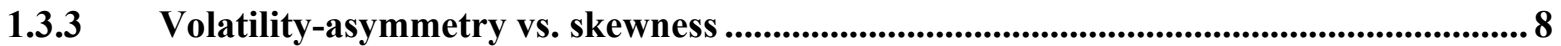

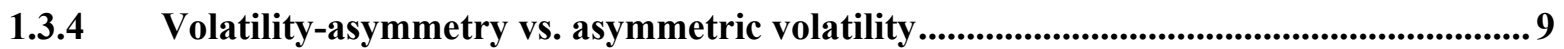

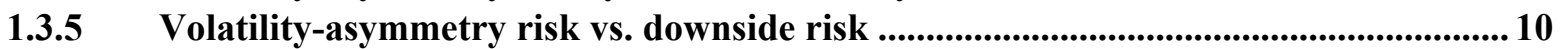

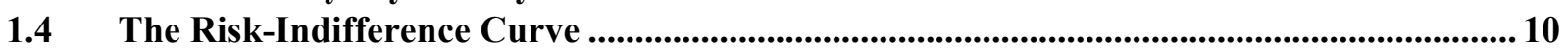

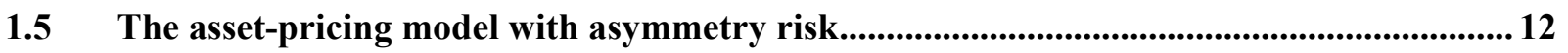

1.6 The Risk-neutral Asymmetry Risk.......................................................................................... 14

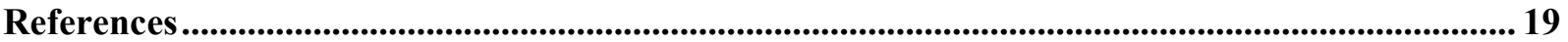

Chapter 2. Asymmetry Beta: Return Predictability and Tail Risk Hedging Ability .......... 21

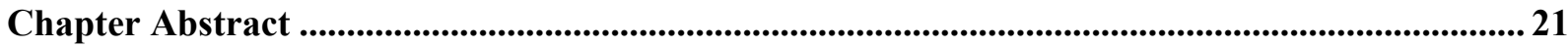

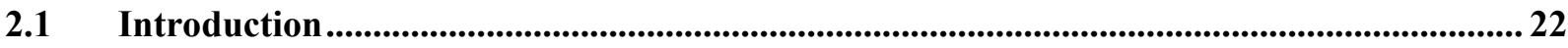

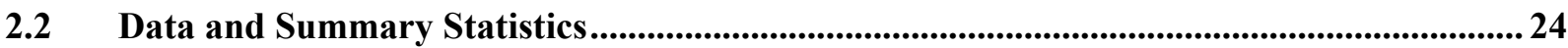

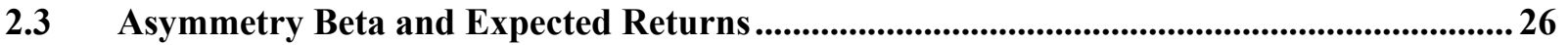

2.3.1 The cross-sectional test for VASY and SKEW ............................................................ 27

2.3.2 The cross-sectional test for coasymmetry and coskewness............................................29

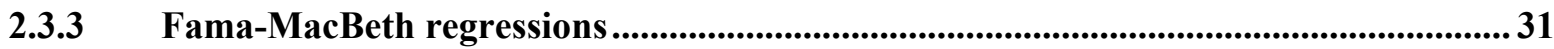

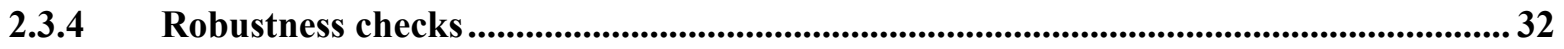

2.4 Empirical Properties of Asymmetry Premium............................................................................. 34

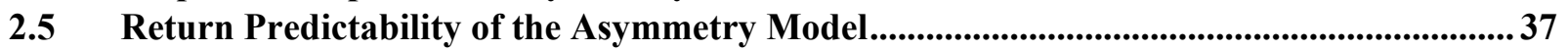

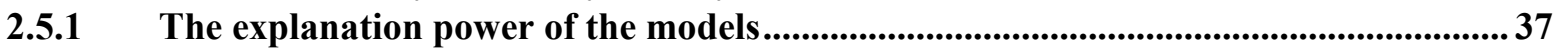

2.5.2 The Predictability of the Models...............................................................................39

2.6 The Hedging Ability of the Asymmetry beta ................................................................................. 40

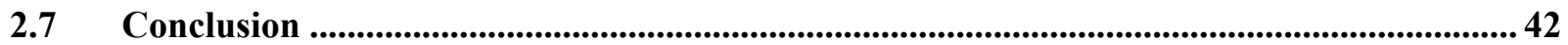

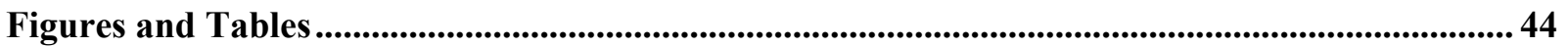

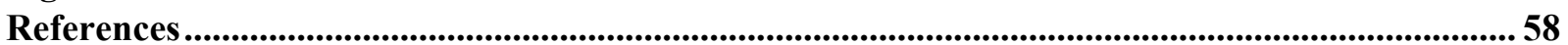

Chapter 3. Implied Equity Premium and Market Beta .................................................. 61

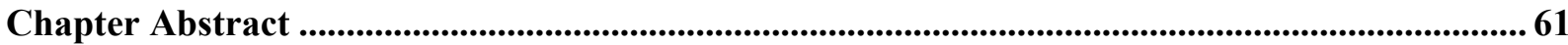

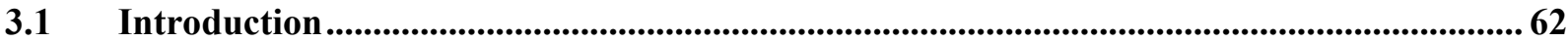

3.2 Risk Neutral Volatility-Asymmetry and Equity Premium..................................................68

3.2.1 Implied volatility with asymmetries in return ........................................................6.69

3.2.2 Volatility-asymmetry and implied equity premium............................................................ 72

3.3 Theory of Implied Market Beta ....................................................................................................... 75

3.3.1 The SHMGV and Implied Volatility-Asymmetry …....................................................76

3.3.2 Implied Risk Premium and Market Beta of Individual Equity .................................. 79

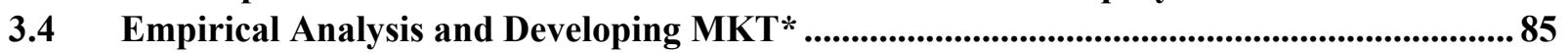

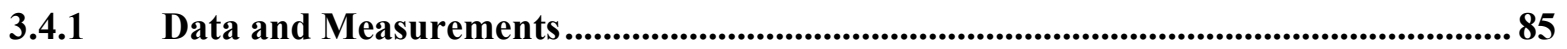

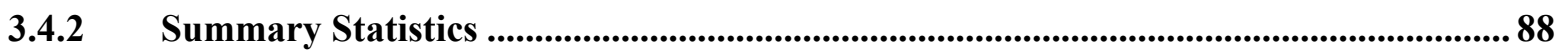

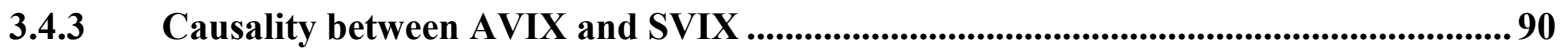


3.4.4 Mimicking Portfolio of Implied Market Index, MKT* ....................................................92

3.4.5 Pricing effectiveness of the implied market model......................................................96

3.4.6 Hedging ability of MKT* beta against bear/crashing markets......................................99

3.4.7 Fama-Macbeth Regressions ................................................................................. 100

3.4.8 Comparative analysis of AVIX-Beta vs. alternative implied and realized betas....... 102

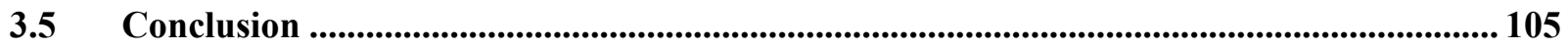

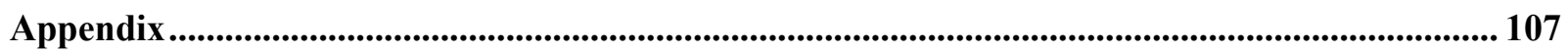

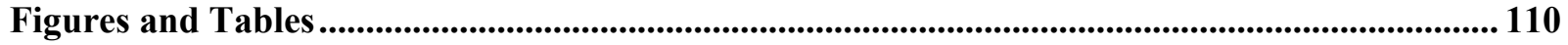

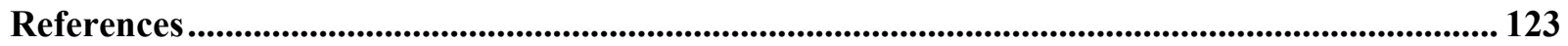


Chapter 1 The Economic Theory of Asymmetry risk 


\subsection{Introduction}

Facing risk and uncertainty, in addition to the expectation of price fluctuation, the prospect of potential investment gain vs. loss is critical for investors' decision-making. The lopsided anticipation of gain/loss induces the asymmetries in return volatility. We develop an economic theory of asymmetry risk incorporated with the classical paradigm of expected utility maximization based on a novel approach for measuring volatility-asymmetries In equilibrium, the market asymmetry risk and the variance of market returns are necessary deterministic components for the formation of equity risk premium. By extending the mean-variance (MV) analysis to a three-dimensional mean-variance-asymmetry (MVA) framework, the model complements the lack of traditional CAPM in pricing assets with asymmetric return distribution.

The attitude of investors toward asymmetric uncertainty of investment payouts is different between the upside and the downside. Conventionally, since potential gains are always preferable so that risk-averse investors could ignore the return variation from the upside, most studies thus focus on the (asymmetric) risk exposure primarily on the below target (lower partial) return distribution. ${ }^{1}$ We argue that risk-averse investors would consider both potential gain and loss when making their investment decision, and one needs to examine the entire return distribution for investment analysis. Although investors like the potential (significant) gain from an investment, the volatility-asymmetry induced by the prospective upside payouts results in additional uncertainty that investors dislike. Thus, the increased uncertainty associated with

\footnotetext{
${ }^{1}$ As early as the 1950s, Roy (1952) and Markowitz (1959) had recognized risk as asymmetric where the safety-first attitude toward downside risk could be more critical than the speculation of upside gains.
} 
higher potential gains is also a risk factor that risk-averse investors should not ignore. This argument is striking but highly intuitive.

Instead of truncating return distribution between upside and downside, we can decompose the volatility between symmetry and asymmetries. If investors are risk-averse, then the risk tradeoff between symmetry (from the expected price fluctuation) and asymmetries (by the potential gain/loss) must critically influence their investment preference and choice.

The asymmetry risk from the decomposition has different characteristics from skewness and other higher-order moments. It is also distinct from asymmetric volatility and downside risk. From a notion of risk-indifference curve that depicts the tradeoff, the marginal substitution of volatility-tolerance for gain/loss diminishes as the magnitude of gain/loss increases. Consequently, investors would require an excess return to compensate for taking an additional risk from the rise in volatility associated with asymmetric payoffs from either the downside or upside potential.

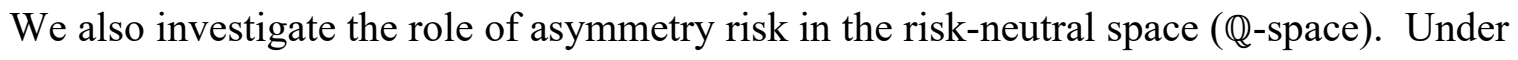
certain conditions, the risk-neutral asymmetry risk complements the negative correlation condition (NCC) in Martin (2017) and thus produces a tight estimation bound to the ex-ante equity risk premium.

\subsection{Review of Asymmetry Risk Measures}

The theory of asymmetry risk results from the early recognition of Roy (1952) and Markowitz (1959) that the (symmetric) mean-variance beta provides poor hedge measures in subsequent downtrend markets and low predicting power of future returns. According to 
Markowitz (1952), the mean-variance approach is valid when investors expect a symmetric return distribution in the long term, or investors' utility functions are quadratic ${ }^{2}$. However, CAPM faces challenges because of the inconsistent empirical results obtained by many researchers. One well-known finding is the beta-anomaly puzzle ${ }^{3}$.

The assumption of symmetric return distribution and quadratic utility function may be unreasonable if investors are not perfectly rational ${ }^{4}$, so they may consider other characteristics other than the variance in making investment decisions, especially in the short run. Barro (2006) investigates the rare economic disasters from global history in the twentieth century and concludes that the disasters can explain the equity risk premium puzzle. Liu et al. (2003) study the event risk and find that the potential large loss from a jump in price causes investors to choose a very different optimal portfolio compared to that from the mean-variance analysis, even if the probability of the loss is very small.

As a response to the problematic nature of the mean-variance framework, some researchers focus on the partial or below target return distribution because investors prefer reducing losses to enhancing gains. Markowitz suggests using semi-variance, defined as the average squared deviation below the mean ${ }^{5}$. Harlow and Rao (1989) provide the generalized mean-lower partial moment framework. Ang, Chen, and Xing (2006) show that stocks with higher down beta have high average returns. The down beta only includes the covariance when the excess market return is below its mean. The ignorance of the above target return distribution

\footnotetext{
${ }^{2}$ Martin (2017) shows that the mean-variance approach is also valid if the absolute risk aversion equals 1.

${ }^{3}$ See Friend and Blume (1970, 1973), Black et al. (1972), Fama and MacBeth (1973), Reinganum (1981), Stambaugh (1982), Lakonishok and Shapiro (1986), Fama and French (1992), and Frazzini and Pedersen (2014).

${ }^{4}$ Starting from Mandelbrot (1963) and Fama (1963), there is considerable evidence that asset returns are non-normal. Cont (2001) and Premaratne and Bera (2005) found that the return distribution is also asymmetric, as large losses are more likely to occur than equally large gains.

${ }^{5}$ See also Jahankhani (1976), Bawa and Lindenberg (1977), Menezes, Geiss, and Tressler (1980).
} 
may cause biased risky estimates, particularly for the multi-period estimation, due to incomplete information of probabilities.

Other empirical findings show that higher-order moments play an essential role in asset pricing $^{6}$. For example, Harvey and Siddique (2000) demonstrate that under a quadratic pricing kernel, conditional skewness explains the cross-sectional variation in expected returns across assets. Dittmar (2002) extends the pricing kernel to be a cubic in the market return and shows that asset returns are affected by covariance, co-skewness, and co-kurtosis with return on aggregate wealth. Although the finite higher moment models consider the whole range of returns, they are insufficient to catch the entire return distribution without assumptions. Another potential problem with moment-based portfolio selection is that the moments may be undefined or infinite (See Chung et al., 2006).

Unlike the above methods, a better way to measure asymmetry risk is to decompose the systematic risk of risky assets into symmetric and asymmetric components. Based on the novel swap-variance $(\mathrm{SWV})^{7}$, we can break down the systematic risk into covariance and coasymmetry. Chapter 2 shows that the asymmetry beta, calculated as the ratio of coasymmetry over the whole market asymmetry, is a superior measure to others.

The benefit for the decomposition is that it can ideally quantify the expected utility without any assumption on the utility function or the return distribution. Take the VIX, a generally accepted index for market volatility. For example, it is asymmetric in that its

\footnotetext{
${ }^{6}$ See also Fang and Lai (1997), Vendrame, Tucker, and Guermat (2016).

${ }^{7}$ Swap-variance is defined as twice the expected difference between arithmetic and logarithmic returns centralized by the mean. Chow, Sopranzetti, \& Wang (2020) show that SWV is a convergence of the weighted sum of infinite moments starting from the second order.
} 
formulation mathematically equivalents a polynomial combination of all ex-ante distributional moments on returns. Therefore, the asymmetry risk plays an essential role in asset pricing.

\subsection{The Measure of Asymmetry Risk}

Under the expected utility maximization framework, the risk is measured as a probability-weighted function of the dispersions, defined as the differences between potential gains/losses and the expected return. Chamberlin (1983) and Meyer (1987) show that the MV model is consistent with the utility theory if the return distribution is elliptically symmetric. We need an infinite number of higher-order moments beyond mean and variance to specify the tails precisely. Hence, traditional risk measures, such as variance, skewness, and kurtosis, have limitations in capturing the asymmetry in return distribution.

\subsubsection{Swap-variance and volatility-asymmetry}

Let $R$ be the one-period rate of return, and $r=\ln (1+R)$ be the log-return. The infinite degree polynomial of return centered on zero converge to $2(R-r)$.

$$
2(R-r)=R^{2}+\left[\sum_{k=3}^{\infty}(-1)^{k}\left(\frac{2}{k}\right) R^{k}\right] \geq 0
$$

The swap-variance (SWV) is defined as twice the expected value of the left side in Equation (1) when $R$ is centered on the mean $\mu$. It is a convergence of the weighted sum of infinite moments starting from the second order, as is shown in Equation (2).

$$
\begin{aligned}
\mathrm{SWV} & =2[E(R-r)-d \mu] \\
& =\frac{\mathrm{VAR}}{(1+\mu)^{2}}+\left[\sum_{k=3}^{\infty}(-1)^{k}\left(\frac{2}{k}\right) \frac{E(R-\mu)^{k}}{(1+\mu)^{k}}\right] \geq 0
\end{aligned}
$$

where VAR represents the variance of the return. 
Since variance describe the symmetric return distribution, the difference between SWV and variance represents the volatility-asymmetry, denotes VASY, as is shown in Equation (3).

$$
\mathrm{VASY}=\mathrm{SWV}-\frac{\mathrm{VAR}}{(1+\mu)^{2}}=\sum_{k=3}^{\infty}(-1)^{k}\left(\frac{2}{k}\right) \frac{E(R-\mu)^{k}}{(1+\mu)^{k}}
$$

The distribution with upside asymmetry has an SWV smaller than variance, and VASY is negative. On the other hand, VASY is positive when the return distribution has a downside asymmetry. This is consistent with the findings from previous research that volatility increases when the stock market drops significantly ${ }^{8}$. For an illustration, we plot three functions of return (assuming $\mu=0), 2(R-r), R^{2}$, and $\mathcal{A}=2(R-r)-R^{2}$ in Figure 1.1.

[Insert Figure 1.1 here]

\subsubsection{The expected utility with volatility-asymmetry}

From Equation (1), the Taylor's linear expansion of the utility function can be characterized by three variables, $R-\mu$, symmetry $S$, and volatility-asymmetry $\mathbb{A}$, for all investors.

$$
U(R)=U(\mu)+U^{\prime}(\mu) \cdot(R-\mu)+\frac{1}{2} U^{\prime \prime}(\mu) \cdot S+\mathbb{U}^{(3)}(U, \mu, R) \cdot \mathbb{A}
$$

where $S=(R-\mu)^{2}, \mathbb{A}=[2(R-r)-2 d \mu]-\left(\frac{R-\mu}{1+\mu}\right)^{2}$ where $d \mu=\mu-\ln (1+\mu), \mathbb{U}^{(3)}(U, \mu, R)=$ $\sum_{k=3}^{\infty} \omega_{k} \Psi^{(k)} \leq 0$ if $U^{\prime \prime \prime}(R) \geq 0, \Psi^{(k)}=\left[\frac{[-(1+\mu)]^{k}}{2(k-1) !} U^{(k)}(\mu)\right]$, and $\omega_{k}=\left[\frac{2(-1)^{k}}{k}\left(\frac{R-\mu}{1+\mu}\right)^{k}\right] / \mathbb{A}$, respectively.

\footnotetext{
${ }^{8}$ For example, see Black (1976), Bekaert and Wu (2000), Avramov, et al. (2006).
} 
In Equation (4), $\mathbb{U}^{(3)}$ represents the aversion (preference) function for the downside asymmetric loss (upside asymmetric gain), and a non-negative $U^{\prime \prime \prime}$ is consistent with Arditti (1967), who shows that investors are willing to accept a lower expected return from an investment with positive skewness of returns and the same variance. Consequently, $\mathbb{U}^{(3)}$ is nonpositive implies that the greater the impact of downside (upside) asymmetry, the more positive (negative) the value of $\mathcal{A}$, and the lower (higher) the utility.

Based on Equations (2) and taking the expected value of both sides in Equation (4), the expected utility of all investors can be determined by three statistics, $\mu$, VAR, and VASY. The more negative (positive) is VASY, the higher (lower) the expected utility.

$$
E U(R)=U(\mu)+\frac{1}{2} U^{\prime \prime}(\mu) \cdot \operatorname{VAR}+\mathbb{U}^{(3)}\left(U, \mu, R^{*}\right) \cdot \mathrm{VASY}
$$

\subsubsection{Volatility-asymmetry vs. skewness}

Skewness has attracted widespread attention as a proxy for asymmetry in investment theory and asset pricing. Tversky and Kahneman (1992) and Barberis and Huang (2008) argue that stocks with positive skewness are associated with a lower expected return. However, Bali, Engle, and Murray (2016) show that the empirical evidence on the impact of skewness on crosssectional stock returns is mixed and inconclusive. More recently, Jondeau, Zhang \& Zhu (2019) found that average monthly skewness across firms predicts future market returns well.

VASY is distinct from skewness in two ways. First, skewness is the ratio of the thirdorder moment with the variance. As moments are highly correlated, skewness may be overestimated (underestimated) due to very low (high) variance and misleading portfolio selection results. On the contrary, VASY is hard to be overvalued (or undervalued) as it is the difference (not the ratio) between higher-order moments and the variance. Second, skewness can 
only tell whether the distribution has a left tail or a right tail from the sign, but it cannot reflect the risk level from the magnitude. VASY can do both. This can be seen from the following example. The skewness of the first two distributions is very close but the volatility-asymmetry of the second distribution is about 2.5 times that of the first one. The first and the third return distributions have precisely the opposite outcomes, but the volatility-asymmetry of the third distribution is much smaller because of more upside gains.

\begin{tabular}{rrrrrrrrrr}
\multicolumn{3}{c}{ Return Distributions only differ on sign } & & & Mean & VAR & VASY & SKEW \\
\hline$-40 \%$ & $-20 \%$ & $-10 \%$ & $0 \%$ & $10 \%$ & & $-12 \%$ & $3.7 \%$ & $0.37 \%$ & -0.35 \\
$-50 \%$ & $-25 \%$ & $-15 \%$ & $0 \%$ & $10 \%$ & & $-16 \%$ & $5.4 \%$ & $0.90 \%$ & -0.36 \\
$40 \%$ & $20 \%$ & $10 \%$ & $0 \%$ & $-10 \%$ & & $12 \%$ & $3.7 \%$ & $-0.04 \%$ & 0.35 \\
\hline
\end{tabular}

Hence, even though the other higher-order moments are zero, VASY is expected to outperform skewness by carrying more information on the asymmetry risk. I test this hypothesis in Chapter 2.

\subsubsection{Volatility-asymmetry vs. asymmetric volatility}

Many research articles have empirically documented the asymmetric volatility, focusing on the causality of the phenomenon. The hypothesis of leverage-effect proposed by Black (1976), Christie (1982), and Schwert (1989) suggests a drop in the value of the stock increases financial leverage, which makes the stock riskier and increases its volatility. More recent explanations address the effect of volatility feedback (Bekaert and $\mathrm{Wu}, 2000)$ and the inference of behavioral preferences (Shefrin, 2005; Avramov et al., 2006; Talpsepp and Rieger, 2010; Dzieliński et al. 2018). As a comparison, the volatility-asymmetry is derived from the utility function. As a result, the volatility-asymmetry provides the theoretical base of the asymmetric volatility observed in the market, and it is different from the above two sources of asymmetric volatility. 


\subsubsection{Volatility-asymmetry risk vs. downside risk}

The asymmetry risk is different from the downside risk explored by many researchers in two ways. Firstly, downside risk mainly focused on the partial or below target returns. Roy (1952) is the first to recommend using the safety-first rule in portfolio selection. Other measures include semi-variance, lower-partial-moments (see Bawa \& Lindenberg 1977, and Harlow \& Rao 1989), and down beta (Ang et al. 2006). The ignorance of the target return distribution may cause biased risky estimates as it is unclear whether these downside risk measures are consistent with the utility theory. Secondly, as is presented in the following section, the utility-tradeoff between variance and volatility-asymmetry indicates that investors have a diminishing marginal rate of risk tolerance substation. Hence, they require higher excess returns from both sides of asymmetry (rather than the downside alone).

\subsection{The Risk-Indifference Curve}

Equation (5) highlights the utility-tradeoff between variance and volatility-asymmetries. Given the same level of mean return and expected utility, investors are willing to take a more (less) symmetric risk (measured by VAR) for risky assets with more upside (downside) asymmetry. More importantly, the marginal rate of risk tolerance substitution between symmetry risk and asymmetry risk diminishes due to decreasing prudence. Kimball (1990) shows that reducing absolute risk-aversion results in decreasing absolute prudence measured by

$-\frac{U^{\prime \prime \prime}}{U^{\prime \prime}}$. We use a more generalized measure of prudence $\left(\frac{\mathbb{U}^{(3)}}{U^{\prime \prime}}\right)$ and show that prudence is positively related to VASY. Hence, the marginal rate of risk tolerance substitution for 
asymmetric payoffs decreases as either the downside asymmetry (potential loss) or the upside asymmetry (potential gain) increases. The utility-tradeoff between VAR and VASY results in a concave risk-indifference curve, as is illustrated in Figure 2.

[Insert Figure 1.2 here]

The risk-indifference curve illustrates the different risk-tolerance levels towards the symmetric variation of returns (VAR) versus asymmetric gains or losses (VASY). Every point on the curve has the same level of expected utility. The shape of the risk-indifference curve is concave and downward sloping, which is consistent with the negative relation between VAR and VASY and the diminishing marginal rate of risk tolerance substitution.

In Equation (3), VAR and VASY also have a linear relationship given the same level of SWV. In other words, for two assets with the same level of total risk, investors will require a higher expected return for one with more asymmetry in either upside or downside to compensate for the utility loss resulting from the diminishing marginal rate of risk tolerance. To illustrate, in Figure 2 , assets $i, j$, and $k$ are located on the same $\mathrm{RCL}_{1}$ line so they have the same level of total risk. However, the investor will not accept assets $i$ or $k$ (compared to $j$ ) because they are inferior to assets $i^{\prime}$ and $k^{\prime}$ according to their risk-indifference curve, respectively. Explicitly, the figure indicates a utility reduction would occur if one were to substitute the symmetry asset $j$ with the asymmetry assets $i$ or $k$. Therefore, if the investor were to invest in asset $i$, their utility would drop down to the less desirable $\mathrm{RIC}_{2}$. Realize that the corresponding $\mathrm{RC}_{2}$ line to the $\mathrm{RI}_{2}$ curve has a higher risk level than the $\mathrm{RCL}_{1}$, and the tangent point $j^{\prime}$ between the $\mathrm{RIC}_{2}$ line and the $\mathrm{RCL}_{2}$ curve represents the symmetry-equivalent asset of $i$ in the risk-return tradeoff for expected utility-maximizing investors. 
Back to Figure 2, the symmetry-equivalent asset of $i$ under risk-aversion (the asset $j^{\prime}$ ) has a higher volatility than that under risk-neutrality (the asset $j$ ). Thus, $j^{\prime}$ has a higher expected return than $j$. Therefore, the excess return of $j^{\prime}$ over $j$ is the precautionary premium of asset $i$ required by investors to compensate for the potential disappointment of taking excess volatility from chasing the rewards associated with asymmetry from the upside tail of the return distribution. We characterize this precaution premium as the (upside) asymmetry risk premium. One can apply similar logic to the asset $k$ and determine the premium for downside asymmetry. Intuitively, the precaution premium of downside asymmetry is associated with the aversion (fear) of losses on the downside. Investors reduce their tolerance of volatility if the distribution of returns on investment is asymmetric toward the downside - for example, assets $k$ vs. $k^{\prime}$ in Figure 2. Therefore, for investors to accept asset $k$, they will require additional returns (the downside asymmetry risk premium) to compensate for their fear of potential losses from the downside asymmetry of the return distribution. The excess return of the symmetry-equivalent asset over the asset characterizes the asymmetry risk premium.

\subsection{The asset-pricing model with asymmetry risk}

In previous sections, we discuss asymmetry risk for individual assets and their relation to the expected utility. As the three statistics mean-variance-VASY can ideally quantify the expected utility, we review the asset-pricing model with asymmetry risk in this section.

In the mean-variance framework, the covariance between individual stock returns and market return represents stocks' contribution to the market variance. Similarly, the coasymmetry (COVASY in Equation 6) of individual stocks contributes to market asymmetry risk. 


$$
\begin{aligned}
\operatorname{Covasy}\left(R_{i}, R_{P}\right) & =\operatorname{CoswV}\left(R_{i}, R_{P}\right)-\frac{\operatorname{Cov}\left(R_{i}, R_{P}\right)}{\left(1+\mu_{P}\right)^{2}} \\
& =\sum_{k=3}^{\infty}(-1)^{k}\left(\frac{2}{k}\right) \frac{\operatorname{CoM}^{k}\left(R_{i}, R_{P}\right)}{\left(1+\mu_{P}\right)^{k}}
\end{aligned}
$$

where $\operatorname{COM}^{k}\left(R_{i}, R_{P}\right)=E\left[\left(R_{i}-\mu_{i}\right)\left(R_{P}-\mu_{P}\right)^{k-1}\right]$ is the $k$ th order co-moments 9

Equations (6) imply that coasymmetry is another non-negligible component of the systematic risk. In other words, the covariance and coasymmetry jointly characterize the systematic risk by capturing the symmetric volatility and asymmetric prospect gain/loss, respectively. Hence, the market's equity risk premium includes the risk premiums from taking the market symmetry risk (measured by variance) and the market asymmetry risk (measured by VASY).

The equity risk premium of individual assets can be estimated from a conditional twofactor model (depending on the asset's asymmetry beta) as is shown in Equation (7), where DASY (UASY) is the factor price of downside (upside) market asymmetry risk. MKT is the factor price of the market symmetry risk $^{10} \cdot b_{i}^{\text {CAPM }}$ is the CAPM beta, and $b_{i}^{\text {DASY }}\left(b_{i}^{\text {UASY }}\right)$ represents the downside (upside) asymmetry beta.

$$
E\left[R_{i}-R_{f}\right]=b_{i}^{\mathrm{CAPM}} \cdot \mathrm{MKT}+b_{i}^{\mathrm{DASY}} \cdot \mathrm{DASY}+b_{i}^{\mathrm{UASY}} \cdot \mathrm{UASY}
$$

In Equation (7), the asymmetry betas can be estimated from Equation (8.2) and Equation (8.3), where $R_{M}$ is the market return, $\operatorname{COVASY}\left(R_{i}, R_{M}\right)$ is the coasymmetry with the market, $I_{i}^{\text {COVASY }}$ is an indicator variable that equals one if the coasymmetry is positive and zero

\footnotetext{
${ }^{9}$ According to Chow, Sopranzetti, \& Wang (2020) $\operatorname{CosWV}\left(R_{i}, R_{P}\right)=2 E\left[\left(\frac{R_{i}-\mu_{i}}{R_{p}-\mu_{p}}\right)\left(R_{p}-r_{p}\right)\right]-2 d \mu_{p}$, where $d \mu_{p}=\mu_{p}-\ln \left(1+\mu_{p}\right)$.

${ }^{10}$ For the details of deriving Equations (7) and (8). See Chow, Sopranzetti, \& Wang (2020).
} 
otherwise. $V A S Y_{\mathrm{M}}^{d}\left(V A S Y_{\mathrm{M}}^{u}\right)$ represents the positive (negative) component of the market asymmetry and is equal to the summation of all positive (negative) coasymmetries.

By definition, the asymmetry betas on both sides are always non-negative, and only one asymmetry beta is associated with each stock. The asymmetry beta cannot be negative because it measures asymmetry risk. Stocks that have a positive (negative) coasymmetry with the market have a(n) downside (upside) asymmetry beta.

$$
\begin{gathered}
\hat{b}_{i}^{\mathrm{CAPM}}=\frac{\operatorname{COV}\left(R_{i}, R_{M}\right)}{\sigma_{M}^{2}} \\
\hat{b}_{i}^{\mathrm{DASY}}=\frac{\operatorname{COVASY}\left(R_{i}, R_{M}\right) \cdot I_{i}^{\mathrm{COVASY}}}{V A S Y_{\mathrm{M}}^{d}} \\
\hat{b}_{i}^{\mathrm{UASY}}=\frac{\operatorname{COVASY}\left(R_{i}, R_{M}\right) \cdot\left(1-I_{i}^{\mathrm{COVASY}}\right)}{V A S Y_{\mathrm{M}}^{u}}
\end{gathered}
$$

\subsection{The Risk-neutral Asymmetry Risk}

Martin (2017) shows that the option-implied variance is the lower bound of the ex-ante equity risk premium.

$$
\mathbb{E}_{t}\left[R_{M, t+1}-R_{f, t}\right]=\left(1+R_{f, t}\right) \operatorname{SVIX}_{t}^{2}-\mathrm{NCC}_{M, t}
$$

where SVIX ${ }_{t}^{2}$ is a proxy for risk-neutral variance and $\mathrm{NCC}_{M, t}$ denotes the negative correlation condition. Martin (2017) demonstrates that $\mathrm{NCC}_{M, t}$ is identically zero if investors have $\log$ utility (i.e., $\mathrm{CRRA}^{11}$ ), and therefore risk-neutral variance perfectly describes the ex-ante equity risk premium. However, when CRRA does not hold, we show that Equation (9) can still be used for ex-ante equity risk premium as $\mathrm{NCC}_{M, t}$ captures the risk-neutral volatility-asymmetry.

\footnotetext{
${ }^{11}$ CRRA represents constant relative risk aversion.
} 
The CBOE volatility index (VIX) also serves as a proxy of implied market volatility. Martin (2017) demonstrates that they are both adequate risk-neutral measures of return variability. The main difference is that VIX is more sensitive to the return distribution's left tail, whereas SVIX is more sensitive to the right tail. The implication is that VIX underestimates the upside's volatility, whereas SVIX undervalues that to the downside.

Mathematically, VIX ${ }^{2}$ is twice the risk-neutral expected difference between arithmetic and logarithmic returns. Letting $r_{t+1}=\ln \left(1+R_{t+1}\right)$ be the next-period log-return, we have

$$
\begin{aligned}
\operatorname{VIX}_{t}^{2} & =2 \mathbb{E}_{t}^{\mathbb{Q}}\left[R_{M, t+1}-r_{M, t+1}\right]=\mathbb{E}_{t}^{\mathbb{Q}}\left[R_{M, t+1}^{2}\right]+\sum_{k=3}^{K \rightarrow \infty} \frac{2(-1)^{k}}{k} \mathbb{E}_{t}^{\mathbb{Q}}\left[R_{M, t+1}^{k}\right] \\
& =2\left[\int_{0}^{F_{t, t+1}} \frac{P u t_{t, t+1}(K)}{K^{2}} d K+\int_{F_{t, t+1}}^{\infty} \frac{\operatorname{Call}_{t, t+1}(K)}{K^{2}} d K\right],
\end{aligned}
$$

Equivalently, VIX ${ }^{2}$ is an entropy with a mean zero. Note that the risk-neutral $(\mathbb{Q}$-space) mean-return for all risky assets is unique and equals the risk-free rate. Therefore, one can ignore the mean-return impact on estimating the return moments and centralize the $\mathbb{Q}$-space volatility calculation at zero without losing generality. We apply this notion simply to the risk-neutral variance as $\mathbb{E}_{t}^{\mathbb{Q}}\left[R_{t+1}^{2}\right]\left(=\operatorname{Var}_{t}^{\mathbb{Q}}\left[R_{t+1}\right]+R_{f, t}^{2}\right)$. Equation (10) then indicates that the difference between VIX ${ }^{2}$ and SVIX $^{2}$ captures the volatility-asymmetry characterized by the polynomial integration of third and infinite high-order (risk-neutral) distributional moments. In short, it is the volatility-asymmetry that makes VIX skewed toward the distribution's left tail, where SVIX is symmetric on both sides of the return distribution.

We now define the risk-neutral volatility-asymmetry in return (denoted by Asy) as follows: 


$$
A s y_{t}\left[R_{t+1}\right]=\mathbb{E}_{t}\left[2\left(R_{t+1}-r_{t+1}\right)-R_{t+1}^{2}\right]=\sum_{k=3}^{K \rightarrow \infty} \frac{2(-1)^{k}}{k} \mathbb{E}_{t}\left(R_{t+1}^{k}\right)
$$

Realizing that the $\mathbb{Q}$-space mean return is the risk-free rate, we have the risk-neutral estimate of the market volatility-asymmetry as follows:

$$
\begin{aligned}
\frac{A s y_{t}^{\mathbb{Q}}\left[R_{M, t+1}\right]}{1+R_{f, t}}= & \frac{\operatorname{VIX}_{t}^{2}}{1+R_{f, t}}-\left(1+R_{f, t}\right) \operatorname{SVIX}_{t}^{2}-\frac{R_{f, t}^{2}}{1+R_{f, t}} \\
= & \frac{2}{S_{t}^{2}} \int_{0}^{F_{t, t+1}}\left(\frac{S_{t}^{2}-K^{2}}{K^{2}}\right) \operatorname{Put}_{t, t+1}(K) d K \\
& -\frac{2}{S_{t}^{2}} \int_{F_{t, t+1}}^{\infty}\left(\frac{K^{2}-S_{t}^{2}}{K^{2}}\right) \operatorname{Call}_{t, t+1}(K) d K-\frac{S_{t}}{F_{t, t+1}}\left(\frac{F_{t, t+1}}{S_{t}}-1\right)^{2}
\end{aligned}
$$




\section{Figures and Tables}

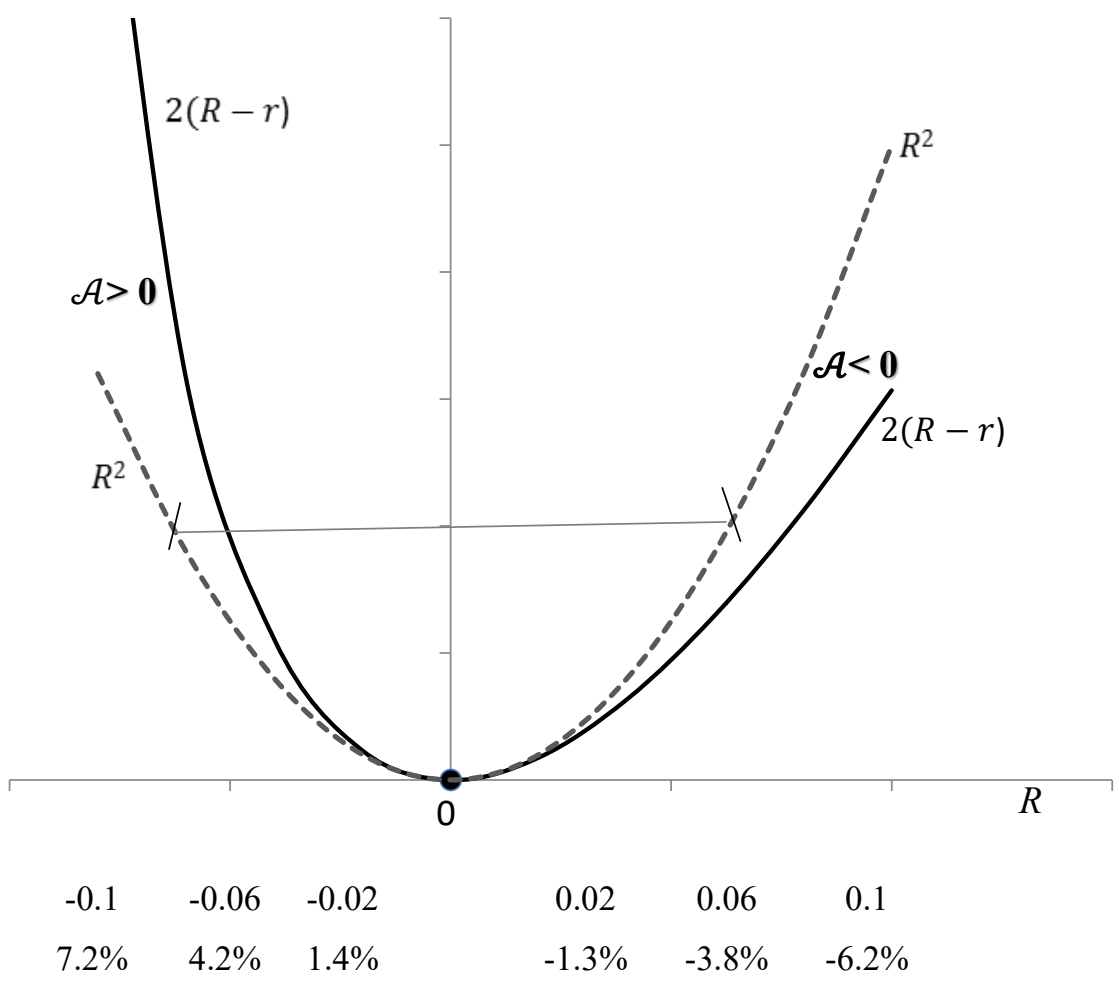

Figure 1.1 Variation-asymmetries in returns

This figure shows the measure of asymmetries in return variation, quantified by the difference between $2(R-r)$ and $R^{2}$, where $-1<R<1$, and $r=\ln (1+R)$. Since $2(R-r)=R^{2}+\left(\sum_{k=3}^{\infty} \frac{2}{k !} R^{k}\right)$, the variable $2(R-r)$ is asymmetric toward zero, but $R^{2}$ is symmetric to zero. Thus, their difference $\mathcal{A}=\left[2(R-r)-R^{2}\right]$ captures the magnitude of the impact of asymmetry on return variation, which has a negative (positive) value if $R$ is positive (negative). Alternatively, $\mathcal{A}$ represents the amount of deduction from (addition to) $R^{2}$ due to the upside (downside) asymmetries on return. Intuitively, $\mathcal{A}$ is resulted by either asymmetric downside losses or asymmetric upside gains. That implies the variance understates (overstates) the downside (upside) risk if returns are asymmetrically distributed. Also, this bias is more significant on the downside than that on the upside in that the rate of increase in $\% \Delta \mathcal{A}$ (percentage change of $\mathcal{A}$ ) as the return declines is faster than that of decrease in $\% \Delta \mathcal{A}$ as the return increases. 


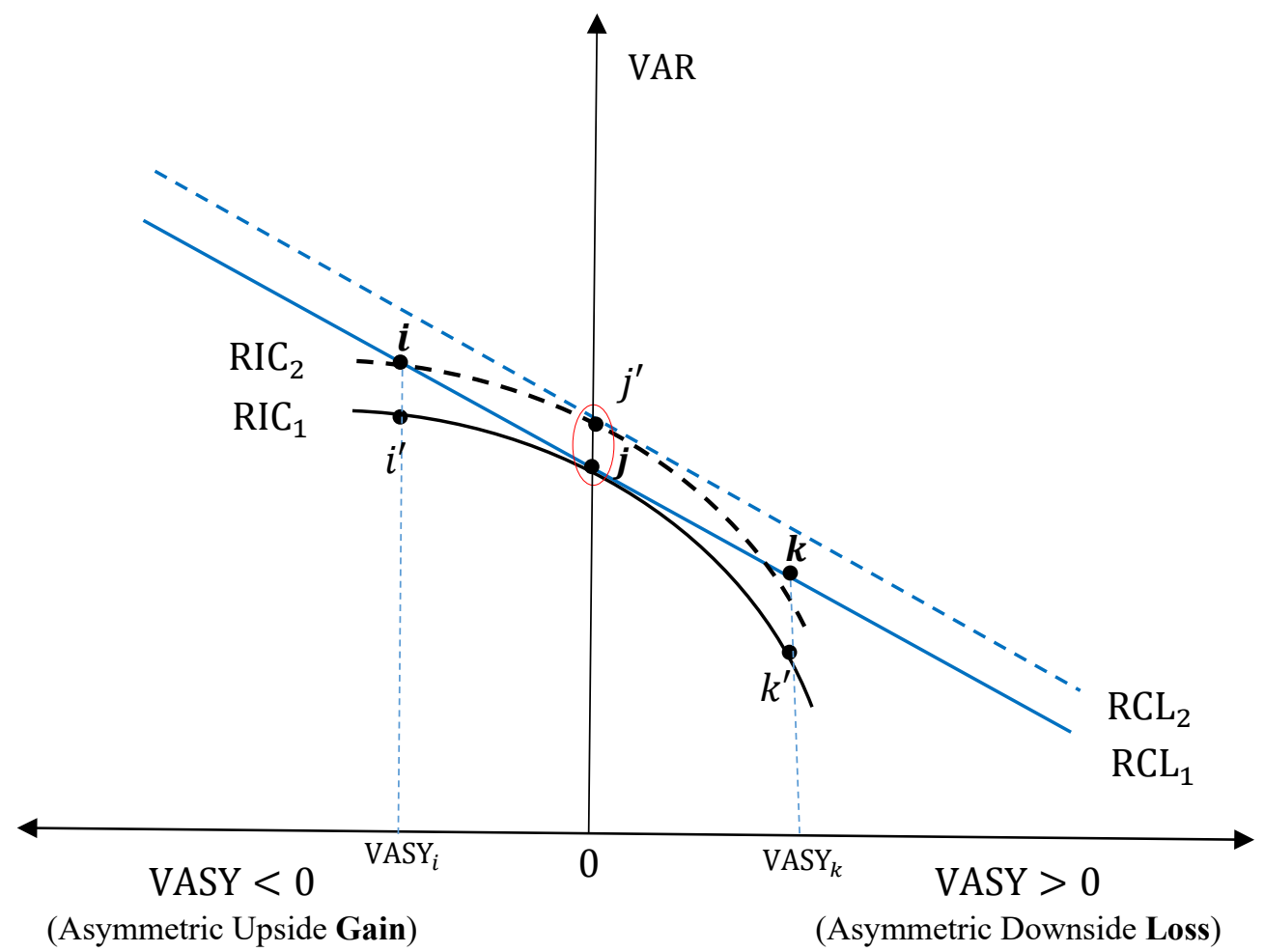

Figure 1.2 Risk-indifference Curve

This figure provides a geometric illustration where RIC is the risk-indifference curve, and the risk constraint line $(\mathrm{RCL})$ is $\mathrm{VAR}=(1+\mu)^{2}(\mathrm{SWV}-\mathrm{VASY})$, from Equation (2). The RCL represents a level of total risk (SWV), and the higher the RC line, the higher the associated expected return. The distinction of $\mathrm{RIC}_{2}$ from $\mathrm{RIC}_{1}$ captures the required excess return by the asymmetry on asset $i$. Specifically, the anticipated return-difference between $j^{\prime}$ and $j$ characters the risk premium of asymmetry on asset $i$ for compensating the loss of utility from $\mathrm{RIC}_{1}$ to $\mathrm{RIC}_{2}$ as well as the increase of risk (to be tolerated) from $\mathrm{RCL}_{1}$ to $\mathrm{RCL}_{2}$. Thus, security $j^{\prime}$ serves as the symmetry-equivalent asset of security $i$, and the return-difference between $j^{\prime}$ and $j$ characterizes the asymmetry risk premium of the asset $i$. Implicitly, one expects that investments with high return-asymmetry (either upside or downside) will earn higher average returns. 


\section{References}

Ang, A., Chen, J., \& Xing, Y. (2006). Downside risk. The Review of Financial Studies, 19, 1191-1239.

Arditti, F. D. (1967). Risk and the required return on equity. The Journal of Finance, 22(1), 19-36.

Avramov, D., Chordia, T., \& Goyal, A. (2006). The impact of trades on daily volatility. The Review of Financial Studies, 19(4), 1241-1277.

Barro, R. J. (2006). Rare disasters and asset markets in the twentieth century. The Quarterly Journal of Economics, 121(3), 823-866.

Bawa, V. S., \& Lindenberg, E. B. (1977). Capital market equilibrium in a mean-lower partial moment framework. Journal of Financial Economics, 5(2), 189-200.

Bekaert, G., \& Wu, G. (2000). Asymmetric volatility and risk in equity markets. The review of financial studies, 13(1), 1-42.

Black, F., (1976). Studies of Stock Price Volatility Changes,' Proceedings of the 1976 Meetings of the American Statistical Association, Business and Economical Statistics Section, 177

Chamberlain, G., Rothschild, M., (1983). Arbitrage, factor structure, and mean-variance analysis on large asset markets. Econometrica 51, 1

Chow, V., Sopranzetti, B. J., \& Wang, Z. (2020). Symmetry vs. Asymmetry, Stochastic Dominance Optimization, and The Impact on Capital Asset Pricing. SSRN.

Christie, A. A. (1982). The stochastic behavior of common stock variances: Value, leverage and interest rate effects. Journal of Financial Economics, 10(4), 407-432.

Chung, Y. P., Johnson, H., \& Schill, M. J. (2006). Asset pricing when returns are nonnormal: FamaFrench factors versus higher-order systematic comoments. The Journal of Business, 79(2), 923-940.

Dittmar, R. F. (2002). Nonlinear pricing kernels, kurtosis preference, and evidence from the cross section of equity returns. The Journal of Finance, 57(1), 369-403.

Dzieliński, M., Rieger, M. O., \& Talpsepp, T. (2018). Asymmetric attention and volatility asymmetry. Journal of Empirical Finance, 45, 59-67.

Harlow, W. V., \& Rao, R. K. (1989). Asset pricing in a generalized mean-lower partial moment framework: Theory and evidence. Journal of financial and quantitative analysis, 285-311.

Harvey, C. R., \& Siddique, A. (2000). Conditional skewness in asset pricing tests. The Journal of Finance, 55(3), 1263-1295.

Jondeau, E., Zhang, Q., \& Zhu, X. (2019). Average skewness matters. Journal of Financial Economics, 134(1), 29-47.

Kimball, M. (1990). Precautionary Saving in the Large and in the Small. Econometrica, 58, 53-73.

Liu, J., Longstaff, F. A., \& Pan, J. (2003). Dynamic asset allocation with event risk. The Journal of Finance, 58(1), 231-259. 
Markowitz, H. (1952). The utility of wealth. Journal of Political Economy, 60(2), 151-158.

Markowitz, H. (1959). Portfolio selection: Efficient diversification of investments. New York: Wiley and Sons.

Martin, I. (2017). What is the expected return on the market? The Quarterly Journal of Economics, 132(1), 367-433.

Meyer, J. (1987). Two-moment decision models and expected utility maximization. The American Economic Review, 421-430.

Roy, A. D. (1952). Safety first and the holding of assets. Econometrica: Journal of the Econometric Society, 431-449.

Talpsepp, T., \& Rieger, M. O. (2010). Explaining asymmetric volatility around the world. Journal of Empirical Finance, 17(5), 938-956.

Schwert, G. W. (1989). Why does stock market volatility change over time?. The journal of finance, 44(5), 1115-1153.

Shefrin, H. (2008). A behavioral approach to asset pricing. Elsevier. 


\section{Chapter 2. Asymmetry Beta: Return Predictability and Tail Risk Hedging Ability}

\section{Chapter Abstract}

We empirically investigate the predictability of asymmetry beta in estimating equity risk premiums for US stocks. The asymmetry beta correctly explains the systematic risk/return relationship under the framework of the asymmetry risk. We find that the downside and upside annualized market asymmetry risk premiums are approximate $1.73 \%$ and $2.10 \%$, respectively. Superior to the conventional multifactor models, our approach reduces half of the CAPM pricing errors. Also, low asymmetry beta stocks provide an effective hedge against crashing markets.

Keywords: Asymmetry Risk, Asymmetry Beta, Tail Risk, Volatility-asymmetries

JEL classification: D81, G02, G11, G12.

This paper is coauthored with Dr. Victor Chow (West Virginia University), and Dr. Zhan Wang (Shanghai Business School). 


\subsection{Introduction}

The economic theory of asymmetry risk in Chapter 1 indicates that the asymmetry risk is a major systematic component and is distinct from other asymmetry measures. The main difference lies in the risk indifference curve that predicts two asymmetry premiums rather than one, implying a V-shaped return/asymmetry risk relationship. The V-shaped relationship has vital implications in asset pricing. Previous asset pricing models may ignore the upside asymmetry premium and underestimate the equity risk premium. The underestimation may partially result in the equity premium puzzle. In addition, the managers may accept the overvalued projects due to the bias in the cost of capital without asymmetry risk adjustment.

If the potential gain/loss is crucial in making investment decisions, stocks with higher asymmetry beta should have higher expected returns. We test this hypothesis and document that the cross-sectional stock returns reflect a persistent and robust asymmetry premium in both upside and downside. This highly significant premium exists even controlling for CAPM beta and various sources of risks related to firm size, the book-to-market ratio, profitability, investment, and momentum.

Earlier tests of the beta/return relationship ${ }^{12}$ focus on the contemporaneous relationship between beta and expected return. For example, Fama and French (1992) find a weak relationship between post-formation market betas and realized average stock returns over the same period. Jagannathan and Wang (1996) argue that a conditional CAPM holds as betas and the market risk premium vary over time. Lewellen and Nagel (2005) say that the conditional CAPM performs almost as poorly as the unconditional CAPM. Our study differs from these

\footnotetext{
${ }^{12}$ For example, see Black, Jensen, and Scholes (1972), Fama and French (1992), Jagannathan and Wang (1996), and Lettau and Ludvigson (2001) for tests of CAPM, and Bansal, Dittmar, and Lundblad (2005) for testing other models.
} 
earlier tests in that we focused on the intertemporal relationship between factor loadings and expected returns ${ }^{13}$. Besides, we use a series of non-overlapping horizons of daily returns rather than overlapping monthly returns in several years. Therefore, our approach improves the statistical power.

As it is hard to directly estimate the asymmetry factor's returns (asymmetry premium), we calculate it by relying on the linear relationship between expected return and the asymmetry beta. We record that the average downside (upside) annualized asymmetry premium is $1.73 \%$ $(2.10 \%)$, with a t-statistic of $4.71(6.62)$, respectively. The t-statistic meets the requirement by Harvey, Liu, and Zhu (2013) that new factors must have a t-statistic greater than 3. We also show that the asymmetry factor is a common source of return variation not explained by conventional risk factors (i.e., MKT, SMB, HML, RMW, CMA, and MOM).

Unlike other factors found empirically or from statistical analysis (e.g., the principal component analysis $)^{14}$, the asymmetry factor has a solid theoretical base. We argue that the asymmetry factor summarizes the impact of all mimicking factors of the market asymmetry. We test this hypothesis by examining the explanation power and predictability of the asymmetry model and conventional multifactor models. Following Fama and French (2015), we compare the average of absolute alphas for all the models. Instead of using portfolios, we use individual stocks. The asymmetry model reduces the CAPM pricing errors by about $50 \%$, which is the most among all models.

\footnotetext{
${ }^{13}$ Shanken (1992), Pástor and Stambaugh (2003), and Levi and Welch (2020) also examine the intertemporal relationship between ex-ante factor loadings and ex-post realized returns.

${ }^{14}$ For example, see Chamberlain and Rothschild (1983), Connor and Korajczyk (1986), and Kelly, Pruitt, and Su (2019).
} 
Finally, we check the hedging ability of asymmetry beta. Although it is common knowledge that the plain CAPM beta is a poor hedge measure, Levi and Welch (2020) empirically showed that the ex-ante CAPM beta has better hedging abilities than the down beta (Ang, Chen, and Xing 2006) during market crashes. That is, low-beta stocks make portfolios "safer" in the bear markets. Instead of using the down beta, we find that the asymmetry beta can provide even better hedging performance than the CAPM beta in bear, extreme bear, and crashing markets. In an extreme bear market, low-beta stocks with the lowest asymmetry beta reduce the daily loss by at least $0.94 \%$ compared to the stocks with the highest asymmetry beta. In short, low CAMP beta stocks with the least asymmetry mitigate downside losses most in the declining markets.

The rest of the paper is organized as follows: Section 2.2 discusses the data and summary statistics. Section 2.3 tests the cross-sectional relationship between the expected excess returns and asymmetry betas. Section 2.4 examines the empirical properties of the asymmetry premium. Section 2.5 tests the ability of the asymmetry model to explain and predict excess returns. Section 2.6 tests the hedging ability of the asymmetry beta. Section 2.7 concludes the paper.

\subsection{Data and Summary Statistics}

For estimating CAPM beta and asymmetry beta, we use daily stock returns from the equity database in the Center for Research in Security Prices (CRSP) that covers all firms incorporated in the US and listed on the NYSE, AMEX, or NASDAQ. The sample period is from 1927 to 2020. Following Levi and Welch (2020), we require each stock to have at least 126 valid daily returns in the calendar year. We estimate the CAPM betas and asymmetry betas on a calendar-year basis. The CAPM beta is calculated from the OLS regression in Equation (1). 
The asymmetry betas are estimated using Equations (8.2) and (8.3) in Chapter 1. We define low volatility stocks as stocks with an RMSE in the OLS regression below the $75^{\text {th }}$ percentile. The value-weighted market return and the risk-free rate are from Kenneth French's website.

$$
R_{i, t}-r_{f, t}=a_{i}+\beta_{i}^{\mathrm{MV}}\left(R_{M, t}-r_{f, t}\right)+e_{i, t}
$$

\section{[Insert Table 1 Here]}

Table 1 reports the summary statistics. In Panel A, we estimate 379,003 non-overlapping annual betas from 98.1 million stock returns in the sample period. Panel B reports the distribution of the CAPM beta $\left(\hat{b}^{\mathrm{CAPM}}\right)$ and the asymmetry beta $\left(\hat{b}^{\mathrm{UASY}}\right.$ and $\left.\hat{b}^{\mathrm{DASY}}\right)$. The median of $\widehat{b}^{\text {CAPM }}$ is 0.69 (close to Levi and Welch's 0.61 ), and it remains almost unchanged for low and high volatility stocks. The low $30 \%$ and the high $30 \%$ of the CAPM betas are 0.05 and 1.51 . This range is close to low-volatility stocks ( 0.10 to 1.44$)$ or high-volatility stocks $(-0.11$ to 1.72$)$. The up/down betas $\left(\hat{b}_{y}^{+} / \hat{b}_{y}^{-}\right)^{15}$ also show a similar pattern as that of the CAPM beta. By contrast, the distribution of asymmetry betas on both sides vary substantially across the volatility levels. High-volatility stocks also have higher median as well as higher value in the low $30 \%$ and high $30 \%$. For example, high-volatility stocks have a median upside asymmetry beta of 2.40 , while low-volatility stocks only have a median upside asymmetry beta of 1.93 . The low $30 \%$ and the high $30 \%$ of asymmetry betas for low-volatility stocks are also less than half of those for highvolatility stocks. The distributions show that the asymmetry betas capture the volatility better than the CAPM betas. In Panel C, we find a low correlation of $-0.07(0.01)$ between CAPM betas and upside (downside) asymmetry betas. The correlation between up/down beta and upside/downside asymmetry beta is also low.

${ }^{15}$ We follow Ang, Chen, and Xing (2006) and calculate the up/down beta from (11.1) and (11.2). 


\subsection{Asymmetry Beta and Expected Returns}

The relationship between factor loadings and risk premia is the foundation of a crosssectional risk-return relationship (Ang et al., 2006). For example, the CAPM predicts that stocks with high market betas have high average returns over the same period. However, Fama and French (1992) find a weak relationship between post-formation market betas and realized average stock returns over the same period.

The shape of the risk-indifference curve implies a V-shaped return/asymmetry risk relationship. To see whether asymmetry risk is priced, we test the cross-sectional relationship between the asymmetry beta and the expected excess returns. If the asymmetry beta exhibits a significantly positive relationship with the excess returns in both upside and downside, the asymmetry beta is a convincible measure for asymmetry risk. This section tests this hypothesis and documents that stocks with higher asymmetry beta have significantly higher average excess returns in the next three years. This strong relationship exists even controlling for CAPM-beta and various sources of systematic risks related to firm size, the book to market ratio, momentum, downside beta, and coskewness. As a comparison, such a relationship does not exist for other asymmetric measures, such as the up/down beta and the coskewness.

Earlier tests of the beta/return relationship focus on the contemporaneous relationship between beta and expected return. Some empirical tests use a horizon of one month. Other researchers use a longer overlapping period (usually five years) with monthly returns. Our approach differs from these earlier tests. Following Levi and Welch (2020), our test focuses on a series of the non-overlapping one-year period with daily returns. The choice of an annual 
horizon is based on two considerations. First, one month of daily returns is too short for acquiring reliable asymmetry beta estimates. Second, the annual horizon can reduce the noise in the conditional asymmetry beta estimation since the asymmetry risk exposure could be timevarying ${ }^{16}$. Fama and French (2006) also suggest using an annual horizon to estimate betas.

\subsubsection{The cross-sectional test for VASY and SKEW}

Based on the theory of asymmetry risk in Chapter 1, VASY is superior to skewness (denotes SKEW hereafter) in measuring asymmetry risk. In this section, we first test this hypothesis. At the beginning of each calendar year $y$, we calculate the ex-ante upside (downside) VASY for all stocks using daily returns in the previous year $(y-1)$. Then, we sort stocks into quintile portfolios based on a(n) descending (ascending) order of the upside (downside) asymmetry beta. We calculate the equal-/value-weighted average monthly excess returns for each portfolio in three post-formation years, $y, y+1$, and $y+2$. The average monthly returns serve as the proxy for the expected returns at the end of the previous year. We also calculate the differences in the expected returns between the portfolios that have the highest and the lowest upside (downside) asymmetry betas, "1-5" ("10-6"). For comparison, we apply the same method to the negative/positive skewness.

Table 2.1 shows the results for equal-weighted portfolios. The left section shows the post-formation average excess returns of the portfolios sorted by VASY. The right section is the result for portfolios sorted by negative/positive skewness.

From Table 2.1, portfolios with the most negative (positive) VASY earn an average excess return of $1.63 \%(1.54 \%)$ in the next year, which is $0.82 \%(0.88 \%)$ higher than that of the

\footnotetext{
${ }^{16}$ For example, see Adrian \& Franzoni (2009).
} 
portfolio with the least negative (positive) asymmetry beta. This difference is significant at a $5 \%$ level with a t-statistic of 3.01 (3.29). Notably, such a distinction exists for three years at a $5 \%$ level of significance. In short, the average excess returns exhibit a V-shaped relation across the upside and downside VASY quintiles, and the differences in excess returns last for at least three years. We also plot the strong V-shaped relationship in Figure 2.1.

Table 2.2 presents the results for value-weighted portfolios. Portfolios with the most negative (positive) VASY earn an average excess return of $1.43 \%, 1.35 \%$, and $1.28 \%(1.34 \%$, $1.36 \%$, and $1.17 \%)$ in the next year, which is $0.64 \%, 0.59 \%$, and $0.53 \%(0.70 \%, 0.72 \%$, and $0.38 \%$ ) higher than that of the portfolio with the least negative (positive) VASY. Past studies found that stocks of smaller size (lower market value) tend to have higher asymmetry risks. Thus the significance of the return difference is expected to reduce for value-weighted portfolios ${ }^{17}$. However, the return differences are still statistically significant at a $5 \%$ level over the next three years.

As a comparison, the negative skewness-sorted portfolios do not display significant results in the out-of-sample average excess returns. Portfolios with the most negative skewness only have slightly higher average excess returns in the next three years. Portfolios with more positive skewness have higher average excess returns in the next two years at a significance of $5 \%$.

[Insert Table 2.1 Here]

[Insert Table 2.2 Here]

To conclude, VASY is more robust than SKEW for measuring asymmetry risk.

\footnotetext{
${ }^{17}$ See, for example, Harvey and Siddique (2000), and Malladi, R., \& Fabozzi, F. J. (2017).
} 


\subsubsection{The cross-sectional test for coasymmetry and coskewness}

In this section, we test which asymmetry risk measure captures the systematic risk. We use the same methodology as in section 2.3 .1 by sorting stocks into quintile portfolios based on negative and positive value of the measure. Then we calculate the equal-/value-weighted average monthly excess returns for each portfolio in three post-formation years, $y, y+1$, and $y+2$, and the differences in the excess returns between the portfolios at two ends. For comparison, we apply the same method to the up/down beta and the coskewness ${ }^{18}$, respectively.

Table 3.1 shows the results for equal-weighted portfolios. The left section shows the post-formation average excess returns of the portfolios sorted by asymmetry beta. The middle section presents the result for portfolios sorted by positive and negative coskewness. The right section is the result for portfolios sorted by up/down beta.

From Table 3.1, portfolios with the most negative coasymmetry (highest upside asymmetry beta) earn an average excess return of $1.45 \%$ in the next year, which is $0.56 \%$ higher than that of the portfolio with the least negative coasymmetry (lowest upside asymmetry beta). This difference is significant at a $1 \%$ level with a t-statistic of 3.10. Notably, such a distinction also exists in the next two and three years at a 5\% level of significance. A similar pattern is found in portfolios with positive coasymmetry (downside asymmetry beta) except that the magnitude of the difference reduces to about $0.40 \%$ but is still significant at the $1 \%$ level. In short, the average excess returns exhibit a V-shaped relation across the upside and downside

\footnotetext{
18 The up beta is calculated as $\frac{\operatorname{cov}\left(\left\{R_{i}, R_{M} \mid R_{M}>\mu_{M}\right\}\right)}{\operatorname{VAR}\left(R_{M} \mid R_{M}>\mu_{M}\right)}$, the down beta is calculated as $\frac{\operatorname{Cov}\left(\left\{R_{i}, R_{M} \mid R_{M}<\mu_{M}\right\}\right)}{\operatorname{VAR}\left(R_{M} \mid R_{M}<\mu_{M}\right)}$, and coskewness is calculated as $\frac{\mathrm{E}\left[\left(R_{i}-\mu_{i}\right)\left(R_{M}-\mu_{M}\right)^{2}\right]}{\sigma_{i} \sigma_{M}^{2}}$, where $\mu_{i}$ is the average excess return of asset $i$, and $\sigma_{i}$ is the standard deviation of asset $i$.
} 
asymmetry beta quintiles, and the differences in excess returns last for at least three years. The strong V-shaped relationship indicates that the asymmetry risk premiums exist on both sides in the cross-section of stock returns.

On the other hand, neither the coskewness nor the up/down beta displays significant results. Portfolios with higher downside/upside betas have lower average excess returns in the next three years. Portfolios with the most negative or positive coskewness also have lower average excess returns. Portfolios with the highest up/down beta also have lower average excess returns in the next three years. These results are contrary to our theory of asymmetry risk. The main reason is that the up/down beta is calculated from a truncated return distribution above or below the mean, which may cause biased risky estimates due to incomplete information. Although coskewness is calculated from the whole return distribution, the preference for positive coskewness makes it impossible to be an ideal measure for asymmetry risk, as we already explained in Chapter 1.

The V-shaped asymmetry beta/return relationship is also significant at $5 \%$ level for value-weighted portfolios, as is shown in Table 3.2, except for the upside asymmetry beta in the third post-formation year, which is significant at the $10 \%$ level.

[Insert Table 3.1 Here]

[Insert Table 3.2 Here]

In summary, the asymmetry beta correctly explains the systematic asymmetry risk/return relationship predicted by our theory, while the up/down beta and coskewness fail in the test. Therefore, the asymmetry beta is a superior measure of asymmetry risk. 


\subsubsection{Fama-MacBeth regressions}

As the cross-sectional test confirms the V-shaped relation, we run the Fama and MacBeth's (1973) regression as a robustness check. Our regressions focus on the firm level. Extant literature has shown that various effects from firm characteristics can also explain the cross-sectional expected returns ${ }^{19}$. To control multiple effects simultaneously, we use betas of conventional risk factors (i.e., SMB, HML, RMW, CMA, and MOM) as control variables. We also control for idiosyncratic risk using the lagged 12-month excess returns, the maximum monthly excess returns, the minimum monthly excess returns ${ }^{20}$, and illiquidity (Amihud, 2002). To avoid putting too much weight on extreme observations, we winsorize all independent variables at the 1\% and 99\% levels, following Knez and Ready (1997) to ensure that extreme outliers do not drive the results.

Specifically, in each month $t$, we run the following cross-sectional regression

$$
R_{i, t}=\gamma_{0, t-1}+\gamma_{1, t-1} \beta_{i, y-1}^{\mathrm{ASY}}+\boldsymbol{\Gamma}_{\boldsymbol{t}-\mathbf{1}} \mathbf{B}_{i, \boldsymbol{y}-\mathbf{1}}+\varepsilon_{i, t-1}
$$

where $R_{i, t}$ is the excess return in month $t, \beta_{y-1}^{\mathrm{ASY}}$ is the asymmetry beta in the previous year, and $\mathbf{B}_{i, y-1}$ is a vector of control variables also calculated in the previous year. We also use an indicator variable, $I_{i}^{\text {COVASY }}$, to distinguish between the upside and downside asymmetry beta.

$$
R_{i, t}=\gamma_{2, t-1}+\gamma_{3, t-1} \beta_{i, y-1}^{\mathrm{DASY}} I_{i}^{\mathrm{COVASY}}+\gamma_{4, t-1} \beta_{i, y-1}^{\mathrm{UASY}}\left(1-I_{i}^{\mathrm{COVASY}}\right)+\boldsymbol{\Gamma}_{\boldsymbol{t}-\mathbf{1}} \mathbf{B}_{\boldsymbol{i}, \boldsymbol{y}-\mathbf{1}}+\varepsilon_{i, t-1}
$$

Table 4 reports the time-series averages of the monthly cross-sectional regression coefficients along with the Newey-West (1987) t-statistics in square brackets. In Specification I, we do not separate upside and downside asymmetry beta. The coefficient of asymmetry beta is

\footnotetext{
${ }^{19}$ For example, the size effect [Banz (1981)], the book-to-market effect [Basu (1983)], the momentum effect [Jegadeesh and Titman (1993)], the volatility effect [Ang, et al. (2006)], the coskewness risk [Harvey and Siddique (2000)], and the cokurtosis risk [Scott and Horvarth (1980), and Dittmar (2002)].

20 The lagged 12-month return is defined as the annual return in the previous year.
} 
0.01 with a t-statistics of 3.30 (3.03). The significantly positive coefficients are consistent with the V-shaped relation between asymmetry beta and expected returns. In Specification II and III, we test the upside and downside asymmetry beta separately, and both coefficients remain positive and statistically significant at 5\% level. In Specification IV, we test Equation (14). The coefficient of the upside asymmetry beta is 0.02 , which is statistically significant at $1 \%$ level (tstatistics of 2.67), while the downside asymmetry beta has a coefficient of 0.02 with a significance level of $10 \%$.

[Insert Table 4 Here]

To summarize, the Fama-Macbeth regressions also reveal intense and persistent asymmetry premiums in both upside and downside. The asymmetry-premiums exist after controlling for CAPM beta and various sources of systematic risks related to firm characteristics.

\subsubsection{Robustness checks}

Table 3.1 and Table 3.2 show a monotonically increasing pattern between realized average returns and ex-ante asymmetry beta. For robustness check, we firstly show that the asymmetry beta is different from the betas of traditional risk factors (i.e., SMB, HML, RMW, CMA, MOM) and coskewness. To do this, we calculate the upside and downside asymmetry beta and the betas on other risk factors for each stock using daily returns in each calendar year. We sort stocks into two quintile portfolios based on their upside and downside asymmetry beta and report the equal-weighted average of the betas on various risk factors in each portfolio in Table 5 .

[Insert Table 5 Here] 
In Table 5, the upside (downside) asymmetry beta ranges from 0.36 to 22.02 ( 0.32 to 11.55). The magnitude of the asymmetry beta is quite different from those of other betas. For example, the CAPM beta ranges from 0.59 to 0.74 ( 0.63 to 0.88 ), the up (down) beta ranges from 0.54 to 0.73 ( 0.68 to 1.10$)$, the SMB beta ranges from 0.46 to 0.79 ( 0.48 to 0.94$)$, and coskewness ranges from -0.06 to $-0.02(-0.29$ to -0.09$)$. Also, except for the asymmetry beta, only the SMB beta and RMW beta exhibit a monotonic V-shape, implying a positive correlation with the asymmetry beta.

We now check the reward for asymmetry risk exposure while controlling for the symmetric risk. To do this, we first form three portfolios sorted on CAPM betas. Then, within each CAPM beta portfolio, we sort stocks into quintile portfolios based on the upside/downside asymmetry betas. After obtaining the double-sorted portfolios, we calculate the valued-weighted monthly average excess returns in three post-formation years. If asymmetry beta is a robust measure for asymmetry risk, we should observe the same pattern for the return/asymmetry beta relationship as in Table 3.2. That is, the higher the asymmetry beta, the higher the average excess return.

[Insert Table 6.1 Here]

Table 6.1 presents the results. The columns labeled $y+1, y+2$, and $y+3$ represent the post-formation monthly average excess returns in the next three years. The column labeled "15" ("10-6") stands for the differences in average excess returns between the first (tenth) and the fifth (sixth) quintile portfolios within each level of CAPM beta. We also report the t-statistics of the return difference. The results are as follows. For low CAPM beta stocks, stocks with the highest upside (downside) asymmetry beta earn an average excess return of $1.58 \%(1.85 \%)$ in 
the next year, which is $0.64 \%(0.86 \%)$ higher than that of the stocks with the lowest upside (downside) asymmetry beta. The differences in excess returns are significant at $1 \%$ level, which is more vital than our cross-sectional test results in Table 3.2. Again, these considerable differences last for three years. A similar relation exists in the medium CAPM beta portfolios with a significance level of 5\% for two years. However, for high CAPM beta portfolio, the significant $\mathrm{V}$-shape only exists in the first post-formation year at $10 \%$ level and attenuates in the second and the third years. This result is consistent with the VAR/VASY tradeoff, as we discussed in Chapter 1. When symmetric risk is high, the marginal effect of asymmetry risk on symmetric risk is diminishing to zero. Thus, investors demand less additional compensations on asymmetry risk.

The value-weighted portfolios exhibit a similar pattern as equal-weighted portfolios, as is shown in Table 6.2. To save space, we do not describe the results in detail.

[Insert Table 6.2 Here]

Overall, after controlling for CAPM beta, the asymmetry beta/return relationship reflects mostly on stocks with low and medium CAPM beta portfolios. This result is consistent with the utility tradeoff analysis between symmetric risk and asymmetry risk in Chapter 1.

\subsection{Empirical Properties of Asymmetry Premium}

Inspired by the results in section 2.3 , we estimate the asymmetry premium in this section. Although the asymmetry factor is unobservable, we create a mimicking factor portfolio based on the linear relationship between the excess return and the asymmetry beta. We document a significant annualized upside (downside) asymmetry premium. We also show that the 
asymmetry factor is a common source of return variation not explained by conventional risk factors (i.e., MKT, SMB, HML, RMW, CMA, and MOM).

We create the mimicking portfolio of the asymmetry factor (i.e., UASY and DASY in Equation 1) through a long/short position in the portfolios (created in section 2.3) with the highest/lowest asymmetry beta. Again, we rebalance the portfolios in the long/short position annually. Since UASY and DASY's asymmetry beta must be one, we adjust the mimicking portfolio return by its beta to get the asymmetry premium. Specifically, we estimate the monthly asymmetry premium by compounding the daily asymmetry premium calculated from Equations (4.1) and (4.2).

$$
\begin{aligned}
& \mathrm{UASY}_{d}= \frac{\bar{R}_{H, d}^{\mathrm{UASY}}-\bar{R}_{L, d}^{\mathrm{UASY}}}{\bar{\beta}_{H, y-1}^{\mathrm{UASY}}-\bar{\beta}_{L, y-1}^{\mathrm{UASY}}} \\
& \mathrm{DASY}_{d}=\frac{\bar{R}_{H, d}^{\mathrm{DASY}}-\bar{R}_{L, d}^{\mathrm{DASY}}}{\bar{\beta}_{H, y-1}^{\mathrm{DASY}}-\bar{\beta}_{L, y-1}^{\mathrm{DASY}}}
\end{aligned}
$$

Panel A of Table 6 reports the summary statistics of the asymmetry premium. The average monthly upside (downside) asymmetry premium is $0.18 \%(0.14 \%)$, with a t-statistic of 6.62 (4.71). The t-statistic meets the requirement by Harvey, Liu, and Zhu (2013) that new factors must have a t-statistic greater than 3 .

We next examine whether the asymmetry premium can be explained by exposure to the conventional risk factors, including MKT, SMB, HML, RMW, CMA, and MOM. Specifically, in each month $t$, we regress asymmetry premiums on a vector of standard risk factor returns, $\boldsymbol{F}$, as is shown in Equation (5.1) and (5.2).

$$
\mathrm{UASY}_{t}=\alpha_{\mathrm{U}}+\boldsymbol{\beta}_{\mathrm{U}} \boldsymbol{F}_{\boldsymbol{t}}+\varepsilon_{t, \mathrm{U}}
$$




$$
\mathrm{DASY}_{t}=\alpha_{\mathrm{D}}+\boldsymbol{\beta}_{\mathrm{D}} \boldsymbol{F}_{\boldsymbol{t}}+\varepsilon_{t, \mathrm{D}}
$$

The $\alpha$ in Eq. (16.1) and (16.2) measures the average asymmetry premium not compensated for exposure to extant risk factors. Since asymmetry risk is predicted to carry a positive premium, UASY (DASY) is expected to generate positive alpha relative to standard factor models if the asymmetry factor is distinct from other risk factors. Our first analysis examines whether the asymmetry premium is explained by exposure to market risk. Panel B of Table 7 shows that both the upside (downside) asymmetry premium positively affect the market factor. However, the market factor only explains $7.68 \%(8.53 \%)$ of the total variation in upside (downside) asymmetry premium. The monthly alpha of UASY (DASY) relative to the CAPM is $0.11 \%(0.08 \%)$, which is highly significant with a t-statistic of $5.70(3.62)$.

We then test whether other standard risk factors can explain the asymmetry premium. Panel B shows that UASY (DASY) produces an alpha of $0.09 \%(0.07 \%)$ per month relative to the Fama and French (1993) three-factor model and an alpha of $0.08 \%(0.08 \%)$ per month relative to the Carhart (1997) four-factor model. Both alphas are statistically distinguishable with zero at a $5 \%$ level. The $\mathrm{R}^{2}$ for each specification ranges from $11.52 \%$ to $12.38 \%$. Finally, UASY (DASY) generates an alpha of $0.12 \%(0.09 \%)$ per month with a t-statistic of 10.93 (5.47) relative to the Fama and French (2015) five-factor model, and the $\mathrm{R}^{2}$ is $24.27 \%$ (15.22\%).

[Insert Table 7 Here]

In short, we find that the annualized downside and upside market asymmetry risk premiums are $2.10 \%$ and $1.73 \%$, respectively, which are both significantly different from zero at $1 \%$ significance level. Moreover, both asymmetry premium cannot be fully explained by 
conventional risk factors. Therefore, asymmetry premium is an essential source of common return variation.

\subsection{Return Predictability of the Asymmetry Model}

We also run a bivariate analysis by constructing portfolios based on asymmetry beta and other beta measures. We find that asymmetry risk is a determinant of other risks related to firm characteristics. With the control of asymmetry beta, the return predictability of other beta measures mostly reduces. However, asymmetry beta still has impressive predictability with the control of other beta measures ${ }^{21}$. In this section, we test how well the asymmetry model can explain and predict excess returns.

\subsubsection{The explanation power of the models}

In this section, we test the asymmetry model's ability to explain excess returns and compare it with other traditional linear factor models. The sample period is from July 1963 to Dec 2020. The sample period starts from July 1963 because this is the earliest month that the returns of RMW and CMA are available. As the asymmetry model is conditional on the sign of the coasymmetry that is time-varying, we test the models using Equation (6) by regressing the stock's daily excess return on contemporaneous factor returns each year.

$$
X R_{i, d}=\alpha_{i}+\sum_{f=1}^{F} \beta_{i}^{f} \lambda_{d}^{f}+\varepsilon_{i, d}
$$

where $X R_{i, d}=R_{i, d}-R_{f, d}$ is the excess return in day $d, \beta_{i}^{f}$ is the factor loading and $\lambda_{d}^{f}$ is the factor price in day $d$. If the model has superior explanation power, the alpha should be smaller than other models. After obtaining the alphas each year for each stock, we sort stocks into 25

\footnotetext{
${ }^{21}$ To save space, we do not show the results but they are available when required.
} 
groups with negative coasymmetry and another 25 groups with positive coasymmetry. Then for each group, we calculate the average alpha, $\bar{\alpha}_{k, y}$, and the time-series average alpha $\bar{\alpha}_{k}$. The explanation power of the models is measured by $A\left|\bar{\alpha}_{k}\right|$, the cross-section average of $\left|\bar{\alpha}_{k}\right|$, which measures the average deviation in excess returns not explained by the model.

If the model completely captures expected returns, the alpha in Equation (6) should not be significantly different from zero. However, we find that all t-statistics are more remarkable than 1.96, so we do not report the t-statistics. This result is consistent with Fama and French (2015). They showed that the GRS test rejects various factor models and concluded that factor models are hard to completely describe the expected returns. Therefore, we focus on the improvements in explaining the excess returns by reporting the percentage of $A\left|\bar{\alpha}_{k}\right|$ compared to that of CAPM.

\section{[Insert Table 8 Here]}

Table 8 presents the result. In Panel A, the $A\left|\bar{\alpha}_{k}\right|$ from CAPM is 3.56 basis points (bps), which is the highest among all models. The $A\left|\bar{\alpha}_{k}\right|$ from the asymmetry model is only $1.24 \mathrm{bps}$, accounting for $34.8 \%$ of the CAPM. This means the asymmetry model reduces the pricing error by about $65.2 \%$. As a comparison, the other multifactor models all have a lower $A\left|\bar{\alpha}_{k}\right|$ compared to that of CAPM, but they only reduce the pricing error by $6.7 \%$ to $19.6 \%$. Thus, the asymmetry model is superior in explaining excess returns. As a robustness check, we divide the whole sample period into two sub-periods. We find that the $A\left|\bar{\alpha}_{k}\right|$ from asymmetry model is quite stable (ranges from $1.21 \mathrm{bps}$ to $1.28 \mathrm{bps}$ ) compared to that of other models, which ranges from 2.18 bps to $3.60 \mathrm{bps}$ for Fama and French three-factor model, $2.28 \mathrm{bps}$ to $3.65 \mathrm{bps}$ for 
Carhart (1997) four-factor model, and 2.45 bps to 4.27 bps for Fama and French five-factor model.

As the coasymmetry is individual stocks' contribution of asymmetry risk to the market, we divide the 50 groups into five categories based on the coasymmetry level. In Panel B, we find that the asymmetry model performs well in all five groups. The $A\left|\bar{\alpha}_{k}\right|$ from asymmetry model is mostly lower than $40 \%$ that of the CAPM $A\left|\bar{\alpha}_{k}\right|$, while the $A\left|\bar{\alpha}_{k}\right|$ from other factor models are mostly higher than $60 \%$ that of the CAPM.

In summary, the asymmetry model has superior explanation power for contemporaneous excess returns. In the next section, we test how well the asymmetry model can predict excess returns compared to other conventional multifactor models.

\subsubsection{The Predictability of the Models}

The predictability of the models is measured by the difference between the predicted returns and the realized returns. In each year, we calculate the predicted returns from Equation (7) and then calculate $\varepsilon_{y}$ from Equation (8). $\varepsilon_{y}$ is the difference between the average daily realize return and the predicted return. Again, we sort stocks into the same 50 groups as we had in section 2.5.1, and the cross-section average of $\left|\bar{\varepsilon}_{k}\right|$ is a measure for model predictability. The lower the $A\left|\bar{\varepsilon}_{k}\right|$, the greater the predictability.

$$
\begin{gathered}
E_{y-1}\left(R_{i, d}\right)=\sum_{f=1}^{F} \beta_{i, y-1}^{f} \bar{\lambda}_{d, y-1}^{f} \\
\varepsilon_{y}=\bar{R}_{i, d, y}-E\left(R_{i, d}\right)_{y-1}
\end{gathered}
$$

[Insert Table 9 Here] 
Table 9 presents the result. The asymmetry model has the least prediction error among all models. The daily prediction error from the asymmetry model is $2.04 \mathrm{bps}$, about half of the CAPM. The other models all have less prediction error than that of CAPM. However, the prediction error reduction is less than $30 \%$ in the whole sample period or two sub-periods. In Panel B of Table 9, the asymmetry model also performs the best under different coasymmetry levels. The reduction in prediction error compared to CAPM ranges from $38 \%$ to $66 \%$ in the whole sample period and ranges from $38 \%$ to $82 \%$ in the two sub-periods. For other models, the reduction is $20 \%$ at most.

Another crucial finding from Table 9 is that the asymmetry model's predictability is getting improved as the prediction errors reduce in the two sub-periods. In comparison, other factor models exhibit decreasing predictability between the two sub-periods. For example, the Fama and French three-factor model's daily prediction error is 2.77 bps from 1963 to 1992, and then increases to 4.27 bps from 1993 to 2020.

In short, we show that the asymmetry model has the best explanation power to excess returns of individual stocks and the most potent predictability for future excess returns among all models. In addition, the predictability of the asymmetry model increases over time.

\subsection{The Hedging Ability of the Asymmetry beta}

In previous sections, we find evidence that asymmetry beta is a superior measure for asymmetry risk. And the asymmetry model also has better explanation power as well as predictability. However, investors may question whether the asymmetry beta can be used to protect their investment? Levi and Welch (2020) empirically show that the symmetric plain beta has better hedging abilities than the asymmetric down beta (Ang, Chen, and Xing, 2006) against 
market crashes. They find that in the extreme bear (bear) market, low CAPM beta stocks have an ex-post average daily loss of $0.8 \%(0.55 \%)$, which is about $2.3 \%(1.8 \%)$ lower than the loss from high CAPM beta stocks. This section shows that investors can have more protection in their investment by investing in low asymmetry beta stocks.

Following Levi and Welch (2020) (LW hereafter), we test the hedging ability based on six market states using unconditional breakpoints at 1/8, 2/8, 6/8, and 7/8 quantiles from 1927 to 2020. Although the period is different from that of LW, the breakpoints are very close with market daily return cutoffs of about $-0.9 \%,-0.4 \%, 0.5 \%$, and $0.9 \%$. We also divide the bear markets into two groups, and the extreme bear market has a loss of at least $-1.42 \%$ with an average loss of $-2.36 \%$, which is also close to LW's breakpoint.

We firstly replicate the results in LW for the daily performance of stocks. We sort stocks into three groups based on the CAPM beta and calculate the average daily return under each market state. Low CAPM beta stocks have a realized return of $-0.77 \%(-0.51 \%)$ in the extreme bear (bear) market, close to LW's $-0.81 \%$. Then, for each level of CAPM beta, we sort stocks into five groups based on the upside/downside asymmetry beta.

Table 10 shows that among the low CAPM beta stocks, the average daily loss from stocks with the lowest upside (downside) asymmetry beta is further reduced by $1.10 \%$ and $0.50 \%$ $(0.94 \%$ and $0.47 \%)$ in extreme bear and bear market. Although high CAPM beta stocks have much higher losses than low CAPM beta stocks do, investors can still save $1.26 \%$ and $0.67 \%$ $(1.35 \%$ and $0.74 \%)$ daily by investing in stocks with the lowest upside (downside) asymmetry beta.

[Insert Table 10 Here] 
In short, we also find strong evidence for the effective hedging ability of asymmetry beta. Low CAPM beta stocks with the least asymmetry risk mitigate downside losses the most in the declining markets.

\subsection{Conclusion}

Inspired by the notion of asymmetry risk and the related theory, we empirically investigate the ability of asymmetry beta for estimating equity risk premiums for US stocks. We also calculate the upside and downside asymmetry premiums, and test the explaining power and predictability of the asset pricing model with the asymmetry factor. Also, we follow Levi and Welch (2020) and examine the hedging ability of the asymmetry beta.

This paper has several main findings. First, we document that stocks with high ex-ante asymmetry betas in either upside or downside have higher ex-post excess returns. The V-shaped return/asymmetry beta relationship is consistent with the theory of the asymmetry risk as predicted by the risk indifference curve. We find that the high average returns earned by stocks with high asymmetry betas are not explained by the conventional risk factors on firm characteristics related to firm size, book-to-market ratio, profitability, investment, and momentum.

Second, we estimate the downside and upside asymmetry premiums based on the linear relationship between expected returns and asymmetry betas. We document that the upside and downside annualized asymmetry premium is $2.10 \%$ and $1.73 \%$, respectively, which are significantly different from zero with t-statistics of 6.62 and 4.71 . The asymmetry premiums cannot be explained by conventional risk factors, i.e., MKT, SMB, HML, RMW, CMA, and MOM. 
Third, we examine the explanation power and predictability of the asset pricing model with the asymmetry factor and document that the asymmetry model reduces the CAPM pricing errors by $50 \%$, which is the most among all other conventional linear multifactor models. Moreover, the predictability of the asymmetry model increases over time.

Finally, we document that low asymmetry beta stocks provide an effective hedge in crashing markets. Investors can save at least $0.94 \%$ daily by investing in stocks with the lowest asymmetry beta. 
Figures and Tables

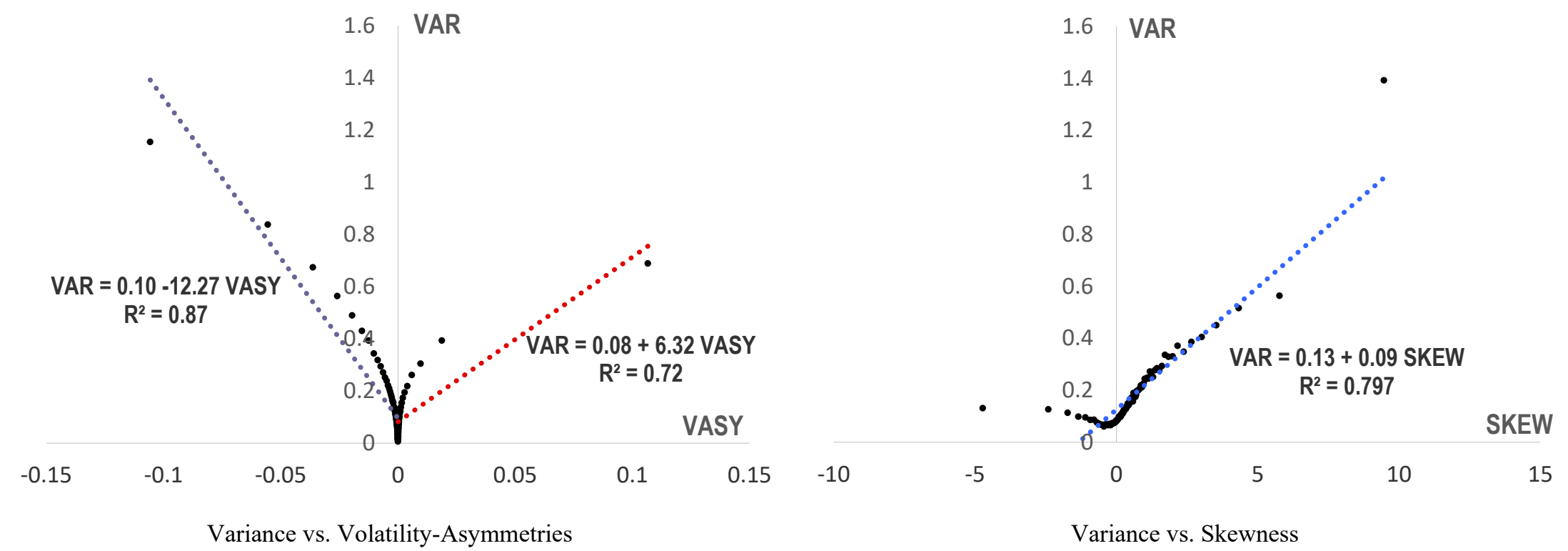

Figure 2.1

Relationship between Variance, Volatility-Asymmetries, and Skewness

This figure plots the relationship between statistics of variance (VAR), volatility-asymmetries (VASY), and skewness (SKEW) from returns on stocks in the US equity markets. All statistics are computed using daily return data over the previous year. The sample contains all stocks listed on the NYSE, AMEX, or NASDAQ for the period from 1927 to 2020 . We group stocks into 100 deciles sorted by VASY or SKEW. The statistics presented in the figure are the average value in the group. 


\section{Table 1}

\section{Summary Statistics}

Panel A reports the sample constitution from 1927 to 2020. Panel B reports the distributions of volatilityasymmetry and the corresponding skewness, coasymmetry and the corresponding coskewness, calendaryear CAPM betas, DOWN betas, UP betas, upside asymmetry betas, and downside asymmetry betas. Panel $\mathrm{C}$ reports the correlations among the betas. We calculate the upside and downside asymmetry betas using (9.2) and (9.3). Low-volatility stocks refer to the stocks that had a RMSE below the 75th percentile in the OLS regression. P25 (P75) refers to the first (the third) quartile.

\section{Panel A: Overall sample}

Daily CRSP observations

Valid stock returns

Not calculable betas ( $<126$ trading days)

Calendar-year betas

\begin{tabular}{ccc} 
All Stocks & & Low-volatility Stocks \\
\hline 98.1 million & & \\
96.3 million & & \\
33,399 & \\
379,003 & 284,252
\end{tabular}

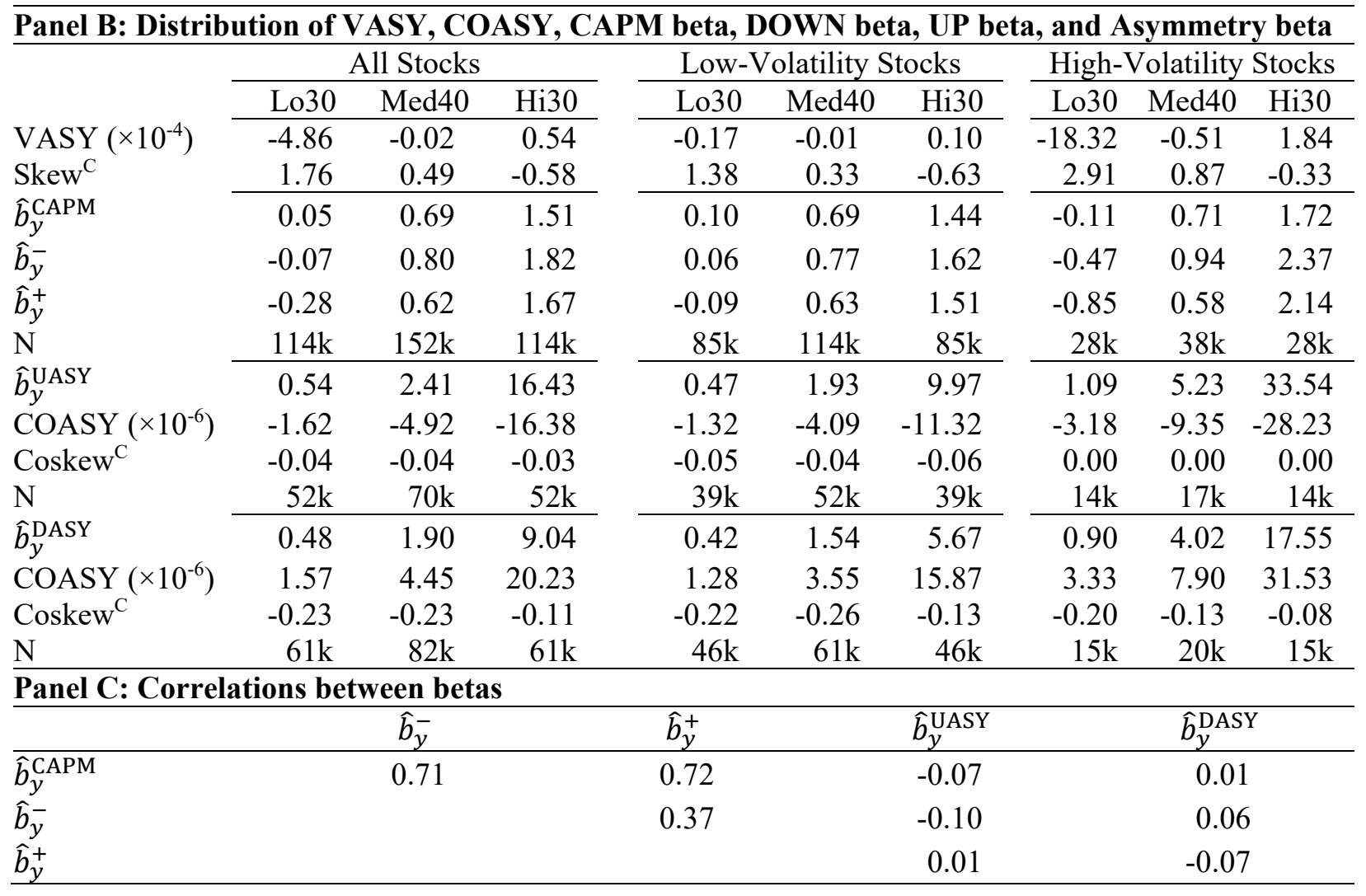


Table 2.1

Cross-section Expected Return on VASY and Skew Sorted (Equal-Weighted) Portfolios

We form equal-weighted quintile portfolios every year by computing the variance, volatility-asymmetries, and skewness of individual stocks, using daily data over the year. The sample contains all stocks listed on the NYSE, AMEX, or NASDAQ for the period from 1927 to 2020 . We use two steps to generate the report. First, stocks are sorted into subgroups based on their VASY (Skew) and VAR. We form ten portfolios by five groups of stocks with positive value in VASY (Skew) and another five groups with negative value in VASY (Skew). Then, we calculate the pre-formation average monthly return and the post-formation average monthly returns in one, two, and three years, respectively. The statistic "1-5" ("10-6") refers to the difference in average returns between portfolio one (ten) and portfolio five (six). The returns are reported in percentage values. The t-statistics are reported in square brackets, where those in bold are statistically significant at the five percent level.

\begin{tabular}{|c|c|c|c|c|c|c|c|c|c|c|c|c|}
\hline \multirow[b]{3}{*}{ Rank } & \multicolumn{6}{|c|}{ Sorted by VASY } & \multicolumn{6}{|c|}{ Sorted by Skew } \\
\hline & \multicolumn{3}{|c|}{$\begin{array}{c}\text { Pre-Formation } \\
\text { Average }\end{array}$} & \multicolumn{3}{|c|}{$\begin{array}{l}\text { Post-Formation } \\
\text { Average Return }\end{array}$} & \multicolumn{3}{|c|}{$\begin{array}{c}\text { Pre-Formation } \\
\text { Average }\end{array}$} & \multicolumn{3}{|c|}{$\begin{array}{l}\text { Post-Formation } \\
\text { Average Return }\end{array}$} \\
\hline & $\begin{array}{l}\text { VASY } \\
\left(\times 10^{-4}\right) \\
\end{array}$ & $\begin{array}{c}\text { VAR } \\
\left(\times 10^{-4}\right) \\
\end{array}$ & Return & $y+1$ & $\mathrm{y}+2$ & $y+3$ & Skew & $\begin{array}{c}\text { VAR } \\
\left(\times 10^{-4}\right) \\
\end{array}$ & Return & $\mathrm{y}+1$ & $y+2$ & $y+3$ \\
\hline 1 & -9.65 & 61.83 & 2.50 & 1.63 & 1.68 & 1.65 & -1.73 & 9.30 & -1.48 & 0.94 & 0.99 & 1.11 \\
\hline 2 & -0.36 & 17.36 & 1.54 & 1.14 & 1.24 & 1.32 & -0.56 & 7.10 & -0.45 & 0.76 & 0.94 & 1.04 \\
\hline 3 & -0.11 & 10.22 & 1.29 & 1.04 & 1.08 & 1.18 & -0.30 & 6.96 & -0.16 & 0.74 & 0.87 & 0.95 \\
\hline 4 & -0.03 & 6.26 & 1.07 & 0.97 & 0.93 & 1.02 & -0.15 & 7.26 & 0.06 & 0.80 & 0.95 & 0.99 \\
\hline 5 & -0.01 & 3.55 & 0.75 & 0.81 & 0.79 & 0.79 & -0.05 & 7.42 & 0.28 & 0.78 & 0.89 & 1.00 \\
\hline $1-5$ & & & $\begin{array}{r}1.75 \\
{[5.77]}\end{array}$ & $\begin{array}{c}0.82 \\
{[3.01]}\end{array}$ & $\begin{array}{c}0.89 \\
{[3.30]}\end{array}$ & $\begin{array}{c}0.86 \\
{[3.32]}\end{array}$ & & & $\begin{array}{c}-1.76 \\
{[-14.08]}\end{array}$ & $\begin{array}{c}0.16 \\
{[1.49]}\end{array}$ & $\begin{array}{c}0.10 \\
{[1.43]}\end{array}$ & $\begin{array}{c}0.11 \\
{[0.93]}\end{array}$ \\
\hline 6 & 0.00 & 2.98 & 0.49 & 0.66 & 0.67 & 0.84 & 0.13 & 8.82 & 0.48 & 0.87 & 0.93 & 1.02 \\
\hline 7 & 0.01 & 4.58 & 0.33 & 0.68 & 0.86 & 0.94 & 0.35 & 11.43 & 0.75 & 1.02 & 1.05 & 1.09 \\
\hline 8 & 0.03 & 6.86 & 0.17 & 0.84 & 0.94 & 1.05 & 0.59 & 14.77 & 1.08 & 1.07 & 1.06 & 1.18 \\
\hline 9 & 0.10 & 11.12 & -0.41 & 0.90 & 1.03 & 1.24 & 0.97 & 19.56 & 1.53 & 1.21 & 1.20 & 1.25 \\
\hline 10 & 1.53 & 25.95 & -1.94 & 1.54 & 1.59 & 1.43 & 2.59 & 42.59 & 2.63 & 1.39 & 1.42 & 1.37 \\
\hline $10-6$ & & & $\begin{array}{c}-2.43 \\
{[-9.35]}\end{array}$ & $\begin{array}{c}0.88 \\
{[3.29]}\end{array}$ & $\begin{array}{c}0.92 \\
{[4.36]}\end{array}$ & $\begin{array}{c}0.59 \\
{[3.03]}\end{array}$ & & & $\begin{array}{r}2.15 \\
{[11.91]}\end{array}$ & $\begin{array}{c}0.52 \\
{[3.68]}\end{array}$ & $\begin{array}{c}0.49 \\
{[3.95]}\end{array}$ & $\begin{array}{r}0.35 \\
{[3.10]}\end{array}$ \\
\hline
\end{tabular}


Table 2.2

Cross-section Expected Return on VASY and Skew Sorted (Value-Weighted) Portfolios

We form equal-weighted quintile portfolios every year by computing the variance, volatility-asymmetries, and skewness of individual stocks, using daily data over the year. The sample contains all stocks listed on the NYSE, AMEX, or NASDAQ for the period from 1927 to 2020 . We use two steps to generate the report. First, stocks are sorted into subgroups based on their VASY (Skew) and VAR. We form ten portfolios by five groups of stocks with positive value in VASY (Skew) and another five groups with negative value in VASY (Skew). Then, we calculate the pre-formation average monthly return and the post-formation average monthly returns in one, two, and three years, respectively. The statistic "1-5" ("10-6") refers to the difference in average returns between portfolio one (ten) and portfolio five (six). The returns are reported in percentage values. The t-statistics are reported in square brackets, where those in bold are statistically significant at the five percent level.

\begin{tabular}{|c|c|c|c|c|c|c|c|c|c|c|c|c|}
\hline \multirow[b]{3}{*}{ Rank } & \multicolumn{6}{|c|}{ Sorted by VASY } & \multicolumn{6}{|c|}{ Sorted by Skew } \\
\hline & \multicolumn{3}{|c|}{$\begin{array}{c}\text { Pre-Formation } \\
\text { Average }\end{array}$} & \multicolumn{3}{|c|}{$\begin{array}{l}\text { Post-Formation } \\
\text { Average Return }\end{array}$} & \multicolumn{3}{|c|}{$\begin{array}{l}\text { Pre-Formation } \\
\text { Average }\end{array}$} & \multicolumn{3}{|c|}{$\begin{array}{l}\text { Post-Formation } \\
\text { Average Return }\end{array}$} \\
\hline & $\begin{array}{l}\text { VASY } \\
\left(\times 10^{-4}\right)\end{array}$ & $\begin{array}{c}\text { VAR } \\
\left(\times 10^{-4}\right)\end{array}$ & Return & $y+1$ & $y+2$ & $y+3$ & Skew & $\begin{array}{c}\text { VAR } \\
\left(\times 10^{-4}\right)\end{array}$ & Return & $y+1$ & $y+2$ & $y+3$ \\
\hline 1 & -8.42 & 54.70 & 2.67 & 1.43 & 1.35 & 1.28 & -1.67 & 7.77 & -1.17 & 0.85 & 0.91 & 0.92 \\
\hline 2 & -0.35 & 16.78 & 1.64 & 1.09 & 1.13 & 1.12 & -0.56 & 6.30 & -0.28 & 0.73 & 0.86 & 0.93 \\
\hline 3 & -0.11 & 9.90 & 1.38 & 1.01 & 1.00 & 1.06 & -0.30 & 6.10 & 0.02 & 0.72 & 0.81 & 0.86 \\
\hline 4 & -0.03 & 6.04 & 1.12 & 0.95 & 0.87 & 0.94 & -0.15 & 6.35 & 0.22 & 0.76 & 0.90 & 0.90 \\
\hline 5 & -0.01 & 3.40 & 0.79 & 0.79 & 0.76 & 0.75 & -0.05 & 6.66 & 0.43 & 0.74 & 0.82 & 0.91 \\
\hline $1-5$ & & & $\begin{array}{c}1.88 \\
{[6.03]}\end{array}$ & $\begin{array}{c}0.64 \\
{[2.50]}\end{array}$ & $\begin{array}{c}0.59 \\
{[2.67]}\end{array}$ & $\begin{array}{c}0.53 \\
{[2.76]}\end{array}$ & & & $\begin{array}{c}-1.60 \\
{[-13.79]}\end{array}$ & $\begin{array}{c}0.11 \\
{[1.12]}\end{array}$ & $\begin{array}{c}0.09 \\
{[1.24]}\end{array}$ & $\begin{array}{c}0.01 \\
{[0.13]}\end{array}$ \\
\hline 6 & 0.00 & 2.88 & 0.53 & 0.64 & 0.64 & 0.79 & 0.13 & 7.87 & 0.61 & 0.83 & 0.86 & 0.93 \\
\hline 7 & 0.01 & 4.40 & 0.39 & 0.66 & 0.83 & 0.87 & 0.35 & 9.98 & 0.88 & 0.97 & 0.95 & 0.97 \\
\hline 8 & 0.03 & 6.52 & 0.25 & 0.82 & 0.89 & 0.95 & 0.59 & 12.64 & 1.21 & 1.01 & 0.95 & 1.04 \\
\hline 9 & 0.10 & 10.51 & -0.28 & 0.85 & 0.95 & 1.09 & 0.96 & 16.56 & 1.67 & 1.12 & 1.08 & 1.08 \\
\hline 10 & 1.10 & 22.15 & -1.50 & 1.34 & 1.36 & 1.17 & 2.47 & 35.00 & 2.59 & 1.22 & 1.17 & 1.07 \\
\hline $10-6$ & & & $\begin{array}{c}-2.03 \\
{[-8.57]}\end{array}$ & $\begin{array}{c}0.70 \\
{[2.85]}\end{array}$ & $\begin{array}{c}0.72 \\
{[3.95]}\end{array}$ & $\begin{array}{c}0.38 \\
{[2.58]}\end{array}$ & & & $\begin{array}{r}1.98 \\
{[11.15]}\end{array}$ & $\begin{array}{c}0.39 \\
{[3.21]}\end{array}$ & $\begin{array}{c}0.31 \\
{[3.19]}\end{array}$ & $\begin{array}{c}0.14 \\
{[1.91]}\end{array}$ \\
\hline
\end{tabular}


Table 3.1

Monthly Excess Returns of Equal-weighted Portfolios Sorted by Coasymmetry, Coskewness, and Up/Down Beta

This table presents the equal-weighted average monthly excess returns of portfolios sorted by coasymmetry, coskewness, and up/down beta. At the beginning of each calendar year, we compute coasymmetry, coskewness, and up/down beta to for stocks that have at least 126 daily returns in the previous year. We form quintile portfolios based on the positive and negative coasymmetry, coskewness, and the up/down beta. We report the equal-weighted average monthly excess returns in the next year $\left(\bar{R}_{y}^{e}\right)$, the second year $\left(\bar{R}_{y+1}^{e}\right)$, and the third year $\left(\bar{R}_{y+2}^{e}\right)$. The returns are reported in percentage values. The sample consists of all CRSP stocks from 1927 to 2020 . The statistic "1-5" ("10-6") refers to the difference in the average monthly excess returns between portfolio $1(10)$ and portfolio $5(6)$. The t-statistics are reported in square brackets. ${ }^{* * *}, * *$, and $*$ stand for statistical significance at $1 \%, 5 \%$, and $10 \%$ level, respectively.

\begin{tabular}{|c|c|c|c|c|c|c|c|c|c|c|c|c|c|c|c|}
\hline \multirow[b]{2}{*}{ Rank } & \multicolumn{2}{|c|}{$\begin{array}{c}\text { Pre-Formation } \\
\text { Average }\end{array}$} & \multicolumn{3}{|c|}{$\begin{array}{l}\text { Post-Formation } \\
\text { Average Return }\end{array}$} & \multicolumn{2}{|c|}{$\begin{array}{c}\text { Pre-Formation } \\
\text { Average }\end{array}$} & \multicolumn{3}{|c|}{$\begin{array}{l}\text { Post-Formation } \\
\text { Average Return }\end{array}$} & \multicolumn{2}{|c|}{$\begin{array}{c}\text { Pre-Formation } \\
\text { Average }\end{array}$} & \multicolumn{3}{|c|}{$\begin{array}{l}\text { Post-Formation } \\
\text { Average Return }\end{array}$} \\
\hline & $\begin{array}{l}\text { Negative } \\
\text { COVASY } \\
\end{array}$ & Return & $y+1$ & $y+2$ & $y+3$ & $\begin{array}{l}\text { Negative } \\
\text { COSKEW }\end{array}$ & Return & $y+1$ & $y+2$ & $y+3$ & $\begin{array}{c}\text { Down } \\
\text { Beta }\end{array}$ & Return & $y+1$ & $y+2$ & $y+3$ \\
\hline 1 & -22.04 & 0.74 & 1.45 & 1.72 & 1.96 & -0.45 & 1.23 & 1.04 & 1.04 & 1.07 & -0.06 & 0.56 & 1.17 & 1.12 & 1.14 \\
\hline 2 & -6.67 & 0.85 & 0.93 & 1.17 & 1.28 & -0.30 & 1.19 & 1.10 & 1.09 & 1.25 & 0.55 & 0.71 & 1.00 & 1.07 & 1.09 \\
\hline 3 & -3.43 & 0.74 & 1.15 & 1.10 & 1.06 & -0.22 & 1.05 & 1.06 & 1.06 & 1.23 & 0.90 & 0.85 & 1.02 & 1.07 & 1.10 \\
\hline 4 & -1.77 & 0.82 & 0.93 & 0.97 & 0.91 & -0.15 & 0.92 & 1.16 & 1.15 & 1.18 & 1.29 & 1.04 & 1.06 & 1.06 & 1.13 \\
\hline 5 & -0.56 & 0.82 & 0.89 & 1.01 & 0.95 & -0.06 & 0.79 & 1.21 & 1.16 & 1.25 & 2.10 & 1.56 & 1.02 & 1.04 & 1.21 \\
\hline $1-5$ & & $\begin{array}{c}-0.09 \\
{[-0.35]}\end{array}$ & $\begin{array}{r}0.56 \\
{[3.10]} \\
\end{array}$ & $\begin{array}{c}0.71 \\
{[2.14]} \\
\end{array}$ & $\begin{array}{c}1.01 \\
{[2.08]} \\
\end{array}$ & & $\begin{array}{r}0.44 \\
{[4.30]} \\
\end{array}$ & $\begin{array}{r}-0.17 \\
{[-2.43]} \\
\end{array}$ & $\begin{array}{c}-0.11 \\
{[-1.20]}\end{array}$ & $\begin{array}{c}-0.18 \\
{[-1.77]} \\
\end{array}$ & & $\begin{array}{c}-1.00 \\
{[-5.14]} \\
\end{array}$ & $\begin{array}{r}0.15 \\
{[0.86]} \\
\end{array}$ & $\begin{array}{c}0.08 \\
{[0.53]}\end{array}$ & $\begin{array}{c}-0.07 \\
{[-0.49]} \\
\end{array}$ \\
\hline Rank & $\begin{array}{l}\text { Positive } \\
\text { COVASY } \\
\end{array}$ & Return & $\mathrm{y}+1$ & $y+2$ & $y+3$ & $\begin{array}{l}\text { Positive } \\
\text { COSKEW } \\
\end{array}$ & Return & $y+1$ & $y+2$ & $y+3$ & $\begin{array}{c}\text { Up } \\
\text { Beta }\end{array}$ & Return & $\mathrm{y}+1$ & $y+2$ & $y+3$ \\
\hline 6 & 0.60 & 0.89 & 0.96 & 0.98 & 1.08 & 0.02 & 0.61 & 1.13 & 1.12 & 1.20 & -0.26 & 0.70 & 1.21 & 1.21 & 1.22 \\
\hline 7 & 2.29 & 0.96 & 0.94 & 1.01 & 1.04 & 0.05 & 0.63 & 1.11 & 1.28 & 0.99 & 0.36 & 0.83 & 1.01 & 1.01 & 1.07 \\
\hline 8 & 4.82 & 1.05 & 1.04 & 1.07 & 1.15 & 0.10 & 0.58 & 1.08 & 1.28 & 1.38 & 0.73 & 0.91 & 0.99 & 1.03 & 1.10 \\
\hline 9 & 9.06 & 1.10 & 1.15 & 1.08 & 1.23 & 0.16 & 0.66 & 0.96 & 1.06 & 1.21 & 1.15 & 1.04 & 1.03 & 1.04 & 1.12 \\
\hline 10 & 23.99 & 1.16 & 1.40 & 1.42 & 1.47 & 0.30 & 0.57 & 0.94 & 0.97 & 1.33 & 2.03 & 1.24 & 1.03 & 1.07 & 1.16 \\
\hline $10-6$ & & $\begin{array}{c}0.27 \\
{[1.51]}\end{array}$ & $\begin{array}{c}0.44 \\
{[2.85]} \\
\end{array}$ & $\begin{array}{c}0.44 \\
{[2.72]}\end{array}$ & $\begin{array}{c}0.39 \\
{[2.82]} \\
\end{array}$ & & $\begin{array}{c}-0.04 \\
{[-0.18]}\end{array}$ & $\begin{array}{c}-0.19 \\
{[-1.27]}\end{array}$ & $\begin{array}{r}-0.15 \\
{[-0.96]} \\
\end{array}$ & $\begin{array}{c}0.13 \\
{[0.51]}\end{array}$ & & $\begin{array}{c}0.54 \\
{[3.42]}\end{array}$ & $\begin{array}{r}-0.18 \\
{[-1.48} \\
\end{array}$ & $\begin{array}{c}-0.14 \\
{[-1.16]} \\
\end{array}$ & $\begin{array}{c}-0.05 \\
{[-0.45]} \\
\end{array}$ \\
\hline
\end{tabular}


Table 3.2

Monthly Excess Returns of Value-weighted Portfolios Sorted by Coasymmetry, Coskewness, and Up/Down Beta

This table presents the value-weighted average monthly excess returns of portfolios sorted by coasymmetry, coskewness, and up/down beta. At the beginning of each calendar year, we compute coasymmetry, coskewness, and up/down beta to for stocks that have at least 126 daily returns in the previous year. We form quintile portfolios based on the positive and negative coasymmetry, coskewness, and the up/down beta. We report the equal-weighted average monthly excess returns in the next year $\left(\bar{R}_{y}^{e}\right)$, the second year $\left(\bar{R}_{y+1}^{e}\right)$, and the third year $\left(\bar{R}_{y+2}^{e}\right)$. The returns are reported in percentage values. The sample consists of all CRSP stocks from 1927 to 2020 . The statistic "1-5" ("10-6") refers to the difference in the average monthly excess returns between portfolio $1(10)$ and portfolio $5(6)$. The t-statistics are reported in square brackets. ***, **, and * stand for statistical significance at $1 \%, 5 \%$, and $10 \%$ level, respectively.

\begin{tabular}{|c|c|c|c|c|c|c|c|c|c|c|c|c|c|c|c|}
\hline \multirow[b]{2}{*}{ Rank } & \multicolumn{2}{|c|}{$\begin{array}{c}\text { Pre-Formation } \\
\text { Average }\end{array}$} & \multicolumn{3}{|c|}{$\begin{array}{l}\text { Post-Formation } \\
\text { Average Return }\end{array}$} & \multicolumn{2}{|c|}{$\begin{array}{c}\text { Pre-Formation } \\
\text { Average }\end{array}$} & \multicolumn{3}{|c|}{$\begin{array}{l}\text { Post-Formation } \\
\text { Average Return }\end{array}$} & \multicolumn{2}{|c|}{$\begin{array}{c}\text { Pre-Formation } \\
\text { Average }\end{array}$} & \multicolumn{3}{|c|}{$\begin{array}{l}\text { Post-Formation } \\
\text { Average Return }\end{array}$} \\
\hline & $\begin{array}{l}\text { Negative } \\
\text { COVASY } \\
\end{array}$ & Return & $y+1$ & $y+2$ & $y+3$ & $\begin{array}{l}\text { Negative } \\
\text { COSKEW }\end{array}$ & Return & $y+1$ & $y+2$ & $y+3$ & $\begin{array}{c}\text { Down } \\
\text { Beta }\end{array}$ & Return & $y+1$ & $y+2$ & $y+3$ \\
\hline 1 & -20.17 & 0.91 & 1.30 & 1.49 & 1.71 & -0.45 & 1.30 & 0.98 & 0.96 & 0.97 & -0.01 & 0.60 & 1.04 & 0.96 & 0.95 \\
\hline 2 & -6.67 & 0.87 & 0.85 & 1.04 & 1.06 & -0.30 & 1.23 & 1.03 & 0.99 & 1.08 & 0.55 & 0.73 & 0.93 & 0.96 & 0.96 \\
\hline 3 & -3.42 & 0.80 & 1.01 & 0.99 & 0.90 & -0.22 & 1.11 & 0.99 & 0.95 & 1.08 & 0.90 & 0.88 & 0.98 & 0.97 & 0.97 \\
\hline 4 & -1.77 & 0.85 & 0.86 & 0.89 & 0.82 & -0.15 & 0.98 & 1.06 & 1.02 & 1.03 & 1.29 & 1.11 & 0.99 & 0.97 & 0.99 \\
\hline 5 & -0.57 & 0.84 & 0.84 & 0.87 & 0.81 & -0.06 & 0.84 & 1.10 & 1.00 & 1.05 & 2.07 & 1.71 & 0.92 & 0.92 & 1.06 \\
\hline $1-5$ & & $\begin{array}{c}0.07 \\
{[0.32]}\end{array}$ & $\begin{array}{r}0.45 \\
{[2.63]} \\
\end{array}$ & $\begin{array}{r}0.62 \\
{[2.07]} \\
\end{array}$ & $\begin{array}{c}0.90 \\
{[1.91]} \\
\end{array}$ & & $\begin{array}{c}0.46 \\
{[4.93]} \\
\end{array}$ & $\begin{array}{r}-0.12 \\
{[-1.75]} \\
\end{array}$ & $\begin{array}{c}-0.04 \\
{[-0.39]}\end{array}$ & $\begin{array}{c}-0.08 \\
{[-0.92]}\end{array}$ & & $\begin{array}{c}-1.11 \\
{[-5.44]} \\
\end{array}$ & $\begin{array}{r}0.12 \\
{[0.68]} \\
\end{array}$ & $\begin{array}{c}0.04 \\
{[0.22]} \\
\end{array}$ & $\begin{array}{c}-0.11 \\
{[-0.84]}\end{array}$ \\
\hline Rank & $\begin{array}{l}\text { Positive } \\
\text { COVASY } \\
\end{array}$ & Return & $\mathrm{y}+1$ & $y+2$ & $y+3$ & $\begin{array}{l}\text { Positive } \\
\text { COSKEW } \\
\end{array}$ & Return & $y+1$ & $y+2$ & $y+3$ & $\begin{array}{c}\text { Up } \\
\text { Beta }\end{array}$ & Return & $\mathrm{y}+1$ & $y+2$ & $y+3$ \\
\hline 6 & 0.60 & 0.90 & 0.91 & 0.88 & 0.95 & 0.02 & 0.64 & 1.03 & 1.00 & 1.02 & -0.23 & 0.78 & 1.07 & 1.02 & 1.01 \\
\hline 7 & 2.30 & 1.00 & 0.90 & 0.92 & 0.93 & 0.05 & 0.72 & 0.99 & 1.14 & 0.87 & 0.37 & 0.84 & 0.94 & 0.91 & 0.93 \\
\hline 8 & 4.81 & 1.12 & 0.98 & 0.97 & 1.02 & 0.10 & 0.65 & 0.94 & 1.10 & 1.09 & 0.73 & 0.95 & 0.94 & 0.94 & 0.97 \\
\hline 9 & 9.05 & 1.18 & 1.09 & 0.97 & 1.09 & 0.16 & 0.59 & 0.87 & 0.96 & 1.00 & 1.15 & 1.10 & 0.97 & 0.96 & 1.00 \\
\hline 10 & 22.72 & 1.31 & 1.24 & 1.23 & 1.22 & 0.30 & 0.49 & 0.85 & 0.82 & 1.04 & 1.99 & 1.36 & 0.95 & 0.97 & 1.02 \\
\hline $10-6$ & & $\begin{array}{c}0.41 \\
{[2.58]} \\
\end{array}$ & $\begin{array}{c}0.33 \\
{[2.34]} \\
\end{array}$ & $\begin{array}{c}0.35 \\
{[2.50]}\end{array}$ & $\begin{array}{c}0.27 \\
{[2.43]} \\
\end{array}$ & & $\begin{array}{c}-0.15 \\
{[-1.28]}\end{array}$ & $\begin{array}{c}-0.18 \\
{[-1.28]}\end{array}$ & $\begin{array}{c}-0.18 \\
{[-1.31]}\end{array}$ & $\begin{array}{c}0.02 \\
{[0.11]} \\
\end{array}$ & & $\begin{array}{c}0.58 \\
{[3.54]}\end{array}$ & $\begin{array}{r}-0.12 \\
{[-1.05} \\
\end{array}$ & $\begin{array}{c}-0.05 \\
{[-0.47]}\end{array}$ & $\begin{array}{c}0.01 \\
{[0.16]} \\
\end{array}$ \\
\hline
\end{tabular}


Table 4

\section{Fama-Macbeth Regressions}

This table presents the results of Fama-MacBeth (1973) regressions of realized monthly excess returns on ex-ante asymmetry beta and betas on firm characteristics. I $^{\text {COVASY }}$ is equal to 1 for stocks with positive COVASY and zero otherwise. The sample consists of all CRSP stocks from 1963 to 2020. Coefficients are in percentage values. The Newey-West (1987) t-statistics are reported in square brackets, where those in bold stand for statistical significance at the five percent level.

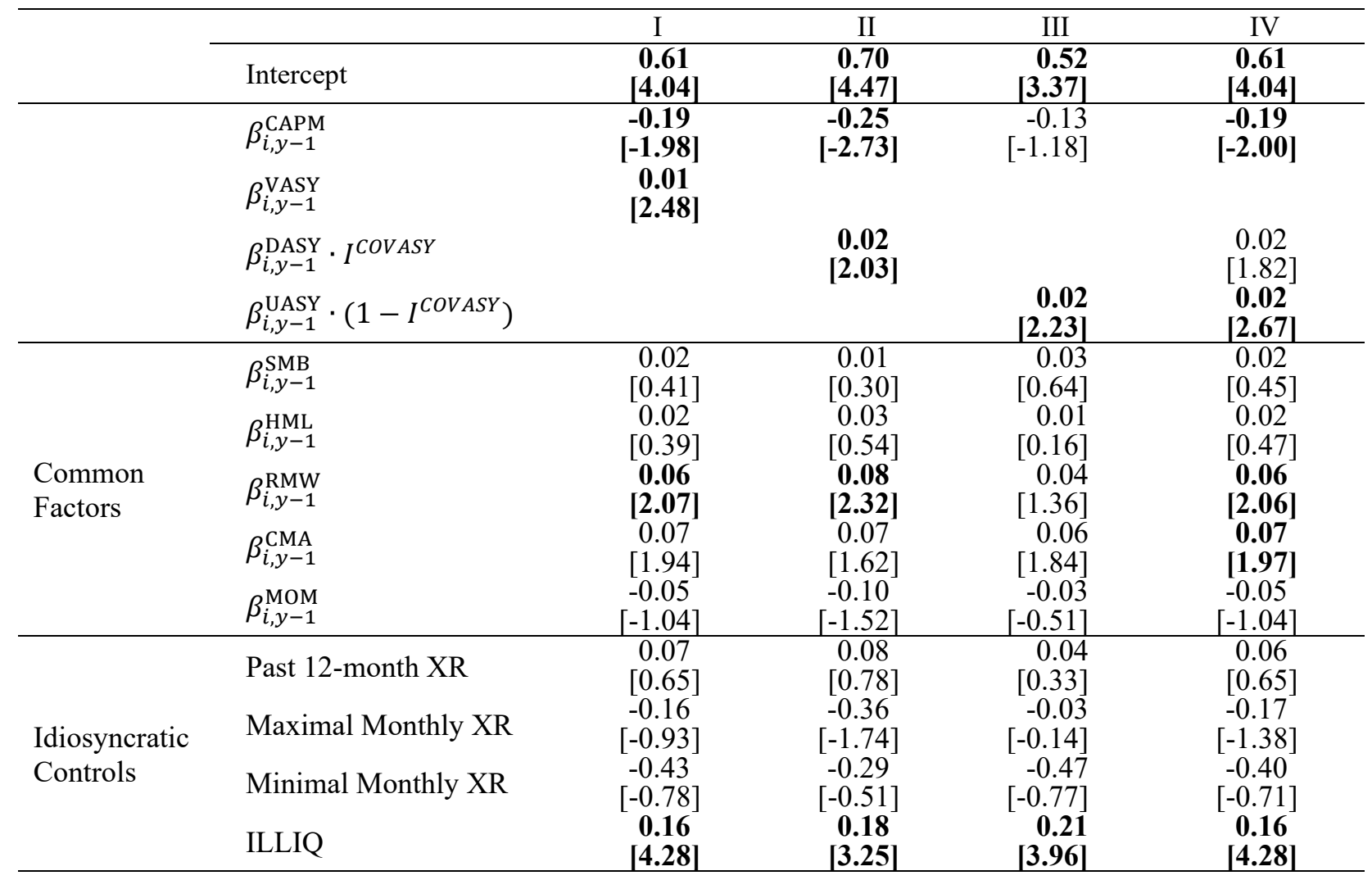




\section{Table 5}

Ex-ante Betas of Portfolios Sorted on Ex-ante Asymmetry betas

This table reports the ex-ante calendar-year betas sorted on ex-ante asymmetry betas. At the beginning of each calendar year (starting from 1928), we use daily returns over the previous year to estimate the exante betas for all stocks with at least 126 daily returns in the last year. Then we form equal-weighted quintile portfolios by their upside and downside asymmetry betas. For each portfolio, we report the down (up) beta, the size beta, the value beta, the momentum beta, the profitability beta, the investment beta, and coskewness. The coasymmetry (COASY) is scaled by multiplying by $10^{6}$. The sample consists of all CRSP stocks from 1927 to 2020.

\begin{tabular}{|c|c|c|c|c|c|c|c|c|c|c|}
\hline Rank & COVASY & $\hat{b}^{\mathrm{UASY}}$ & $\hat{b}^{\mathrm{MV}}$ & $\hat{b}^{\mathrm{UP}}$ & $\hat{b}^{\mathrm{SMB}}$ & $\hat{b}^{\mathrm{HML}}$ & $\hat{b}^{\mathrm{MOM}}$ & $\hat{b}^{\mathrm{RMW}}$ & $\hat{b}^{\mathrm{CMA}}$ & COSKEW \\
\hline 1 & -22.04 & 22.02 & 0.62 & 0.68 & 0.79 & 0.18 & -0.14 & -0.32 & -0.01 & -0.02 \\
\hline 2 & -6.67 & 4.47 & 0.74 & 0.73 & 0.68 & 0.18 & -0.10 & -0.19 & -0.02 & -0.05 \\
\hline 3 & -3.43 & 2.29 & 0.71 & 0.70 & 0.55 & 0.18 & -0.09 & -0.11 & 0.01 & -0.04 \\
\hline 4 & -1.77 & 1.15 & 0.65 & 0.63 & 0.48 & 0.19 & -0.06 & -0.07 & 0.03 & -0.03 \\
\hline 5 & -0.56 & 0.36 & 0.59 & 0.54 & 0.46 & 0.19 & -0.05 & -0.04 & 0.02 & -0.06 \\
\hline & COVASY & $\hat{b}^{\mathrm{DASY}}$ & $\hat{b}^{\mathrm{MV}}$ & $\hat{b}^{\text {DW }}$ & $\hat{b}^{\text {SMB }}$ & $\hat{b}^{\mathrm{HML}}$ & $\hat{b}^{\mathrm{MOM}}$ & $\hat{b}^{\mathrm{RMW}}$ & $\hat{b}^{\mathrm{CMA}}$ & COSKEW \\
\hline 6 & 0.60 & 0.32 & 0.63 & 0.68 & 0.48 & 0.17 & -0.06 & -0.07 & 0.03 & -0.20 \\
\hline 7 & 2.29 & 0.97 & 0.79 & 0.86 & 0.52 & 0.18 & -0.04 & -0.10 & 0.03 & -0.29 \\
\hline 8 & 4.82 & 1.81 & 0.88 & 1.00 & 0.62 & 0.22 & -0.05 & -0.14 & 0.04 & -0.23 \\
\hline 9 & 9.06 & 3.43 & 0.90 & 1.08 & 0.77 & 0.24 & -0.07 & -0.16 & 0.03 & -0.15 \\
\hline 10 & 23.99 & 11.55 & 0.88 & 1.10 & 0.94 & 0.29 & -0.14 & -0.27 & 0.09 & -0.09 \\
\hline
\end{tabular}


Table 6.1

Monthly Excess Returns of Equal-weighted Portfolios Double Sorted by Ex-ante CAPM Beta and Asymmetry Beta

This table presents the equal-weighted average monthly excess returns of portfolios sorted by CAPM beta and upside/downside asymmetry beta. At the beginning of each calendar year, we compute CAPM beta and asymmetry beta for stocks that have at least 126 daily returns in the previous year. Then we form $3 \times 5$ portfolios and report the equal-weighted average monthly excess returns in the next year, the second year, and the third year. The returns are reported in percentage values. The sample consists of all CRSP stocks from 1927 to 2020. The statistic "1-5" ("10-6") refers to the difference in the average monthly excess returns between portfolio 1 (10) and portfolio 5 (6). The t-statistics are reported in square brackets. $* * *, * *$, and $*$ stand for statistical significance at $1 \%, 5 \%$, and $10 \%$ level, respectively.

\begin{tabular}{|c|c|c|c|c|c|c|c|c|c|c|c|c|c|c|c|}
\hline \multirow[b]{3}{*}{ Rank } & \multicolumn{5}{|c|}{ Low CAPM Beta } & \multicolumn{5}{|c|}{ Medium CAPM Beta } & \multicolumn{5}{|c|}{ High CAPM Beta } \\
\hline & \multicolumn{2}{|c|}{$\begin{array}{c}\text { Pre-Formation } \\
\text { Average }\end{array}$} & \multicolumn{3}{|c|}{$\begin{array}{l}\text { Post-Formation } \\
\text { Average Return }\end{array}$} & \multicolumn{2}{|c|}{$\begin{array}{c}\text { Pre-Formation } \\
\text { Average }\end{array}$} & \multicolumn{3}{|c|}{$\begin{array}{l}\text { Post-Formation } \\
\text { Average Return }\end{array}$} & \multicolumn{2}{|c|}{$\begin{array}{c}\text { Pre-Formation } \\
\text { Average }\end{array}$} & \multicolumn{3}{|c|}{$\begin{array}{l}\text { Post-Formation } \\
\text { Average Return }\end{array}$} \\
\hline & $\begin{array}{c}\text { Upside } \\
\text { Asymmetry } \\
\text { Beta }\end{array}$ & Return & $y+1$ & $y+2$ & $y+3$ & $\begin{array}{c}\text { Upside } \\
\text { Asymmetry } \\
\text { Beta }\end{array}$ & Return & $y+1$ & $y+2$ & $y+3$ & $\begin{array}{c}\text { Upside } \\
\text { Asymmetry } \\
\text { Beta }\end{array}$ & Return & $y+1$ & $y+2$ & $y+3$ \\
\hline 1 & 87.68 & 0.55 & 1.58 & 1.74 & 2.06 & 41.34 & 0.81 & 1.47 & 1.45 & 1.09 & 31.04 & 1.55 & 1.53 & 1.39 & 1.21 \\
\hline 2 & 29.59 & 0.63 & 1.19 & 1.22 & 1.22 & 19.50 & 0.91 & 1.00 & 1.34 & 1.37 & 10.81 & 1.41 & 1.06 & 1.03 & 0.98 \\
\hline 3 & 17.73 & 0.48 & 1.01 & 0.96 & 0.99 & 12.62 & 0.93 & 0.97 & 1.18 & 1.07 & 5.35 & 1.49 & 0.93 & 1.21 & 0.98 \\
\hline 4 & 8.81 & 0.55 & 1.04 & 1.01 & 0.86 & 4.80 & 0.92 & 1.00 & 1.10 & 1.07 & 2.60 & 1.71 & 0.96 & 0.97 & 0.74 \\
\hline 5 & 3.41 & 0.56 & 0.94 & 0.99 & 0.84 & 1.10 & 0.98 & 0.95 & 1.08 & 1.14 & 0.76 & 1.37 & 0.95 & 1.12 & 0.95 \\
\hline $1-5$ & & $\begin{array}{c}-0.01 \\
{[-0.09]}\end{array}$ & $\begin{array}{c}0.64 \\
{[3.42]}\end{array}$ & $\begin{array}{c}0.75 \\
{[2.44]}\end{array}$ & $\begin{array}{c}1.22 \\
{[2.31]}\end{array}$ & & $\begin{array}{c}-0.16 \\
{[-0.89]}\end{array}$ & $\begin{array}{c}0.52 \\
{[2.39]}\end{array}$ & $\begin{array}{c}0.37 \\
{[2.19]}\end{array}$ & $\begin{array}{c}-0.05 \\
{[-0.12]}\end{array}$ & & $\begin{array}{c}0.18 \\
{[0.65]}\end{array}$ & $\begin{array}{r}0.58 \\
{[2.32]}\end{array}$ & $\begin{array}{c}0.27 \\
{[1.14]}\end{array}$ & $\begin{array}{c}0.26 \\
{[1.59]}\end{array}$ \\
\hline Rank & $\begin{array}{c}\text { Downside } \\
\text { Asymmetry } \\
\text { Beta } \\
\end{array}$ & Return & $y+1$ & $\mathrm{y}+2$ & $y+3$ & $\begin{array}{c}\text { Downside } \\
\text { Asymmetry } \\
\text { Beta } \\
\end{array}$ & Return & $\mathrm{y}+1$ & $y+2$ & $y+3$ & $\begin{array}{c}\text { Downside } \\
\text { Asymmetry } \\
\text { Beta }\end{array}$ & Return & $\mathrm{y}+1$ & $y+2$ & $y+3$ \\
\hline 6 & 0.48 & 0.65 & 0.99 & 1.03 & 1.11 & 0.55 & 0.96 & 1.01 & 1.11 & 0.98 & 0.83 & 1.16 & 0.84 & 1.05 & 1.00 \\
\hline 7 & 1.51 & 0.82 & 0.97 & 1.12 & 1.09 & 1.80 & 0.99 & 1.04 & 1.11 & 0.93 & 2.14 & 1.40 & 1.10 & 0.92 & 0.98 \\
\hline 8 & 2.96 & 0.94 & 1.06 & 1.06 & 1.11 & 3.25 & 0.93 & 1.09 & 1.11 & 1.26 & 3.93 & 1.13 & 0.93 & 1.02 & 1.01 \\
\hline 9 & 5.54 & 0.65 & 1.37 & 1.19 & 1.05 & 5.60 & 1.11 & 1.24 & 1.11 & 1.12 & 6.34 & 1.48 & 0.86 & 1.21 & 1.10 \\
\hline 10 & 13.71 & 0.87 & 1.85 & 1.52 & 1.57 & 14.44 & 1.01 & 1.45 & 1.59 & 1.44 & 14.49 & 1.61 & 1.24 & 1.25 & 1.28 \\
\hline $10-6$ & & $\begin{array}{c}0.22 \\
{[1.51]}\end{array}$ & $\begin{array}{c}0.86 \\
{[3.95]}\end{array}$ & $\begin{array}{c}0.49 \\
{[2.15]}\end{array}$ & $\begin{array}{c}0.46 \\
{[2.86]}\end{array}$ & & $\begin{array}{c}0.05 \\
{[0.27]}\end{array}$ & $\begin{array}{c}0.44 \\
{[3.02]}\end{array}$ & $\begin{array}{c}0.48 \\
{[2.54]}\end{array}$ & $\begin{array}{c}0.46 \\
{[2.62]}\end{array}$ & & $\begin{array}{c}0.45 \\
{[2.24]}\end{array}$ & $\begin{array}{c}0.40 \\
{[1.84]}\end{array}$ & $\begin{array}{c}0.20 \\
{[1.32]}\end{array}$ & $\begin{array}{c}0.28 \\
{[1.82]}\end{array}$ \\
\hline
\end{tabular}


Table 6.2

Monthly Excess Returns of Value-weighted Portfolios Double Sorted by Ex-ante CAPM Beta and Asymmetry Beta

This table presents the equal-weighted average monthly excess returns of portfolios sorted by CAPM beta and upside/downside asymmetry beta. At the beginning of each calendar year, we compute CAPM beta and asymmetry beta for stocks that have at least 126 daily returns in the previous year. Then we form $3 \times 5$ portfolios and report the equal-weighted average monthly excess returns in the next year, the second year, and the third year. The returns are reported in percentage values. The sample consists of all CRSP stocks from 1927 to 2020. The statistic "1-5" ("10-6") refers to the difference in the average monthly excess returns between portfolio 1 (10) and portfolio 5 (6). The t-statistics are reported in square brackets. $* * *, * *$, and $*$ stand for statistical significance at $1 \%, 5 \%$, and $10 \%$ level, respectively.

\begin{tabular}{|c|c|c|c|c|c|c|c|c|c|c|c|c|c|c|c|}
\hline \multirow[b]{3}{*}{ Rank } & \multicolumn{5}{|c|}{ Low CAPM Beta } & \multicolumn{5}{|c|}{ Medium CAPM Beta } & \multicolumn{5}{|c|}{ High CAPM Beta } \\
\hline & \multicolumn{2}{|c|}{$\begin{array}{c}\text { Pre-Formation } \\
\text { Average }\end{array}$} & \multicolumn{3}{|c|}{$\begin{array}{l}\text { Post-Formation } \\
\text { Average Return }\end{array}$} & \multicolumn{2}{|c|}{$\begin{array}{c}\text { Pre-Formation } \\
\text { Average }\end{array}$} & \multicolumn{3}{|c|}{$\begin{array}{l}\text { Post-Formation } \\
\text { Average Return }\end{array}$} & \multicolumn{2}{|c|}{$\begin{array}{c}\text { Pre-Formation } \\
\text { Average }\end{array}$} & \multicolumn{3}{|c|}{$\begin{array}{l}\text { Post-Formation } \\
\text { Average Return }\end{array}$} \\
\hline & $\begin{array}{c}\text { Upside } \\
\text { Asymmetry } \\
\text { Beta }\end{array}$ & Return & $y^{+1}$ & $y+2$ & $y+3$ & $\begin{array}{c}\text { Upside } \\
\text { Asymmetry } \\
\text { Beta }\end{array}$ & Return & $y+1$ & $y+2$ & $y+3$ & $\begin{array}{c}\text { Upside } \\
\text { Asymmetry } \\
\text { Beta }\end{array}$ & Return & $y+1$ & $y+2$ & $y+3$ \\
\hline 1 & 86.50 & 0.72 & 1.41 & 1.51 & 1.75 & 19.48 & 0.96 & 1.36 & 1.30 & 0.96 & 30.02 & 1.80 & 1.36 & 1.21 & 1.05 \\
\hline 2 & 31.01 & 0.63 & 1.05 & 1.08 & 0.96 & 18.88 & 0.97 & 0.91 & 1.16 & 1.18 & 11.13 & 1.51 & 1.00 & 0.97 & 0.89 \\
\hline 3 & 17.70 & 0.51 & 0.91 & 0.86 & 0.81 & 12.63 & 0.95 & 0.92 & 1.07 & 0.94 & 5.53 & 1.47 & 0.90 & 1.07 & 0.87 \\
\hline 4 & 8.79 & 0.56 & 0.96 & 0.91 & 0.77 & 4.83 & 0.93 & 0.94 & 1.02 & 0.95 & 2.54 & 1.62 & 0.94 & 0.94 & 0.64 \\
\hline 5 & 3.64 & 0.58 & 0.85 & 0.86 & 0.72 & 1.20 & 0.93 & 0.91 & 0.97 & 1.01 & 0.75 & 1.18 & 0.89 & 1.03 & 0.86 \\
\hline $1-5$ & & $\begin{array}{c}0.14 \\
{[0.83]}\end{array}$ & $\begin{array}{c}0.56 \\
{[3.30]}\end{array}$ & $\begin{array}{c}0.65 \\
{[2.23]}\end{array}$ & $\begin{array}{c}1.03 \\
{[2.01]}\end{array}$ & & $\begin{array}{c}0.03 \\
{[0.06]}\end{array}$ & $\begin{array}{c}0.45 \\
{[2.24]}\end{array}$ & $\begin{array}{c}0.33 \\
{[2.06]}\end{array}$ & $\begin{array}{c}-0.05 \\
{[-0.12]}\end{array}$ & & $\begin{array}{c}0.62 \\
{[2.46]}\end{array}$ & $\begin{array}{r}0.47 \\
{[2.05}\end{array}$ & $\begin{array}{c}0.18 \\
{[0.85]}\end{array}$ & $\begin{array}{c}0.19 \\
{[1.43]}\end{array}$ \\
\hline Rank & $\begin{array}{c}\text { Downside } \\
\text { Asymmetry } \\
\text { Beta } \\
\end{array}$ & Return & $y+1$ & $y+2$ & $y+3$ & $\begin{array}{c}\text { Downside } \\
\text { Asymmetry } \\
\text { Beta } \\
\end{array}$ & Return & $\mathrm{y}+1$ & $y+2$ & $y+3$ & $\begin{array}{c}\text { Downside } \\
\text { Asymmetry } \\
\text { Beta }\end{array}$ & Return & $\mathrm{y}+1$ & $y+2$ & $y+3$ \\
\hline 6 & 0.49 & 0.65 & 0.92 & 0.92 & 0.97 & 0.55 & 0.95 & 0.97 & 1.01 & 0.87 & 0.83 & 1.17 & 0.82 & 0.94 & 0.90 \\
\hline 7 & 1.51 & 0.82 & 0.91 & 1.01 & 0.93 & 1.81 & 1.01 & 0.99 & 1.02 & 0.84 & 2.14 & 1.45 & 1.06 & 0.88 & 0.88 \\
\hline 8 & 2.96 & 0.92 & 1.00 & 0.94 & 0.96 & 3.25 & 0.95 & 1.04 & 1.02 & 1.10 & 3.34 & 1.52 & 0.88 & 0.92 & 0.92 \\
\hline 9 & 5.55 & 0.67 & 1.26 & 1.03 & 0.90 & 5.60 & 1.17 & 1.18 & 1.02 & 0.98 & 6.33 & 1.56 & 0.84 & 1.14 & 0.97 \\
\hline 10 & 12.97 & 0.92 & 1.64 & 1.26 & 1.25 & 14.19 & 1.13 & 1.36 & 1.40 & 1.21 & 15.18 & 1.92 & 1.13 & 1.11 & 1.05 \\
\hline $10-6$ & & $\begin{array}{c}0.27 \\
{[1.66]}\end{array}$ & $\begin{array}{c}0.72 \\
{[3.96]}\end{array}$ & $\begin{array}{c}0.34 \\
{[1.90]}\end{array}$ & $\begin{array}{c}0.28 \\
{[2.34]}\end{array}$ & & $\begin{array}{c}0.18 \\
{[1.10]}\end{array}$ & $\begin{array}{c}0.39 \\
{[2.96]}\end{array}$ & $\begin{array}{c}0.39 \\
{[2.53]}\end{array}$ & $\begin{array}{c}0.34 \\
{[2.40]}\end{array}$ & & $\begin{array}{c}0.75 \\
{[2.24]}\end{array}$ & $\begin{array}{c}0.31 \\
{[1.48]}\end{array}$ & $\begin{array}{c}0.17 \\
{[1.30]}\end{array}$ & $\begin{array}{c}0.15 \\
{[1.22]}\end{array}$ \\
\hline
\end{tabular}




\section{Table 7}

\section{Empirical Properties of Asymmetry Premium}

This table presents summary statistics for monthly returns of the upside (downside) asymmetry factor, UASY (DASY). MKT, SMB, and HML are market factor, size factor, and value factor in Fama and French (1993). MOM is the momentum factor in Carhart (1997). RMW and CMA are profitability factor and investment factor in Fama and French (2015). Panel A reports the summary statistics from 1928 to 2020. Panel B reports the results of time-series regressions of asymmetry premium on common risk factors.

\begin{tabular}{ccccccccc}
\hline \multicolumn{1}{l}{ Panel A. Summary statistics of monthly asymmetry premium } \\
\hline \multirow{2}{*}{ UASY } & Mean & Std Dev & Min & P25 & Median & P75 & P95 & Max \\
& $\mathbf{0 . 1 7}$ & 4.08 & -79.71 & -0.61 & 0.04 & 0.83 & 3.44 & 196.93 \\
DASY & $\mathbf{0 . 1 4}$ & & & & & & & \\
& {$[\mathbf{4 . 7 1}]$} & 4.79 & -92.87 & -0.91 & 0.11 & 1.19 & 5.21 & 60.49 \\
\hline
\end{tabular}

Panel B. Time series regressions of asymmetry premium on standard risk factors

\begin{tabular}{|c|c|c|c|c|c|c|c|c|}
\hline & $\alpha$ & MKT & SMB & HML & MOM & RMW & CMA & $\operatorname{Adj}-R^{2}$ \\
\hline \multirow{4}{*}{ UASY } & $\begin{array}{c}0.11 \\
{[5.70]}\end{array}$ & 0.76 & & & \multirow{4}{*}{0.31} & & & 7.68 \\
\hline & $\begin{array}{c}0.09 \\
{[5.06]}\end{array}$ & 0.76 & 0.72 & 0.71 & & & & 11.52 \\
\hline & $\begin{array}{c}0.08 \\
{[4.55]}\end{array}$ & 0.78 & 0.71 & 0.79 & & & & 12.12 \\
\hline & $\begin{array}{c}0.12 \\
{[10.93]}\end{array}$ & 0.24 & 0.41 & -0.47 & & -1.18 & -0.32 & 24.27 \\
\hline \multirow{4}{*}{ DASY } & $\begin{array}{c}\mathbf{0 . 0 8} \\
{[3.62]}\end{array}$ & 0.94 & & & & & & 8.53 \\
\hline & $\begin{array}{c}0.07 \\
{[3.16]}\end{array}$ & 1.02 & 1.07 & 0.25 & \multirow{3}{*}{-0.36} & & & 11.81 \\
\hline & $\begin{array}{c}\mathbf{0 . 0 8} \\
{[3.69]}\end{array}$ & 0.99 & 1.08 & 0.16 & & & & 12.38 \\
\hline & $\begin{array}{c}0.09 \\
{[5.47]}\end{array}$ & 0.67 & 0.79 & -0.18 & & -0.45 & -0.30 & 15.22 \\
\hline
\end{tabular}




\section{Table 8}

\section{Explanation power of asymmetry-model and linear factor models}

The table tests the ability of asymmetry-model and linear factor models to explain excess returns of stocks. For each model, we regress the excess daily returns on the contemporaneous factor prices in each year. We form 25 portfolios with positive coasymmetry and another 25 portfolios with negative coasymmetry. Panel A reports the average of the absolute intercepts (in bps) of each model and the percentage to that of CAPM. Panel B reports the results under five coasymmetry levels.

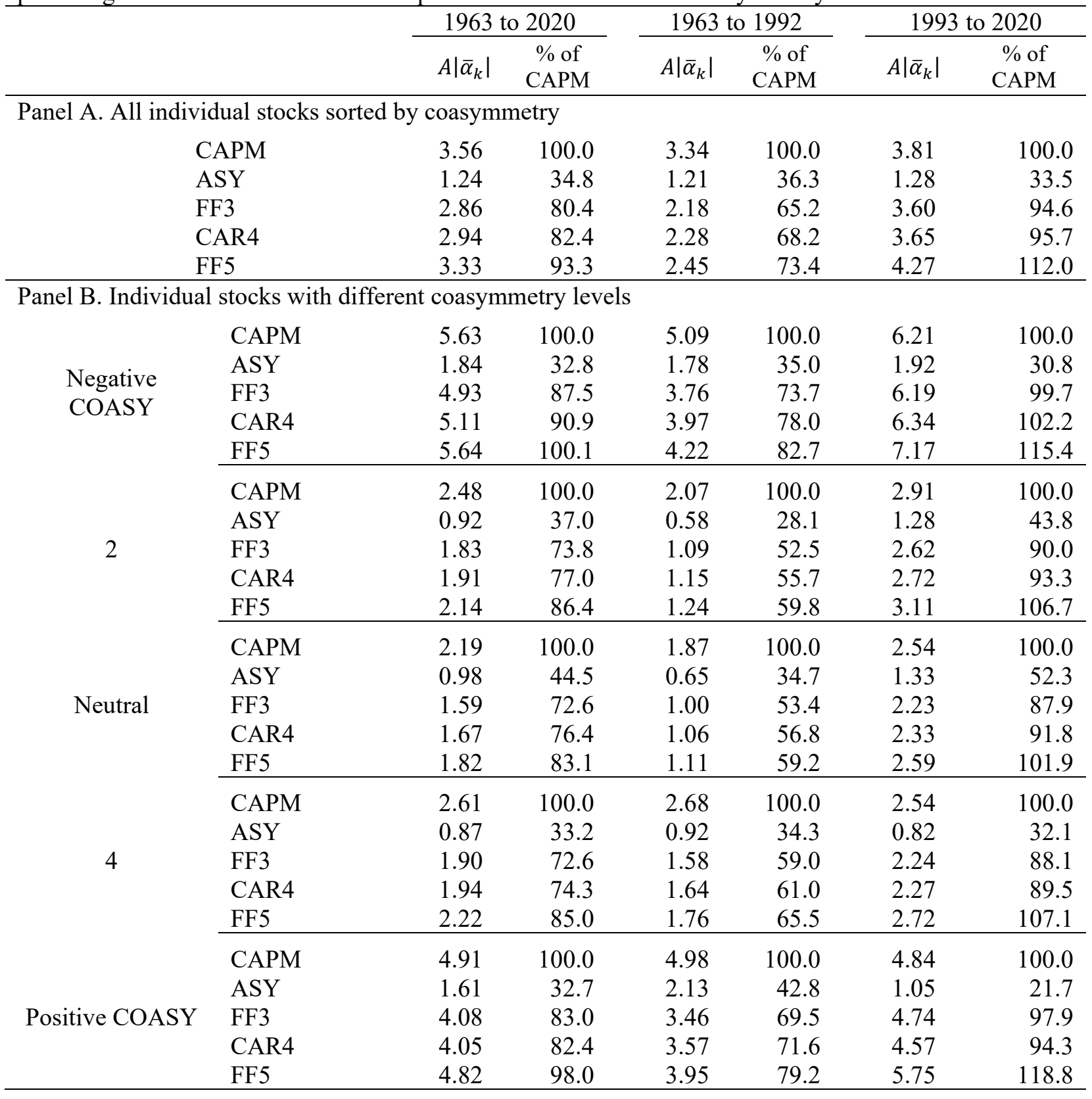




\section{Table 9}

Predictability of asymmetry-model and linear factor models

The table tests the ability of asymmetry-model and linear factor models to explain excess returns of stocks. For each model, we calculate the predicted returns based on the betas and daily average factors in the previous year. We form 25 portfolios with positive coasymmetry and another 25 portfolios with negative coasymmetry. Panel A reports the average of the absolute intercepts (in bps) of each model and the percentage to that of CAPM. Panel B reports the results under five coasymmetry levels.

\begin{tabular}{|c|c|c|c|c|c|c|c|}
\hline & \multicolumn{2}{|c|}{1963 to 2020} & \multicolumn{2}{|c|}{1963 to 1992} & \multicolumn{2}{|c|}{1993 to 2020} \\
\hline & & $A\left|\bar{\varepsilon}_{k}\right|$ & $\begin{array}{c}\% \text { of } \\
\text { CAPM }\end{array}$ & $A\left|\bar{\varepsilon}_{k}\right|$ & $\begin{array}{c}\% \text { of } \\
\text { CAPM }\end{array}$ & $A\left|\bar{\varepsilon}_{k}\right|$ & $\begin{array}{c}\% \text { of } \\
\text { CAPM }\end{array}$ \\
\hline \multicolumn{8}{|c|}{ Panel A. All individual stocks sorted by coasymmetry } \\
\hline \multicolumn{2}{|c|}{ CAPM } & 4.29 & 100.0 & 3.94 & 100.0 & 4.65 & 100.0 \\
\hline \multicolumn{2}{|c|}{ ASY } & 2.04 & 47.6 & 2.08 & 52.9 & 2.00 & 43.0 \\
\hline \multicolumn{2}{|c|}{ FF3 } & 3.51 & 81.8 & 2.77 & 70.3 & 4.27 & 91.9 \\
\hline \multicolumn{2}{|c|}{ CAR4 } & 3.62 & 84.5 & 2.88 & 73.2 & 4.39 & 94.5 \\
\hline \multicolumn{2}{|c|}{ FF5 } & 3.97 & 92.7 & 3.10 & 78.6 & 4.88 & 105.0 \\
\hline \multicolumn{8}{|c|}{ Panel B. Individual stocks with different coasymmetry levels } \\
\hline \multirow{5}{*}{$\begin{array}{l}\text { Negative } \\
\text { COASY }\end{array}$} & CAPM & 4.33 & 100.0 & 4.93 & 100.0 & 4.93 & 100.0 \\
\hline & ASY & 2.74 & 63.3 & 3.13 & 63.5 & 3.13 & 63.5 \\
\hline & FF3 & 3.67 & 84.8 & 4.53 & 91.9 & 4.53 & 91.9 \\
\hline & CAR4 & 3.81 & 88.0 & 4.63 & 93.8 & 4.63 & 93.8 \\
\hline & FF5 & 4.02 & 92.7 & 4.93 & 100.0 & 4.93 & 100.0 \\
\hline \multirow{5}{*}{2} & CAPM & 4.83 & 100.0 & 5.12 & 100.0 & 5.12 & 100.0 \\
\hline & ASY & 2.38 & 49.4 & 2.36 & 46.2 & 2.36 & 46.2 \\
\hline & FF3 & 4.00 & 82.9 & 4.80 & 93.8 & 4.80 & 93.8 \\
\hline & CAR4 & 4.14 & 85.7 & 4.85 & 94.8 & 4.85 & 94.8 \\
\hline & FF5 & 4.50 & 93.2 & 5.49 & 107.3 & 5.49 & 107.3 \\
\hline \multirow{5}{*}{ Neutral } & CAPM & 3.88 & 100.0 & 4.52 & 100.0 & 4.52 & 100.0 \\
\hline & ASY & 1.74 & 44.7 & 1.83 & 40.5 & 1.83 & 40.5 \\
\hline & FF3 & 3.19 & 82.1 & 4.13 & 91.5 & 4.13 & 91.5 \\
\hline & CAR4 & 3.31 & 85.1 & 4.27 & 94.6 & 4.27 & 94.6 \\
\hline & FF5 & 3.64 & 93.7 & 4.66 & 103.1 & 4.66 & 103.1 \\
\hline \multirow{5}{*}{4} & CAPM & 4.09 & 100.0 & 4.41 & 100.0 & 4.41 & 100.0 \\
\hline & ASY & 1.91 & 46.6 & 1.89 & 42.8 & 1.89 & 42.8 \\
\hline & FF3 & 3.25 & 79.5 & 4.01 & 91.1 & 4.01 & 91.1 \\
\hline & CAR4 & 3.36 & 82.2 & 4.19 & 95.1 & 4.19 & 95.1 \\
\hline & FF5 & 3.67 & 89.7 & 4.55 & 103.2 & 4.55 & 103.2 \\
\hline \multirow{5}{*}{ Positive COASY } & CAPM & 4.30 & 100.0 & 4.27 & 100.0 & 4.27 & 100.0 \\
\hline & ASY & 1.44 & 33.4 & 0.77 & 18.1 & 0.77 & 18.1 \\
\hline & FF3 & 3.42 & 79.5 & 3.88 & 90.9 & 3.88 & 90.9 \\
\hline & CAR4 & 3.50 & 81.3 & 4.02 & 94.2 & 4.02 & 94.2 \\
\hline & FF5 & 4.05 & 94.0 & 4.78 & 112.2 & 4.78 & 112.2 \\
\hline
\end{tabular}




\section{Table 10}

\section{Downside Loss on Stocks with Asymmetry Betas}

This table presents the average daily excess returns of stocks in extreme bear markets with market condition breakpoints determined by unconditional daily stock market return percentiles from 1927 to 2020. At the beginning of each calendar year (starting from 1928), we use daily returns over the previous year to estimate the CAPM betas and upside/downside asymmetry betas for all stocks that have at least 126 daily returns. Then, we sort stocks into $15(3 \times 5)$ groups and report the average daily excess returns (in percentages) for each group in extreme bear and bear market. The sample period is from 1927 to 2020

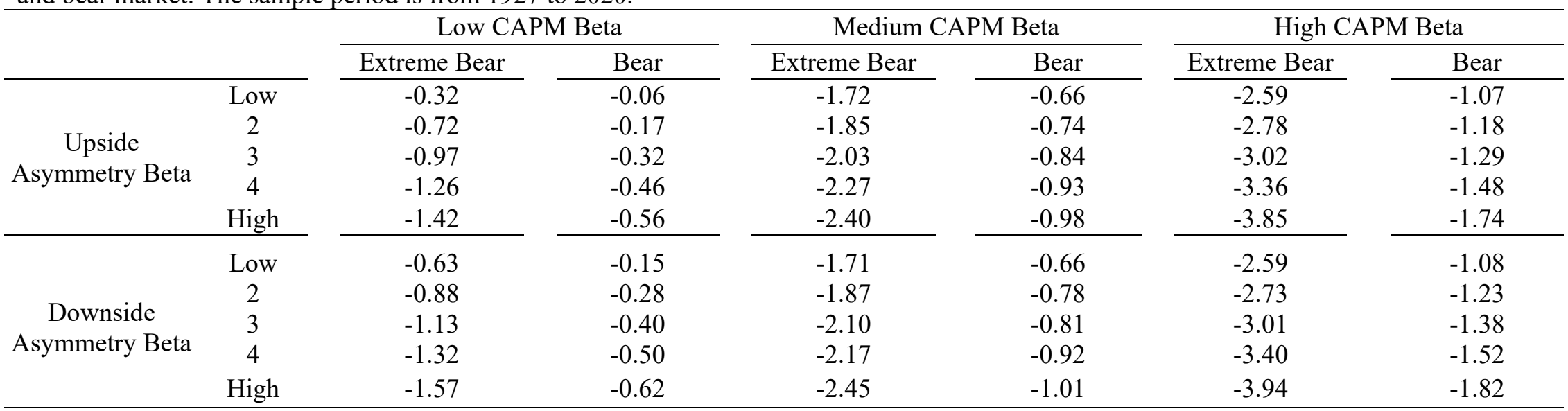




\section{References}

Adrian, T., \& Franzoni, F. (2009). Learning about beta: Time-varying factor loadings, expected returns, and the conditional CAPM. Journal of Empirical Finance, 16(4), 537-556.

Amihud, Y., 2002. Illiquidity and stock returns: cross-section and time-series effects. Journal of financial markets, 5(1), pp.31-56.

Ang, A., Chen, J., \& Xing, Y. (2006). Downside risk. The Review of Financial Studies, 19, 1191-1239.

Ang, A., Hodrick, R. J., Xing, Y., \& Zhang, X. (2006). The cross-section of volatility and expected returns. The Journal of Finance, 61(1), 259-299.

Aparicio, F. M., \& Estrada, J. (2001). Empirical distributions of stock returns: European securities markets, 1990-95. The European Journal of Finance, 7(1), 1-21.

Bali, T., Engle, R., \& Murray, S. (2014). Empirical asset pricing: The cross section of stock returns: An overview. Wiley StatsRef: Statistics Reference Online, 1-8.

Bansal, R., Dittmar, R. F., \& Lundblad, C. T. (2005). Consumption, dividends, and the cross section of equity returns. The Journal of Finance, 60(4), 1639-1672.

Banz, R. W. (1981). The relationship between return and market value of common stocks. Journal of financial economics, 9(1), 3-18.

Barberis, N., \& Huang, M. (2008). Stocks as lotteries: The implications of probability weighting for security prices. American Economic Review, 98(5), 2066-2100.

Barnea, A., \& Downes, D. H. (1973). A reexamination of the empirical distribution of stock price changes. Journal of the American Statistical Association, 68(342), 348-350.

Basu, S. (1983). The relationship between earnings' yield, market value and return for NYSE common stocks: Further evidence. Journal of financial economics, 12(1), 129-156.

Black, F., Jensen, M. C., \& Scholes, M. S. (1972). The capital asset pricing model: Some empirical tests. in M. Jensen (ed.), Studies in the Theory of Capital Markets, Praeger, New York.

Bookstaber, R. M., \& McDonald, J. B. (1987). A general distribution for describing security price returns. Journal of business, 401-424.

Carhart, M. M. (1997). On persistence in mutual fund performance. The Journal of Finance, 52(1), 57-82.

Chamberlain, G. (1983). A characterization of the distributions that imply mean-Variance utility functions. Journal of Economic Theory, 29(1), 185-201.

Connor, G., Korajczyk, R.A., (1986). Performance measurement with the arbitrage pricing theory: a new framework for analysis. Journal of Financial Economics, 15, 373-394 
Fama, E., (1965). The behavior of stock-market prices. Journal of Business 38(1), 34-105.

Fama, E. F., \& MacBeth, J. D. (1973). Risk, return, and equilibrium: Empirical tests. Journal of Political Economy, 81(3), 607-636.

Fama, E. F., \& French, K. R. (1992). The cross-section of expected stock returns. The Journal of Finance, 47(2), 427-465.

Fama, E. F., \& French, K. R. (1993). Common risk factors in the returns on stocks and bonds. Journal of Financial Economics, 33, 3-56.

Fama, E. F., \& French, K. R. (2006). The value premium and the CAPM. The Journal of Finance, 61(5), 2163-2185.

Fama, E. F., \& French, K. R. (2015). A five-factor asset pricing model. Journal of Financial Economics, 116(1), 1-22.

Ferson, W. E., \& Harvey, C. R. (1991). The variation of economic risk premiums. Journal of Political Economy, 99(2), 385-415.

Harvey, C. R., Liu, Y., \& Zhu, H. (2016). ... and the cross-section of expected returns. The Review of Financial Studies, 29(1), 5-68.

Jagannathan, R., \& Wang, Z. (1996). The conditional CAPM and the cross-section of expected returns. The Journal of Finance, 51(1), 3-53.

Jegadeesh, N., \& Titman, S. (1993). Returns to buying winners and selling losers: Implications for stock market efficiency. The Journal of Finance, 48(1), 65-91.

Kelly, B., \& Jiang, H. (2014). Tail risk and asset prices. The Review of Financial Studies, 27(10), 28412871.

Kelly, B. T., Pruitt, S., \& Su, Y. (2019). Characteristics are covariances: A unified model of risk and return. Journal of Financial Economics, 134(3), 501-524.

Knez, P. J., \& Ready, M. J. (1997). On the robustness of size and book-to-market in cross-sectional regressions. The Journal of Finance, 52(4), 1355-1382.

Kraus, A., \& Litzenberger, R. (1983). On the distributional conditions for a consumption-oriented three moment CAPM. The Journal of Finance, 38(5), 1381-1391.

Lettau, M., \& Ludvigson, S. (2001). Consumption, aggregate wealth, and expected stock returns. The Journal of Finance, 56(3), 815-849.

Levi, Y., \& Welch, I. (2020). Symmetric and asymmetric market betas and downside risk. The Review of Financial Studies, 33(6), 2772-2795. 
Lewellen, J., \& Nagel, S. (2005). The Conditional CAPM Does Not Explain Asset Pricing Anomalies. Journal of Financial Economics.

Malladi, R., \& Fabozzi, F. J. (2017). Equal-weighted strategy: Why it outperforms value-weighted strategies? Theory and evidence. Journal of Asset Management, 18(3), 188-208.

Mandelbrot, B., (1963). The variation of certain speculative prices. Journal of Business, 36(4), 394.

Pástor, L', \& Stambaugh, R. F. (2003). Liquidity risk and expected stock returns. Journal of Political economy, 111(3), 642-685.

Rozeff, M. S., \& Kinney Jr, W. R. (1976). Capital market seasonality: The case of stock returns. Journal of Financial Economics, 3(4), 379-402.

Scott, R. C., \& Horvath, P. A. (1980). On the direction of preference for moments of higher order than the variance. The Journal of Finance, 35(4), 915-919.

Shanken, J. (1992). On the estimation of beta-pricing models. The Review of Financial Studies, 5(1), 133.

Tversky, A., \& Kahneman, D. (1992). Advances in prospect theory: Cumulative representation of uncertainty. Journal of Risk and uncertainty, 5(4), 297-323. 


\title{
Chapter 3. Implied Equity Premium and Market Beta
}

\author{
Chapter Abstract
}

We extend the ex-ante mean-variance (SVIX) models of Martin (2017) and Martin-Wagner (2019) to a mean-variance-asymmetry (AVIX) framework for incorporating higher-moment and co-moment risk in asset pricing. AVIX is a risk-neutral measure of the left-tail asymmetries in return that corrects the SVIX approach's downside bias. The options implied market beta of equity is a weighted sum of the beta of SVIX and that of AVIX. Empirically, the implied betas possess significant predictability of risk/return relationship and the hedging ability against bear/crashing markets. We develop an investible portfolio $\mathrm{MKT}^{*}$ that mimics realized outcomes on the implied market index adjusted for volatility-asymmetry.

Keywords: Implied Equity Premium, Implied Market Beta, Implied Beta, VIX, SVIX, AVIX

JEL classification: D81, G02, G11, G12.

This paper is coauthored with Dr. Victor Chow (West Virginia University), and Dr. Zhan Wang (Shanghai Business School). 


\subsection{Introduction}

An essential recent breakthrough in asset pricing theory, proved by Martin (2017), is that the arbitrage-free risk-neutral volatility of returns, mimicked by a portfolio of options contracts, directly measures the ex-ante equity risk premium. Stock options prices imply equity premium, and the investor required risk compensation to equity investment is thus dynamically priceable in real-time. Martin and Wagner (2019), hereafter MW, further show that a linear structure of the stock's option-implied variance characterizes ex-ante expected excess returns on individual equity without parameter estimations. Unlike conventional (ex-post) factor models, MW's approach requires no sample estimate of the covariance matrix of stocks with pricing factors in measuring equity risk premium.

MW illustrates that the risk-neutral variance (denoted SVIX ${ }^{2}$ ) is an unbiased volatility measure for pricing risk premium of stocks if investors possess log utility. The log utility has a constant relative risk aversion (CRRA) function in which the relative risk aversion (RRA) coefficient equals one. Since the aggregation of higher degree RRA coefficients corresponding to higher-order return-moments is zero for the logarithmic utility-of-wealth function, the (symmetric) SVIX approach is thus adequate. ${ }^{22}$ Nevertheless, Chabi-Yo, Leisen, and Renault (2014) show that in general, i.e., RRA coefficient is not one, the skewness (co-skewness) and higher return moments (co-moments) are essential to characterize the expected excess return on

\footnotetext{
${ }^{22}$ As early as 1983, Pulley (1983) has shown that the mean-variance model is an approximation to the expected logarithmic utility maximization.
} 
risky assets. Empirically, Schneider, Wagner, and Zechner (2020) discover that individual stocks' option-implied skewness strongly correlates with their (ex-post) residual co-skewness corresponding to market returns. It highlights that the market skewness risk is an essential factor in asset pricing, where a long-short portfolio from implied skewness sorted stocks can mimic the factor. Chabi-yo and Loudis (2020) find that the risk-neutral moments of variance, skewness, and kurtosis are necessary to determine the lower and upper bounds of the conditional expected excess market return. Furthermore, Liu (2021) shows that to provide the tightest bounds on pricing kernel, one needs to consider the return on assets with non-trivial high-order moments. In short, the impact of the higher-order return moments and co-moments is critical for estimating ex-ante equity premium.

Our paper makes several contributions. First, this study extends the SVIX models of Martin (2017) and MW (2019) to incorporate the higher-moment and co-moment risk, free from functional form restrictions on utility and return distribution. It begins by defining the AVIX measure for correcting the left-tail bias of volatility-asymmetry in the SVIX. The calculation of $\mathrm{AVIX}^{2}$ is straightforward by taking the non-negative value of the difference between Chicago Board of Options Exchange (CBOE) VIX ${ }^{2}$ and Martin's SVIX ${ }^{2}$. AVIX summarizes all higherorder return moments in that VIX ${ }^{2}$ is twice the risk-neutral expected difference between arithmetic and logarithmic returns. Mathematically, $\operatorname{VIX}_{t}^{2}=2 \mathbb{E}_{t}^{\mathbb{Q}}\left[R_{t+1}-r_{t+1}\right]$, where $\mathbb{E}_{t}^{\mathbb{Q}}$ is the risk-neutral $(\mathbb{Q}$-space) expectation operator, $R$ denotes the one-period return, and $r=\ln (1+R)$ 
is the $\log$ return. ${ }^{23}$ From a mathematical property on log-return such that $(R-r)=\frac{R^{2}}{2}+$ $\sum_{k=3}^{K \rightarrow \infty}(-1)^{k} \frac{R^{k}}{k}, \mathrm{VIX}^{2}$ is statistically a risk-neutral moment-generating function of return from the second to infinitive order. Since the $\mathbb{Q}$-space expected return for all risky assets uniquely equals the risk-free rate, VIX correctly ignores the impact of mean on measuring the return volatility without losing generality. For convenience, we define $(R-r)$ as a second and high order moment-generating variable (SHMGV). Asymmetrically, $2(R-r)>R^{2}$ for $R<0$, and vice versa. Thus, VIX is relatively more sensitive to the return distribution's left tail than the SVIX, and vice versa.

Intuitively, VIX underestimates the volatility associated with upside gains, where SVIX undervalues that with downside losses. The combination of SVIX and AVIX thus produces a tight estimation bound to the ex-ante equity risk premium. Specifically, based on the property of SHMGV, we describe that the covariance of market return with its SHMGV characterizes the AVIX and closely relates to the negative correlation condition (NCC) in Martin (2017). Thus, the sum of $\left(1+R_{f, t}\right) \operatorname{SVIX}_{t}^{2}$ and $\mathrm{AVIX}_{t}^{2}$ represents the option-implied market equity premium, denoting $\mathrm{IEP}_{t}$, where $R_{f, t}$ is the risk-free rate. By applying our approach to the $\mathrm{S} \& \mathrm{P} 500$ index (SPX) options data, our summary statistics reveal that the AVIX accounts for at least 6.6 percent of the implied equity premium. The impact increases to 12 percent in highly volatile markets.

\footnotetext{
${ }^{23}$ We assume $-1<\mathrm{R}<1$.
} 
Second, we apply AVIX to the asset pricing of individual equity and develop the optionimplied market beta (denoted by $\left.\mathbb{B}_{i}^{\mathrm{MKT}}\right)$ as a weighted sum of the SVIX-beta $\left(\mathbb{B}_{i}^{\text {SVIX }}\right)$ and AVIXbeta $\left(\mathbb{B}_{i}^{\mathrm{AVIX}}\right)$. By embedding volatility-asymmetry in the implied market beta and the implied market premium, our model retains the same simplicity as the classical capital asset pricing model (CAPM). One can compute the real-time implied risk-premium of individual stocks by simply taking the product of $\mathbb{B}_{i, t}^{\mathrm{MKT}}$ and $\mathrm{IEP}_{t}$. No parameter estimation (e.g., the variancecovariance matrix in multifactor regression) is necessary. Since the implied beta is additive, the same computing procedure can be applied to calculate the implied premium for a portfolio of stocks.

In theory, we prove that based on weak assumptions on utility function, two variables (return and SHMGV) and their associated parameters of investor risk preference completely characterize the stochastic discount factor (SDF). The mathematical expression is $m_{t+1}=1-$ $\gamma_{t} R_{t+1}-\delta_{t}\left(R_{t+1}-r_{t+1}\right)$, where $m_{t+1}$ is the SDF between periods $t$ and $t+1, \gamma_{t}$ equals the Arrow-Pratt index of (first-degree) RRA, and $\delta_{t}$ is a weighted sum of the second to infinitive degree RRA. The parameter $\delta_{t}$, corresponding to the SHMGV, represents investor relative risk preference toward asymmetries in returns. Having SVIX and VIX as the lower bound of the exante risk premium, the inequality $\gamma_{t} \geq 1$ and $\frac{\delta_{t}}{\gamma_{t}} \leq-1$ must hold, accordingly. ${ }^{24}$ We conclude that with the SDF decomposition in equilibrium, investors demand compensation for two types

\footnotetext{
${ }^{24}$ That is, $\frac{\delta_{t}}{\gamma_{t}} \leq-1$ is sufficient for VIX to be the lower bound on the equity premium. We provide proof in Appendix B.
} 
of risk: (1) the covariance risk as in the CAPM and (2) the coasymmetry risk as expressed by the covariance of returns on the stock with the market SHMGV, i.e., $\operatorname{Cov}_{t}\left[R_{i, t+1},\left(R_{M, t+1}-r_{M, t+1}\right)\right]$. The coasymmetry risk reveals the impact of higher-order conditional co-moments (including coskewness, co-kurtosis, etc.) on the expected return of risky assets.

Third, we develop an investment strategy based on the implied market betas to form a portfolio, denoted $\mathrm{MKT}^{*}$, that mimics the implied market factor (with the adjustment for volatility-asymmetry) for asset pricing. A critical insight of capital asset pricing is that returns are compensation for bearing systematic risk. Assets with higher beta should have higher expected returns if the model is valid. We empirically find a robust cross-section ex-ante return/beta relationship from portfolios of stocks sorted by the implied market beta. Specifically, the implied market beta possesses a monotonically positive relationship with the average future return across all holding periods of one, three, six, and twelve months, respectively. The average excess return between the top and the bottom decile of implied beta sorted portfolios is approximately 243 and 171 basis points per month for equal- and value-weighted calculation, accordingly. Based on the robust empirical results of the linear relationship between ex-ante return and implied market beta, we apply the notion of security market line (SML) in CAPM to develop the mimicking market portfolio $\mathrm{MKT}^{*}$. The returns on $\mathrm{MKT}^{*}$ replicate the realized $(\mathbb{P}$ space) outcomes on the ( $\mathbb{Q}$-space) implied market index inferred from options prices.

As shown in Figure 3, MKT* outperforms the SPX, highlighting its superiority to serve as a proxy of the market portfolio in asset pricing. Intuitively, MKT* tracks investible returns on 
the risk-adjusted long-term growth of the equity markets implied by options prices, where SPX moves up and down along $\mathrm{MKT}^{*}$ over time. We further develop an implied market model with $\mathrm{MKT}^{*}$ and find that residual returns, relative to the implied market beta times MKT*, are unique to individual stocks. Using index return data in Kenneth R. French's Data Library, the results from our in-sample and out-of-sample analysis indicate that no non-market pricing factors, except the size (SMB) with weak evidence of support, can explain the residual return on stocks. Consequently, the payoffs on an investment strategy of allocating $x$-percent (equals a stock's current implied market beta) of capital to $\mathrm{MKT}^{*}$ and $(1-x)$ of that to the risk-free asset could replicate next-period returns on the stock investment. This two-fund mimicking portfolio of equity provides useful applications to financial risk management.

$\mathrm{MKT}^{*}$ significantly mitigates downside market risk exposure. It generates only onequarter of loss on SPX in bear/crashing markets. By employing testing methodologies in Levi and Welch (2020), we discover stocks with a low MKT* beta have significantly less loss than those with low CAPM and other alternative betas in the days when equity markets experience notable losses. It makes the $\mathrm{MKT}^{*}$ beta a superior hedging measure.

Fourth, this paper documents that the volatility-asymmetry is a determinant driving the market risk. From our comparative analysis with various betas, we find that with the control of AVIX-beta, the return predictability of SVIX-beta and other alternative beta coefficients mostly vanish. On the contrary, AVIX-beta retains its predictability of ex-ante equity premium with the control of SVIX-beta and other betas. Since AVIX-beta and SVIX-beta are highly correlated 
(with a correlation of 90 percent), our empirical result implies that increased coasymmetry risk is the driver of increasing covariance risk.

We organize the rest of the paper as follows. Section 3.2 presents the derivation of the risk-neutral measure of volatility-asymmetry AVIX and its application to measure the implied equity premium with asymmetry. Section 3.3 illustrates the theory of implied market beta. We report results from our empirical analysis and show the development of MKT* in Section 3.4. Section 3.5 concludes the paper.

\subsection{Risk Neutral Volatility-Asymmetry and Equity Premium}

Martin (2017) shows that the option-implied variance $\left(\mathrm{SVIX}^{2}\right)$ is the lower bound of the ex-ante equity risk premium. Let $m_{t+1}$ denote the SDF that prices time $t+1$ payoffs $\left(X_{t+1}\right)$ from the perspective of time $t, R_{M, t+1}$ be the one-period market return, and $R_{f}$ be the risk-free rate of interest, respectively. Based on this notion of the risk-neutral (no-arbitrage) expectation of future payoffs that

$$
\mathbb{E}_{t}^{\mathbb{Q}}\left[X_{t+1}\right]=\left(1+R_{f, t}\right) \mathbb{E}_{t}\left[m_{t+1} X_{t+1}\right],
$$

Martin derives the risk-neutral variance and the implied equity premium as follows:

$$
\operatorname{Var}_{t}^{\mathbb{Q}}\left(R_{M, t+1}\right)=\left(1+R_{f, t}\right) \mathbb{E}_{t}\left[m_{t+1} R_{M, t+1}^{2}\right]-R_{f, t}^{2} .
$$

and 


$$
\mathbb{E}_{t}\left[R_{M, t+1}-R_{f, t}\right]=\frac{\operatorname{Var}_{t}^{\mathbb{Q}}\left[R_{M, t+1}\right]}{1+R_{f, t}}-\mathrm{NCC}_{M, t}
$$

where $\mathrm{NCC}_{M, t}\left(=\operatorname{Cov}_{t}\left[m_{t+1}\left(1+R_{M, t+1}\right), R_{M, t+1}\right]\right)$ denotes the negative correlation condition that ensures $\frac{V a r_{t}^{\mathbb{Q}}\left[R_{M, t+1}\right]}{1+R_{f, t}}$ as the lower bound of the equity premium estimation. As long as RRA in the economy is at least $1, \mathrm{NCC}$ is negative in value. We will show later in (12) that $\mathrm{NCC}_{M}$ captures the volatility-asymmetries. Now, given that

$$
\left(1+R_{f, t}\right) \operatorname{SVIX}_{t}^{2}=\frac{\operatorname{Var}_{t}^{\mathbb{Q}}\left(R_{M, t+1}\right)}{1+R_{f, t}}=\frac{2}{S_{t}^{2}}\left[\int_{0}^{F_{t, t+1}} P u t_{t, t+1}(K) d K+\int_{F_{t, t+1}}^{\infty} \operatorname{Call}_{t, t+1}(K) d K\right]
$$

where $P u t_{t, t+1}(K)$ and $\operatorname{Call}_{t, t+1}(K)$ denote the time $t$ prices of European puts and calls on the market that expire at time $t+1$ with strike $K$, and $F_{t, t+1}$ denotes the forward (to time $\mathrm{t}+1$ ) price of the market, the following inequality holds:

$$
\mathbb{E}_{t}\left[R_{t+1}-R_{f, t}\right] \geq\left(1+R_{f, t}\right) \operatorname{SVIX}_{t}^{2}
$$

Noticeably, Martin (2017) demonstrates that if (but not only if) the investor has log utility (i.e., CRRA), NCC is identically zero, and then, the inequality (1.5) holds with equality.

\subsubsection{Implied volatility with asymmetries in return}


The CBOE volatility index (VIX), different from SVIX, also serves as a proxy of implied market volatility. The question arises as to whether VIX is also a volatility-bound for measuring the ex-ante equity risk premium. Martin (2017) demonstrates that they both are adequate riskneutral measures of return variability. The main difference is that VIX is more sensitive to the return distribution's left tail, whereas SVIX is more sensitive to the right tail. The implication is that VIX underestimates the upside's volatility, where SVIX undervalues that to the downside.

Mathematically, VIX ${ }^{2}$ is twice the risk-neutral expected difference between arithmetic and logarithmic returns. Letting $r_{t+1}=\ln \left(1+R_{t+1}\right)$ be the next-period log-return, we have

$$
\begin{aligned}
\mathrm{VIX}_{t}^{2} & =2 \mathbb{E}_{t}^{\mathbb{Q}}\left[R_{M, t+1}-r_{M, t+1}\right]=\mathbb{E}_{t}^{\mathbb{Q}}\left[R_{M, t+1}^{2}\right]+\sum_{k=3}^{K \rightarrow \infty} \frac{2(-1)^{k}}{k} \mathbb{E}_{t}^{\mathbb{Q}}\left[R_{M, t+1}^{k}\right] \\
& =2\left[\int_{0}^{F_{t, t+1}} \frac{P u t_{t, t+1}(K)}{K^{2}} d K+\int_{F_{t, t+1}}^{\infty} \frac{\operatorname{Call}_{t, t+1}(K)}{K^{2}} d K\right]
\end{aligned}
$$

One can thus view $\mathrm{VIX}_{t}^{2}$ as a dynamic (risk-neutral) second and high moment-generating function (SHMGF) of the future market returns. Equivalently, VIX ${ }^{2}$ is an entropy with a mean zero. Note that the risk-neutral ( $\mathbb{Q}$-space) mean-return for all risky assets is unique and equals the risk-free rate. Therefore, one can ignore the mean-return impact on estimating the return moments and centralize the $\mathbb{Q}$-space volatility calculation at zero without losing generality. We apply this notion simply to the risk-neutral variance as $\mathbb{E}_{t}^{\mathbb{Q}}\left[R_{t+1}^{2}\right]\left(=\operatorname{Var}_{t}^{\mathbb{Q}}\left[R_{t+1}\right]+R_{f, t}^{2}\right)$. Equation (2) then indicates that the difference between VIX ${ }^{2}$ and SVIX ${ }^{2}$ captures the volatility-asymmetry characterized by the polynomial integration of third and infinite high-order (risk-neutral) 
distributional moments. In short, it is the volatility-asymmetry that makes VIX skewed toward the distribution's left tail, where SVIX is symmetric on both sides of the return distribution.

To further analyze the structure difference between VIX and SVIX (with a centralization at zero), we depict the mathematical relationship between $2(R-r)$ and $R^{2}$ in Figure 1 . Our focus is on the variable of asymmetry: asy $=2(R-r)-R^{2}=\sum_{k=3}^{K \rightarrow \infty} \frac{2(-1)^{k}}{k} R^{k}$. One can view asy as a variable that generates third and higher distributional moments in return and thus captures the volatility-asymmetry. Figure 1 intuitively illustrates that the volatility-asymmetry makes VIX deviate from SVIX. The value of asy is positive (negative) in the left (right) tail of the return distribution. Noticeably, the return-elasticity of asymmetry $\left(\frac{\% \Delta a s y}{\% \Delta R}\right)$ is more significant on the downside loss $(R<0)$ than that on the upside gain $(R>0)$.

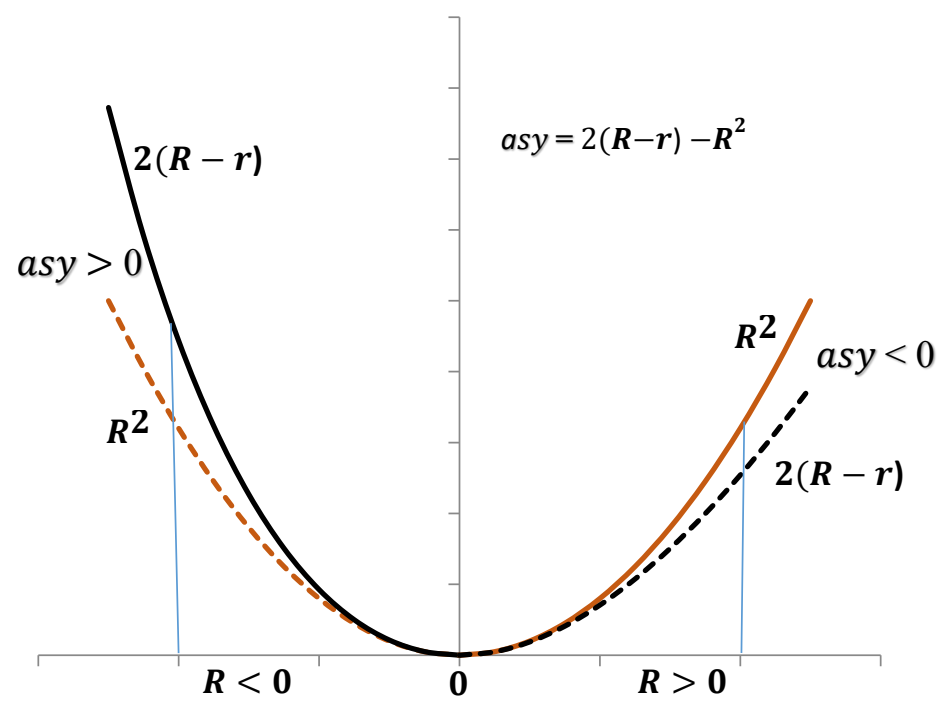

Figure 3.1 Volatility Bound of Equity Premium 
Figure 1 indicates only the left-tail volatility-asymmetry downward biases SVIX in measuring the ex-ante equity risk premium. Therefore, the (symmetric) risk-neutral variance $\mathrm{SVIX}^{2}$ is a better proxy for implied equity premium in the uptrend market, but the (asymmetric) volatility index VIX ${ }^{2}$ is a relatively robust measure to the downtrend. In summary,

$\begin{cases}\text { Implied Equity Premium }_{t}=\left(1+R_{f, t}\right) \mathrm{SVIX}_{t}^{2}, & \text { if investors anticipate upward in market price. } \\ \text { Implied Equity Premium }_{t}=\frac{\mathrm{VIX}_{t}^{2}}{1+R_{f, t}}, & \text { if investors anticipate downward in market price. }\end{cases}$

\subsubsection{Volatility-asymmetry and implied equity premium}

We now define the volatility-asymmetry in return (denoted by Asy) as follows:

$$
A s y_{t}\left[R_{t+1}\right]=\mathbb{E}_{t}\left[2\left(R_{t+1}-r_{t+1}\right)-R_{t+1}^{2}\right]=\sum_{k=3}^{K \rightarrow \infty} \frac{2(-1)^{k}}{k} \mathbb{E}_{t}\left(R_{t+1}^{k}\right)
$$

According to (3.1) and realizing that the $\mathbb{Q}$-space mean return is the risk-free rate, we have the riskneutral estimate of the market volatility-asymmetry as follows:

$$
\begin{aligned}
\frac{\operatorname{Asy}_{t}^{\mathbb{Q}}\left[R_{M, t+1}\right]}{1+R_{f, t}}= & \frac{\operatorname{VIX}_{t}^{2}}{1+R_{f, t}}-\left(1+R_{f, t}\right) \operatorname{SVIX}_{t}^{2}-\frac{R_{f, t}^{2}}{1+R_{f, t}} \\
= & \psi_{t}\left(\frac{\operatorname{Cov}_{t}^{\mathbb{Q}}\left[R_{M, t+1},\left(R_{M, t+1}-r_{M, t+1}\right)\right]}{1+R_{f, t}}\right)+\vartheta_{f, t} \\
= & \frac{2}{S_{t}^{2}} \int_{0}^{F_{t, t+1}}\left(\frac{S_{t}^{2}-K^{2}}{K^{2}}\right) P u t_{t, t+1}(K) d K \\
& -\frac{2}{S_{t}^{2}} \int_{F_{t, t+1}}^{\infty}\left(\frac{K^{2}-S_{t}^{2}}{K^{2}}\right) \operatorname{Call}_{t, t+1}(K) d K-\frac{S_{t}}{F_{t, t+1}}\left(\frac{F_{t, t+1}}{S_{t}}-1\right)^{2},
\end{aligned}
$$


where $\operatorname{Cov}_{t}^{\mathbb{Q}}\left[R_{t+1},\left(R_{t+1}-r_{t+1}\right)\right]=\sum_{k=2}^{K \rightarrow \infty} \frac{(-1)^{k}}{k} \operatorname{Cov}_{t}^{\mathbb{Q}}\left[R_{t+1}, R_{t+1}^{k}\right], \psi_{t}$ is a function of $\frac{\mathbb{E}_{t}^{\mathbb{Q}}\left(R_{t+1}^{k}\right)}{\mathbb{E}_{t}^{\mathbb{Q}}\left(R_{t+1}^{k+1}\right)}$, and $\vartheta_{f, t}$ is a function of the risk-free rate and near-zero in value. ${ }^{25}$ The Asy summarizes higher exante moments from the third order to an infinitive degree, which can be characterized by the riskneutral covariance $\operatorname{Cov}_{t}^{\mathbb{Q}}\left(R_{t+1},\left(R_{t+1}-r_{t+1}\right)\right)$. Noticeably, with moments centralized at zero, $\operatorname{Cov}_{t}^{\mathbb{Q}}\left(R_{t+1},\left(R_{t+1}-r_{t+1}\right)\right)$ is negative in value, if $R_{t+1}<0$, and vice versa. Also, corresponding to the sign of $A s y_{t}$ concerning that of $R_{t+1}, \lambda_{t}$ is then non-positive.

Now, according to (3.1), and (3.2), we rearrange (1.3) so that

$$
\mathbb{E}_{t}\left[R_{M, t+1}-R_{f, t}\right]=\frac{\mathrm{VIX}_{t}^{2}}{1+R_{f, t}}-\left(\mathrm{NCC}_{M, t}+\frac{A s y_{t}^{\mathbb{Q}}\left[R_{M, t+1}\right]}{1+R_{f, t}}+\frac{R_{f, t}^{2}}{1+R_{f, t}}\right)
$$

There are three parameters inside the round bracket on the right-hand side of equation (4), where $\mathrm{NCC}_{M, t} \leq 0$, and $\frac{R_{f, t}^{2}}{1+R_{f, t}}>0$. If $A s y_{t}^{\mathbb{Q}}\left[R_{M, t+1}\right]>0$, then the aggregated value of the three parameters in the bracket is greater (or less negative) than the value of $\mathrm{NCC}_{M}$. Compare (4) with (1.3), $\frac{\mathrm{VIX}_{t}^{2}}{1+R_{f, t}}$ deducts less negative (or adds less positive) quantity than $\frac{\operatorname{Var}_{t}^{\mathbb{Q}}\left[R_{M, t+1}\right]}{1+R_{f, t}}$ to

$25 \frac{A s y_{t}^{\mathbb{Q}}\left(R_{M, t+1}\right)}{1+R_{f, t}}=2 \mathbb{E}_{t}\left[m_{t+1}\left(R_{M, t+1}-r_{t+1}\right)\right]-\mathbb{E}_{t}\left[m_{t+1} R_{M, t+1}^{2}\right]=\sum_{k=3}^{K \rightarrow \infty} \frac{2(-1)^{k}}{k} \mathbb{E}_{t}\left[m_{t+1} R_{t+1}^{k}\right]=$ $\frac{1}{1+R_{f, t}} \sum_{k=2}^{K \rightarrow \infty} \frac{2(-1)^{k+1}}{k+1} \operatorname{Cov}_{t}^{\mathbb{Q}}\left[R_{t+1}, R_{t+1}^{k}\right]+\vartheta_{t}$, where $\vartheta_{t}=\sum_{k=2}^{K \rightarrow \infty} \frac{2(-1)^{k+1}}{k+1}\left(\frac{R_{f, t}}{1+R_{f, t}}\right) E_{t}^{\mathbb{Q}}\left[R_{t+1}^{k}\right] \approx 0$. 
equal $\mathbb{E}_{t}\left[R_{M, t+1}-R_{f, t}\right]$. Therefore, the left-tail volatility-asymmetry makes the VIX more tightly bound to the equity premium than the SVIX. ${ }^{26}$ We summarize that in the following inequality:

$$
\mathbb{E}_{t}\left[R_{M, t+1}-R_{f, t}\right] \geq \frac{\operatorname{Var}_{t}^{\mathbb{Q}}\left[R_{M, t+1}\right]}{1+R_{f, t}}+\frac{\max \left(A s y_{t}^{\mathbb{Q}}\left[R_{M, t+1}\right], 0\right)}{1+R_{f, t}} \geq\left(1+R_{f, t}\right) \operatorname{SVIX}_{t}^{2}
$$

For convenience, we define a volatility-asymmetry index as follows:

$$
\operatorname{AVIX}_{t}^{2}=\max \left(\frac{S_{t}}{F_{t+1}} A s y_{t}^{\mathbb{Q}}\left[R_{M, t+1}\right], 0\right)
$$

where $\frac{S_{t}}{F_{t+1}}=\frac{1}{1+R_{f, t}} \cdot{ }^{27}$ The inequality (5) indicates the tightness of the VIX bound on the distribution's left-tail makes the AVIX ${ }^{2}$ a good proxy of the NCC. Consequently, without loss of generality, one can calculate an unbiased option-implied equity premium (IEP) by simply adding the AVIX to the SVIX such that

$$
\mathrm{IEP}_{t}=\left(1+R_{f, t}\right) \mathrm{SVIX}_{t}^{2}+\mathrm{AVIX}_{t}^{2}
$$

In the next section, we apply the above results to individual equity.

\footnotetext{
${ }^{26} \mathrm{We}$ show later that as long as the relative risk aversion to the covariance risk is greater than the risk-preference to the higher co-moment risk, $\left|\frac{A s y_{t}^{\mathbb{Q}}\left[R_{M, t+1}\right]}{1+R_{f, t}}\right| \leq\left|\mathrm{NCC}_{M, t}\right|$. We also derive the sufficient condition for $\frac{\mathrm{VIX}_{t}^{2}}{1+R_{f, t}}$ to be the lower bound on the equity premium in Appendix B.

${ }^{27}$ We add a squared symbol on the AVIX notation to be consistent with VIX and SVIX in that Asy is the difference between VIX ${ }^{2}$ and SVIX ${ }^{2}$ shown in (3.2).
} 


\subsection{Theory of Implied Market Beta}

To derive the implied equity risk premium and market beta for individual stocks, we reexamine the pricing kernel theory. Let $W_{t}$ be the aggregate wealth at time $t$, and $R_{W, t+1}(=$ $\left.\frac{W_{t+1}-W_{t}}{W_{t}}\right)$ be the return on end-of-period aggregate wealth. Without loss of generality, we employ the market return $R_{M, t+1}$ as a proxy of $R_{W, t+1}$ and assume risk-averse investors are maximizing their utility of wealth, where the utility function is concave. Let $U(W)$ be the utility function of a representative investor, which is infinitely differentiable. The representative agent's utility function is unknown, but we assume $U^{\prime}>0, U^{\prime \prime}<0$, and $U^{\prime \prime \prime}>0$. From a power series expansion of $U^{\prime}\left(W_{t+1}\right)$ at $W_{t}$, we have

$$
U^{\prime}\left(W_{t+1}\right)=U^{\prime}\left(W_{t}\right)+W_{t} U^{\prime \prime}\left(W_{t}\right) R_{M, t+1}+\sum_{k=2}^{K \rightarrow \infty} \frac{W^{k} U^{(k+1)}\left(W_{t}\right)}{k !} R_{M, t}^{k}{ }^{28}
$$

Since the SDF represents the investor's intertemporal marginal rate of substitution, from the above equation, we can rewrite that as:

$$
m_{t+1}=\frac{U^{\prime}\left(W_{t+1}^{*}\right)}{U^{\prime}\left(W_{t}\right)}=1-\gamma_{t} \cdot R_{M, t+1}-\sum_{k=2}^{K \rightarrow \infty} \delta_{t}^{(k)} \frac{R_{M, t+1}^{k}}{k !}
$$

where $W_{t+1}^{*}$ denotes the optimal wealth at time $\mathrm{t}+1$ for all risk-averse investors such that $U^{\prime}\left(\frac{W_{t+1}^{*}}{W_{t}}\right)=0$ under the first order condition of utility maximization, $\gamma_{t}\left(=\frac{-U^{\prime \prime}\left(W_{t+1}^{*}\right)}{U^{\prime}\left(W_{t}\right)} W_{t} \geq 0\right)$ is

\footnotetext{
${ }^{28}$ Equivalently, one can view this expansion as that to $U^{\prime}\left(R_{M, t+1}\right)$ at zero. Then, we have $U^{\prime}\left(R_{M, t+1}\right)=U^{\prime}(0)+$ $W_{t} U^{\prime \prime}(0) R_{M, t+1}+\sum_{k=2}^{\infty} \frac{W^{k} U^{(k+1)}(0)}{k !} R_{M, t}^{k}$.
} 
the Arrow-Pratt RRA corresponding to market return, $\delta_{t}^{(k)}\left(=\frac{-U^{(k+1)}\left(W_{t+1}^{*}\right)}{U^{\prime}\left(W_{t}\right)} W_{t}^{k}\right)$ represents the RRA corresponding to the $k$ th order of return moment, and where $U^{(k)}$ denotes the $k$ th derivative of the utility function for $k \geq 3$. For the $\log$ utility function, this equality holds $\sum_{k=2}^{\infty} \delta_{t}^{(k)}=0$. Then, the higher order of return variation could be irrelevant to the SDF generating process, and the second distributional moment is sufficient for the risk determination.

In short, if the higher order of distributional moments $\left(R_{M, t+1}^{k}\right.$, for $\left.k \geq 2\right)$ in (8.2) is irrelevant to investment decision making, we have the result of the traditional CAPM in equilibrium. If the pricing kernel is quadratic in form $(K=2)$, one obtains the three-moment (skewness) model of Harvey and Siddique (2000) and Schneider, Wagner and Zechner (2020). Further, if we truncate (8.2) cubed (i.e., $K=3$ ), then the kurtosis preference is embedded in the four-moment asset pricing structure presented by Dittmar (2002).

\subsubsection{The SHMGV and Implied Volatility-Asymmetry}

Recall that twice the difference of arithmetic and logarithmic returns on the market portfolio is a SHMGV that summarizes the second and all higher orders of market return variations in a polynomial form.

$$
R_{M, t+1}-r_{M, t+1}=\frac{R_{M, t+1}^{2}}{2}+\sum_{k=3}^{K \rightarrow \infty}(-1)^{k}\left(\frac{R_{M, t+1}^{k}}{k}\right)=\operatorname{SHMGV}_{M, t+1} \geq 0
$$


Now, by substituting (9) to (8.2) and with some mathematical arrangement, we can simplify the SDF as follows:

$$
m_{t+1}=1-\gamma_{t} R_{M, t+1}-\delta_{t}\left(R_{M, t+1}-r_{M, t+1}\right)=1-\gamma_{t} R_{g, t+1}
$$

where

$$
R_{g, t+1}=R_{M, t+1}+\left(\frac{\delta_{t}}{\gamma_{t}}\right) \operatorname{SHMGV}_{M, t+1}
$$

where $\delta_{t}=\sum_{k=2}^{K \rightarrow \infty} \frac{(-1)^{k}}{(k-1) !}\left(\omega_{k} \delta_{t}^{(k)}\right)$ is a weighted sum of all higher order RRA coefficients, and where $\omega_{k}=\frac{(-1)^{k} k^{-1} R_{M, t+1}^{k}}{\left(R_{M, t+1}-r_{M, t+1}\right)}$, in which $\sum_{k=2}^{K \rightarrow \infty} \omega_{k}=1$. In Appendix A, we show that with $U^{\prime \prime \prime}>0$, $\delta_{t} \leq 0$. Further, recall that the quantity $(R-r)$ captures asymmetries in return variation (see Figure 1), and the coefficient $\delta_{t}$ measures investors' attitude toward the volatility-asymmetries of market return at time $t$. Importantly, equations (10.1) and (10.2) show that $R_{g}$ is the volatility symmetry-equivalent return of $R_{M}$, which represents the optimal growth rate of wealth adjusted by the volatility-asymmetry. Therefore, with the adjustment of asymmetries in the market return distribution, the only parameter of risk-attitude associated with $R_{g}$ in the SDF determination is the RRA coefficient $\gamma$. Recall that $\sum_{k=2}^{K \rightarrow \infty} \delta_{t}^{(k)}=0$, if $U$ in (8) is a logarithmic function. Then, consistent with Martin (2017), Kremens and Martin (2019), and MW (2019), for the log investor, $R_{g}=R_{M}$, and the $\mathbb{Q}$-space mean-variance model is valid.

Without functional form assumption of utility, in the absence of risk-less arbitrage opportunity, for all risky asset $i$, the following equation holds: 


$$
\mathbb{E}_{t}\left[R_{i, t+1}-R_{f, t}\right]=\frac{\operatorname{Cov}_{t}^{\mathbb{Q}}\left[R_{i, t+1}, R_{g, t+1}\right]}{1+R_{f, t}}
$$

Since the market beta of stock in equilibrium is the ratio of its risk-premium to that of the market portfolio, it is necessary to examine the market pricing structure. By setting $i=M$ in (11.1), replacing $R_{g}$ by (10.2), and applying the mean-value theorem to the covariance calculation, we have $^{29}$

$$
\mathbb{E}_{t}\left[R_{M, t+1}-R_{f, t}\right]=\frac{\operatorname{Var}_{t}^{\mathbb{Q}}\left[R_{M, t+1}\right]}{1+R_{f, t}}+\frac{\frac{\delta_{t}}{\gamma_{t}} \operatorname{Cov}_{t}^{\mathbb{Q}}\left[R_{M, t+1}, \operatorname{SHMGV}_{M, t+1}\right]}{1+R_{f, t}}
$$

Given that the risk-neutral variance serves as a lower bound of the equity premium, the second term of the above equation's right-hand side is non-negative. By comparing (11.2) with (1.3), (4), and (5), we rewrite the NCC in Martin (2017) as follows:

$$
-\mathrm{NCC}_{M, t}=\frac{\delta_{t}}{\gamma_{t}}\left(\frac{\operatorname{Cov}_{t}^{\mathbb{Q}}\left[R_{M, t+1}, \operatorname{SHMGV}_{M, t+1}\right]}{1+R_{f, t}}\right) \cong \frac{\max \left(\operatorname{Asy}_{t}^{\mathbb{Q}}\left[R_{M, t+1}\right], 0\right)}{1+R_{f, t}} \geq 0
$$

In short, the core determinants of the NCC are the risk-neutral covariance of market return with its SHMGV and the associated risk-aversion parameter $\frac{\delta}{\gamma}$. Recall the sufficient condition to have the non-positive NCC is $\gamma_{t} \geq 1$, and given $U^{\prime \prime \prime}>0$, the higher-order RRA $\delta$ is less than or equal to zero. Then, the value of $\operatorname{Cov}_{t}^{\mathbb{Q}}\left[R_{M, t+1}, \operatorname{SHMGV}_{M, t+1}\right]$ in (12) must also be

\footnotetext{
${ }^{29}$ Based on the assumption that $R_{M, t+1}$ is continuously distributed within $(-1,1)$, we employ the mean-value theorem in calculus to ensure that the existence of a $\frac{\delta_{t}}{\gamma_{t}}$ such that $\mathbb{E}_{t}^{\mathbb{Q}}\left[R_{M, t+1} \cdot \frac{\delta_{t}}{\gamma_{t}}\left(R_{M, t+1}-r_{M, t+1}\right)\right]=\frac{\delta_{t}}{\gamma_{t}} \mathbb{E}_{t}^{\mathbb{Q}}\left[R_{M, t+1} \cdot\left(R_{M, t+1}-\right.\right.$ $\left.\left.r_{M, t+1}\right)\right]$.
} 
non-positive. ${ }^{30}$ We show in Appendix B that this inequality $\frac{\delta_{t}}{\gamma_{t}} \leq-1$ is a sufficient condition for $\frac{\mathrm{VIX}_{t}^{2}}{1+R_{f, t}}$ to be the lower bound on the equity premium. Consequently, substituting (12) to (1.3), we have the sum of the implied variance $\left(1+R_{f, t}\right) \operatorname{SVIX}_{t}^{2}$ and the implied volatility-asymmetry $\operatorname{AVIX}_{t}^{2}$ in (7) as an approximate to the ex-ante market premium.

$$
\mathbb{E}_{t}\left[R_{M, t+1}-R_{f, t}\right] \cong \frac{\operatorname{Var}_{t}^{\mathbb{Q}}\left(R_{M, t+1}\right)+\max \left(A s y_{t}^{\mathbb{Q}}\left[R_{M, t+1}\right], 0\right)}{1+R_{f, t}}=\mathrm{IEP}_{t}
$$

\subsubsection{Implied Risk Premium and Market Beta of Individual Equity}

Now, according to (11.1) with (10.2), the decomposition of ex-ante risk-premium for individual equity is as follows:

$$
\mathbb{E}_{t}\left[R_{i, t+1}-R_{f, t}\right]=\frac{\operatorname{Cov}_{t}^{\mathbb{Q}}\left[R_{i, t+1}, R_{M, t+1}\right]}{1+R_{f, t}}+\frac{\frac{\delta_{t}}{\gamma_{t}} \operatorname{Cov}_{t}^{\mathbb{Q}}\left[R_{i, t+1}, \operatorname{SHMGV}_{M, t+1}\right]}{1+R_{f, t}}
$$

where the second term on the right-hand side of (14) is the NCC of stock $i\left(\mathrm{NCC}_{i, t}\right)$. Kadan and Tang (2018) show that the NCC holds for individual stocks with a positive beta if the relative risk aversion is high enough to make the covariance between stocks and the market outweigh the

\footnotetext{
${ }^{30}$ Given that $\gamma_{t} \geq 1$ and $\delta_{t} \leq 0$, this condition, $\operatorname{Cov}_{t}^{\mathbb{Q}}\left[R_{M, t+1},\left(R_{M, t+1}-r_{M, t+1}\right)\right] \approx \mathbb{E}_{t}^{\mathbb{Q}}\left[R_{M, t+1}\left(R_{M, t+1}-r_{M, t+1}\right)\right] \leq 0$, must hold to ensure the inequality in (12). Since $\left(R_{M, t+1}-r_{M, t+1}\right) \geq 0$, to have $\operatorname{Cov}_{t}^{\mathbb{Q}}\left[R_{M, t+1},\left(R_{M, t+1}-r_{M, t+1}\right)\right] \leq 0$ only if $R_{M, t+1} \geq 0$. Consequently, the value of $A s y_{t}^{\mathbb{Q}}\left(R_{M, t+1}\right)$ has to be non-negative.
} 
variance of stocks. By dividing (14) by (11.2), we obtain the risk-neutral market beta for a stock $i$ such that

$$
\begin{aligned}
\beta_{i, M, t}^{\mathbb{Q}} & =\frac{\mathbb{E}_{t}\left[R_{i, t+1}-R_{f, t}\right]}{\mathbb{E}_{t}\left[R_{M, t+1}-R_{f, t}\right]}=\frac{\operatorname{Cov}_{t}^{\mathbb{Q}}\left[R_{i, t+1}, R_{g, t+1}\right]}{\operatorname{Cov}_{t}^{\mathbb{Q}}\left[R_{M, t+1}, R_{g, t+1}\right]} \\
& =\frac{\operatorname{Cov}_{t}^{\mathbb{Q}}\left[R_{i, t+1}, R_{M, t+1}\right]-\operatorname{NCC}_{i, t}}{\operatorname{Var}_{t}^{\mathbb{Q}}\left[R_{M, t+1}\right]-\mathrm{NCC}_{M, t}}
\end{aligned}
$$

Next, following Martin and Wagner (2019), we define a return generating process of stocks corresponding to the market growth factor as

$$
R_{i, t+1}-R_{f, t}=\alpha_{i, t}^{\mathbb{Q}}+\beta_{i, g, t}^{\mathbb{Q}}\left(R_{g, t+1}-R_{f, t}\right)+\varepsilon_{i, t+1},
$$

where

$$
\beta_{i, g, t}^{\mathbb{Q}}=\frac{\operatorname{Cov}_{t}^{\mathbb{Q}}\left[R_{i, t+1}, R_{g, t+1}\right]}{\operatorname{Var}_{t}^{\mathbb{Q}}\left[R_{g, t+1}\right]}
$$

$\mathbb{E}_{t}^{\mathbb{Q}}\left(\varepsilon_{i, t+1}\right)=0$, and $\operatorname{Cov}_{t}^{\mathbb{Q}}\left[\varepsilon_{i, t+1}, R_{g, t+1}\right]=0$. We note that from (11.1),

$$
\begin{aligned}
\operatorname{Var}_{t}^{\mathbb{Q}}\left[R_{g, t+1}\right] & =\varphi \operatorname{Cov}_{t}^{\mathbb{Q}}\left[R_{M, t+1}, R_{g, t+1}\right] \\
& =\varphi\left(\operatorname{Var}_{t}^{\mathbb{Q}}\left[R_{M, t+1}\right]+\frac{\delta_{t}}{\gamma_{t}} \operatorname{Cov}_{t}^{\mathbb{Q}}\left[R_{M, t+1}, \operatorname{SHMGV}_{M, t+1}\right]\right) \\
& \cong \varphi \operatorname{Var}_{t}^{\mathbb{Q}}\left[R_{M, t+1}\right]+\varphi\left(\max \left(\operatorname{Asy}_{t}^{\mathbb{Q}}\left[R_{M, t+1}\right], 0\right)\right),
\end{aligned}
$$


where $\varphi=\frac{\mathbb{E}_{t}\left[R_{g, t+1}-R_{f, t}\right]}{\mathbb{E}_{t}\left[R_{M, t+1}-R_{f, t}\right]} \geq 1 .{ }^{31}$ Alternatively, without loss of generality, consider the following (ex-ante) market model of the return generating process for individual stocks.

$$
R_{i, t+1}-R_{f, t}=a_{i, t}^{\mathbb{Q}}+b_{i, M, t}^{\mathbb{Q}}\left(R_{M, t+1}-R_{f, t}\right)+e_{i, t+1}
$$

where

$$
b_{i, M, t}^{\mathbb{Q}}=\frac{\operatorname{Cov}_{t}^{\mathbb{Q}}\left[R_{i, t+1}, R_{M, t+1}\right]}{\operatorname{Var}_{t}^{\mathbb{Q}}\left[R_{M, t+1}\right]}
$$

where $\mathbb{E}_{t}^{\mathbb{Q}}\left(e_{i, t+1}\right)=0$, and $\operatorname{Cov}_{t}^{\mathbb{Q}}\left[e_{i, t+1}, R_{M, t+1}\right]=0 .{ }^{32}$ By taking the difference of residual variance between (16.1) and (18.1) and with some mathematical arrangements using (17), we have the following approximation: ${ }^{33}$

$$
\operatorname{Var}_{t}^{\mathbb{Q}}\left[\varepsilon_{i, t+1}\right] \cong \operatorname{Var}_{t}^{\mathbb{Q}}\left[e_{i, t+1}\right]-\max \left(A s y_{t}^{\mathbb{Q}}\left[R_{i, t+1}\right], 0\right)
$$

where $A s y_{t}^{\mathbb{Q}}\left[R_{i, t+1}\right]$ is the risk-neutral volatility-asymmetry of stock $i$, which can be calculated from option prices of the stock, according to (3.2).

${ }^{31}$ Based on (11.1), $\frac{\mathbb{E}_{t}\left[R_{g, t+1}-R_{f, t}\right]}{\mathbb{E}_{t}\left[R_{M, t+1}-R_{f, t}\right]}=\frac{\operatorname{Var}_{t}^{\mathbb{Q}}\left[R_{g, t+1}\right]}{\operatorname{Cov}_{t}^{\mathbb{Q}}\left[R_{M, t+1}, R_{g, t+1}\right]}=\varphi$.

${ }^{32}$ Since $R_{g, t}$ is a function of $R_{M, t}$, the assumption that $\operatorname{Cov}_{t}^{\mathbb{Q}}\left[\varepsilon_{i, t+1}, R_{g, t+1}\right]=0$ in (16.1) ensures that $\operatorname{Cov}_{t}^{\mathbb{Q}}\left[e_{i, t+1}, R_{M, t+1}\right]=0$ as well.

${ }^{33}$ The difference of residual variances can be written as $\operatorname{Var}_{t}^{\mathbb{Q}}\left[\varepsilon_{i, t+1}\right]-\operatorname{Var}_{t}^{\mathbb{Q}}\left[e_{i, t+1}\right]=b_{i, M, t}^{\mathbb{Q} 2} \operatorname{Var}_{t}^{\mathbb{Q}}\left[R_{M, t+1}\right]-$ $\beta_{i, g, t}^{\mathbb{Q} 2} \operatorname{Var}_{t}^{\mathbb{Q}}\left[R_{g, t+1}\right] \approx b_{i, M, t}^{\mathbb{Q} 2} \operatorname{Var}_{t}^{\mathbb{Q}}\left[R_{M, t+1}\right]-\varphi \beta_{i, g, t}^{\mathbb{Q} 2}\left[\operatorname{Var}_{t}^{\mathbb{Q}}\left[R_{M, t+1}\right]+\max \left(\operatorname{Asy}_{t}^{\mathbb{Q}}\left[R_{M, t+1}\right], 0\right)\right]$. Further, from (16.2), (17), and (18.2), we have $b_{i, M t}^{\mathbb{Q} 2}=\varphi \beta_{i, g, t}^{\mathbb{Q} 2}$, and $\max \left(A s y_{t}^{\mathbb{Q}}\left[R_{i, t+1}\right], 0\right) \approx \varphi \beta_{i, g, t}^{\mathbb{Q} 2}\left[\max \left(A s y_{t}^{\mathbb{Q}}\left[R_{M, t+1}\right], 0\right)\right]$. 
Martin and Wagner (2019) show that $\operatorname{Var}_{t}^{\mathbb{Q}}\left[R_{i, t+1}\right] \approx\left(2 \beta_{i, t}^{\mathbb{Q}}-k\right) \operatorname{Var}_{t}^{\mathbb{Q}}\left[R_{g, t+1}\right]+$ $\operatorname{Var}_{t}^{\mathbb{Q}}\left[\varepsilon_{i, t+1}\right]$ in that $\beta_{i, t}^{\mathbb{Q} 2} \approx 2 \beta_{i, t}^{\mathbb{Q}}-k$, where $k$ is a constant. Replacing $\operatorname{Var}_{t}^{\mathbb{Q}}\left[\varepsilon_{i, t+1}\right]$ by the approximation in (19) and realizing that equations (11.1) and (16.2) imply $\beta_{i, t}^{\mathbb{Q}} \operatorname{Var}_{t}^{\mathbb{Q}}\left[R_{g, t+1}\right]=$ $\left(1+R_{f, t}\right) \mathbb{E}_{t}\left[R_{i, t+1}-R_{f, t}\right]$, we then have

$\mathbb{E}_{t}\left[R_{i, t+1}-R_{f, t}\right] \cong \frac{\operatorname{Var}_{t}^{\mathbb{Q}}\left[R_{i, t+1}\right]+\max \left(A s y_{t}^{\mathbb{Q}}\left[R_{i, t+1}\right], 0\right)+k \operatorname{Var}_{t}^{\mathbb{Q}}\left[R_{g, t+1}\right]-\operatorname{Var}_{t}^{\mathbb{Q}}\left[e_{i, t+1}\right]}{2\left(1+R_{f, t}\right)}$

Market value weighting (20), one obtains

$$
\begin{aligned}
& \mathbb{E}_{t}\left[R_{M, t+1}-R_{f, t}\right] \\
& \cong \frac{\sum_{i=1}^{N} w_{i, t} \operatorname{Var}_{t}^{\mathbb{Q}}\left[R_{i, t+1}\right]+\sum_{i=1}^{N} w_{i, t} \max \left(\operatorname{As} y_{t}^{\mathbb{Q}}\left[R_{i, t+1}\right], 0\right)+k \operatorname{Var}_{t}^{\mathbb{Q}}\left[R_{g, t+1}\right]-\sum_{i=1}^{N} w_{i, t} \operatorname{Var}_{t}^{\mathbb{Q}}\left[e_{i, t+1}\right]}{2\left(1+R_{f, t}\right)}
\end{aligned}
$$

Subtracting (21) by (20), we find that

$$
\begin{aligned}
\mathbb{E}_{t}\left[R_{i, t+1}-R_{M, t+1}\right] & \\
& \cong\left(\frac{\operatorname{Var}_{t}^{\mathbb{Q}}\left[R_{i, t+1}\right]-\sum_{i=1}^{N} w_{i, t} \operatorname{Var}_{t}^{\mathbb{Q}}\left[R_{i, t+1}\right]}{2\left(1+R_{f, t}\right)}\right) \\
& +\left(\frac{\max \left(A s y_{t}^{\mathbb{Q}}\left[R_{i, t+1}\right], 0\right)-\sum_{i=1}^{N} w_{i, t} \max \left(\operatorname{Asy}_{t}^{\mathbb{Q}}\left[R_{i, t+1}\right], 0\right)}{2\left(1+R_{f, t}\right)}\right) \\
& -\left(\frac{\operatorname{Var}_{t}^{\mathbb{Q}}\left[e_{i, t+1}\right]-\sum_{i=1}^{N} w_{i, t} \operatorname{Var}_{t}^{\mathbb{Q}}\left[e_{i, t+1}\right]}{2\left(1+R_{f, t}\right)}\right)
\end{aligned}
$$


Again, following the assumption of Martin and Wagner (2019), the final term on the right-hand side of (22) is zero on a value-weighted average. For convenience, let $\overline{\operatorname{SVIX}}_{t}^{2}=\sum_{i=1}^{N} w_{i, t} \mathrm{SVIX}_{i, t}^{2}$ and $\overline{\mathrm{AVIX}}_{t}^{2}=\sum_{i=1}^{N} w_{i, t} \mathrm{AVIX}_{i, t}^{2}$. Then, we rewrite (22) as:

$$
\mathbb{E}_{t}\left[R_{i, t+1}-R_{M, t+1}\right] \cong \frac{\left(1+R_{f, t}\right)}{2}\left(\operatorname{SVIX}_{i, t}^{2}-\overline{\operatorname{SVIX}}_{t}^{2}\right)+\frac{1}{2}\left(\mathrm{AVIX}_{i, t}^{2}-\overline{\operatorname{AVIX}}_{t}^{2}\right)
$$

In equilibrium, the market beta is the ratio of risk-premium between a stock and the market. Based on (22), (23.1) and (23.2), we now define the ex-ante option-implied market beta of stocks (denoted $\mathbb{B}_{i, t}^{\mathrm{MKT}}$ ) as a weighted sum of its decomposed implied-betas corresponding to SVIX and AVIX, accordingly.

$$
\mathbb{B}_{i, t}^{\mathrm{MKT}}=\left(1-w_{t}^{\mathrm{A}}\right) \mathbb{B}_{i, t}^{\mathrm{SVIX}}+w_{t}^{\mathrm{A}} \mathbb{B}_{i, t}^{\mathrm{AVIX}}
$$

where

$$
\begin{aligned}
\mathbb{B}_{i, t}^{\mathrm{SVIX}} & =\frac{\operatorname{SVIX}_{t}^{2}+\frac{1}{2}\left(\operatorname{SVIX}_{i, t}^{2}-\overline{\operatorname{SVIX}}_{t}^{2}\right)}{\operatorname{SVIX}_{t}^{2}}, \\
\mathbb{B}_{i, t}^{\mathrm{AVIX}} & =\frac{\mathrm{AVIX}_{t}^{2}+\frac{1}{2}\left(\operatorname{AVIX}_{i, t}^{2}-\overline{\operatorname{AVIX}}_{t}^{2}\right)}{\mathrm{AVIX}_{t}^{2}},
\end{aligned}
$$

and

$$
w_{t}^{\mathrm{A}}=\frac{\mathrm{AVIX}_{t}^{2}}{\left(1+R_{f, t}\right) \mathrm{SVIX}_{t}^{2}+\mathrm{AVIX}_{t}^{2}}
$$


Note that the ratio of market variance to average stock variance, $\frac{\mathrm{SVIX}_{t}^{2}}{\overline{\mathrm{SVIX}}_{t}^{2}}$, can be interpreted as a measure of the average risk-neutral correlation between stocks. ${ }^{34}$ Then, the difference between $\operatorname{SVIX}_{i, t}^{2}$ and $\overline{\operatorname{SVIX}}_{t}^{2}$ in (24.2) and that between $\mathrm{AVIX}_{i, t}^{2}$ and $\overline{\mathrm{AVIX}}_{t}^{2}$ in (24.3) characterize the stock's risk-neutral covariance and coasymmetry with the market return, respectively. Further, as shown in Figure 1, both SVIX and AVIX are noticeably a convex function of returns. Then, these two inequalities, $\operatorname{SVIX}_{t}^{2}<\overline{\operatorname{SVIX}}_{t}^{2}$ and $\operatorname{AVIX}_{t}^{2}<\overline{\mathrm{AVIX}}_{t}^{2}$, follow from Jensen's inequality. The convexity of SVIX and AVIX makes the implied market beta to be nonadditive.

However, given the norm that a portfolio of options is more valuable than an option on a portfolio, conservatively, one could view SVIX and AVIX of an equity portfolio as a portfolio of options on its component stocks instead of a weighted sum of options on the portfolio. It then results in $\operatorname{SVIX}_{p, t}^{2}=\sum_{i=1}^{n} w_{i} \operatorname{SVIX}_{i, t}^{2}$ and $\mathrm{AVIX}_{p, t}^{2}=\sum_{i=1}^{n} w_{i} \mathrm{AVIX}_{i, t}^{2}$. Consequently, the implied market beta is linearly additive so that $\mathbb{B}_{p, t}^{\mathrm{MKT}}=\sum_{i=1}^{n} w_{i} \mathbb{B}_{i, t}^{\mathrm{MKT}}$, and $\mathbb{B}_{M, t}^{\mathrm{MKT}}=1$ (by setting $p=M$ and $n=N$ ). Finally, one can apply (24) and (7) to calculate the option-implied risk premium for stocks/portfolios $\left(\mathrm{IEP}_{i}\right)$ as follows:

$$
\mathrm{IEP}_{i, t}=\mathbb{B}_{i, t}^{\mathrm{MKT}} \cdot \mathrm{IEP}_{t}
$$

Notably, as illustrated in (7), (24), and (25), the impact of higher moments and co-moments on the equity risk premium is embedded in the implied market beta and the corresponding market

\footnotetext{
${ }^{34}$ See Martin and Wagner (2019) for the proof.
} 
premium. Thus, no additional factor (e.g., skewness) is necessary for pricing asymmetry-risk in our model.

\subsection{Empirical Analysis and Developing MKT*}

The focus of our empirical analysis is twofold. The first objective is to examine the predictability of the option-implied betas in (24). Should the stocks with high (low) risk-neutral betas generate a relatively high (low) future realized return on average? If the implied beta does predict equity risk-premium, what are its implications and applications to asset pricing? The second objective addresses the hedging ability of the implied betas against tail risk exposure. Will stocks with low implied beta have less recognized loss than those with high beta in bear or crashing markets? To answer these questions, we apply our models to options and return data of the constituents in the SPX.

\subsubsection{Data and Measurements}

SVIX / AVIX Indices. First, we replicate the one-month SVIX ${ }^{2}$ in Martin (2017) by using the SPX options data from OptionMetrics. ${ }^{35}$ The sample period is from January 4, 1996, to December 31, 2020. We employ the same data set to calculate AVIX ${ }^{2}$. The options data includes strike prices, highest bids, and lowest asks of all out-of-money calls and puts, but excludes options with zero bid prices. To be consistent with VIX's formulation, we follow CBOE procedure using near- and next-term put and call options with maturities between 23 and 37

\footnotetext{
${ }^{35}$ Our annualized lower bound is 5.05\%, which is close to Martin's 5\%. (See Table 1 in Martin, 2017).
} 
days. $^{36}$ The option price is the average of the highest bid and the lowest ask. With this sampling process, we obtain $2,999,678$ daily options data for computing the non-overlapping monthly $\mathrm{SVIX}^{2} / \mathrm{AVIX}^{2}$. Correspondingly, we obtain the price and return information for the underlying stocks/Index from the database of the Center for Research in Security Prices (CRSP) with the share code 10 or 11 .

SVIX/AVIX Betas. For computing the implied betas of SVIX and AVIX, we follow the sampling procedures in MW and Schneider, Wagner, and Zechner (2020) using price information of options from the database Volatility Surface in OptionMetrics. To be consistent with the indices of VIX, SVIX, and AVIX, the firms we analyze are the SPX constituents with a sample period from January 4, 1996, to December 31, 2020. ${ }^{37}$ By matching options data with the underlying equity date from CRSP, we obtain 3,001,025 daily observations in the merged data set. Our sample contains an average number of 497 firms per day.

Implied Skewness Beta. For comparison, we also calculate the implied skewness beta based on Schneider, Wagner, and Zechner (2020). Analogous to (24.2) and (24.3), one could view that the deviation of a stock's risk-neutral skewness $\left(\operatorname{SKEW}_{i, t}\right)$ from the average implied skewness of equity $\left(\overline{\mathrm{SKEW}}_{t}\right)$ characterizes the risk-neutral co-skewness of the stock with the market. So that we can calculate the risk-neutral skewness beta as:

\footnotetext{
${ }^{36}$ Before October 6, 2014, we use near- and next-term options with maturities of more than seven days.

${ }^{37}$ We obtain the SPX constituents from the website of S\&P Dow Jones Indices.
} 


$$
\mathbb{B}_{i, t}^{\mathrm{SKEW}}=\frac{\operatorname{SKEW}_{t}+\frac{1}{2}\left(\mathrm{SKEW}_{i, t}-\overline{\operatorname{SKEW}}_{t}\right)}{\mathrm{SKEW}_{t}}
$$

where SKEW $t=\mathrm{USK}_{t}+\mathrm{LSK}_{t}$. USK and LSK stand for upper and lower SKEW such that

$$
\mathrm{USK}_{t}=\frac{6}{p_{t, t+1}}\left(\int_{F_{t, t+1}}^{\infty} \log \left(\frac{K}{F_{t, t+1}}\right) \sqrt{\frac{K}{F_{t, t+1}}} \frac{\operatorname{Call}_{t, t+1}(K)}{K^{2}} d K\right),
$$

and

$$
\operatorname{LSK}_{t}=\frac{-6}{p_{t, t+1}}\left(\int_{0}^{F_{t, t+1}} \log \left(\frac{F_{t, t+1}}{K}\right) \sqrt{\frac{K}{F_{t, t+1}}} \frac{P u t_{t, t+1}(K)}{K^{2}} d K\right) .
$$

Then, one can calculate the implied beta corresponding to USK and LSK by these equations: $\mathbb{B}_{i, t}^{\mathrm{USK}}=\frac{\mathrm{USK}_{t}+\frac{1}{2}\left(\mathrm{USK}_{i, t}-\overline{\mathrm{USK}}_{t}\right)}{\mathrm{USK}_{t}}$, and $\mathbb{B}_{i, t}^{\mathrm{LSK}}=\frac{\mathrm{LSK}_{t}+\frac{1}{2}\left(\mathrm{LSK}_{i, t}-\overline{\mathrm{LSK}_{t}}\right)}{\mathrm{LSK}_{t}}$, receptively.

Lagged Realized betas. For examining the cross-section of the earning predictability and hedging ability of option-implied market beta, we compare them with lagged realized betas including the CAPM beta $\left(\beta_{i, t-1}^{\mathrm{CAPM}}\right)$; the Fama and French (2015) factor-betas of size $\left(\beta_{i, t-1}^{\mathrm{SMB}}\right)$, value $\left(\beta_{i, t-1}^{\mathrm{HML}}\right)$, profitability $\left(\beta_{i, t-1}^{\mathrm{RMW}}\right)$, and investment $\left(\beta_{i, t-1}^{\mathrm{CMA}}\right)$; the momentum beta $\left(\beta_{i, t-1}^{\mathrm{MOM}}\right)$ based on Carhart (1997); the down beta $\left(\beta_{i, t-1}^{\text {Down }}\right)$ from Ang, Chen, and Xing (2006); and the skewness beta $\left(\beta_{i, t-1}^{\text {Skew }}\right)$ according to Harvey and Siddique (2000). We estimate the lagged realized beta coefficients from a multifactor (including SMB, HML, RMW, CMA, and MOM) regression based on the daily returns in the previous 12-month horizon, starting and ending on the third Friday of the month. 
To minimize the effects of illiquidity, we require stocks to have a minimum of 126 trading days in 12-month horizon. The downside betas and skewness betas are calculated as follows:

$$
\beta_{i}^{\text {Down }}=\frac{\operatorname{COV}\left(R_{i}, R_{M} \mid R_{M}<\mu_{M}\right)}{\operatorname{VAR}\left(R_{M} \mid R_{M}<\mu_{M}\right)},
$$

and

$$
\beta_{i}^{\text {Skew }}=\frac{\mathrm{E}\left[\left(R_{i}-\mu_{i}\right)\left(R_{M}-\mu_{M}\right)^{2}\right]}{\sqrt{\operatorname{VAR}\left(R_{i}\right)} \cdot \operatorname{VAR}\left(R_{M}\right)},
$$

where COV and VAR denote the covariance and variance, accordingly.

Return Calculation. We use a fixed horizon starting and ending on the third Friday of each month as a base for all cross-sectional analysis, where the specified horizon matches the horizon of the standard stock options (Schneider and Trojani, 2015). To avoid the impact of extreme tails of returns on the analysis, we winsorize returns on individual stocks at the $1 \%$ and 99\% levels, following Knez and Ready (1997).

\subsubsection{Summary Statistics}

Before presenting our analysis's summary statistics, we depict the daily movement of VIX, AVIX, and SVIX over the sample period between 1996 and 2020 in Figure 2. The movement pattern of AVIX is almost identical to that of VIX and SVIX. Although the magnitude of AVIX is relatively small, the changes in the value of AVIX are more significant than that of VIX and SVIX, particularly during the high time with high market volatility (e.g., the years 2009 and 2020). As summarized in Panel A of Table 1, the average IEP ranges from 0.73 percent to 
68.07 percent. The range of $\left(1+R_{f}\right) \mathrm{SVIX}^{2}$ is 0.68 percent to 58.94 percent, and that of $\mathrm{AVIX}^{2}$ is from zero to 11.8 percent, respectively.

[Insert Figure 3.2 Here]

On average, the IEP is 4.74 percent per year, which is 45 basis points (bps) higher than Martin's lower bound of 4.29 percent. This additional premium of 45 bps captured by AVIX represents the excess return required by investors to compensate for potential losses from the left-tail volatility-asymmetry in market returns. We note that the value-weighted average value of SVIX and AVIX of stocks is larger than the index value of SVIX and AVIX, and their difference varies on every level of distribution. This finding indicates the ex-ante correlation between stocks is dynamic and changeable by different market conditions. The risk-neutral skewness (SKEW) of the market index and individual stocks is generally negative in value over the sample period, with an average value of -0.76 and -0.56 , indicating that investors' primary concern is potential (possible) future downside losses in assessing investment risk.

For calculating implied betas of individual equity, we winsorize all independent variables at the 1 percent and 99 percent levels, using the sampling procedures in Knez and Ready (1997), to avoid analytical outcomes driven by extreme outliers from the sample. Panel B of Table 1 reports the weighted sum of SVIX-beta (AVIX-beta), ranging from -0.41 to 8.94 ( -4.77 to 35.38), with results in the implied market beta $\mathbb{B}_{i}^{M \mathrm{kT}}$ from the minimum of -0.55 to the maximum of 10.29. All implied betas skew positively with a median value around one. The mean-value and the standard deviation of SKEW-beta are significantly lower than those of the AVIX-beta. The 
SKEW-beta of stocks is generally positive in value with the median of 0.95. Since the implied skewness SKEW is less than zero, which results in a negative weight to the market beta, $\mathbb{B}_{i}^{\text {SKEW }}$ is not a composite of $\mathbb{B}_{i}^{\mathrm{MKT}}$. The low correlation between the SKEW-beta and the three implied betas, shown in Panel D of Table 1, supports our argument, even though SKEW highly correlates with SVIX and AVIX (reported in Panel C of Table 1).

For the index portfolio, SKEW almost perfectly and negatively correlates with AVIX (with the correlation coefficient of -99 percent shown in Panel C of Table 1). However, the correlation between SKEW and AVIX becomes less significant for individual equity, with a coefficient of -86 percent on average. Also, notably, the correlation coefficient between the average AVIX of stocks ( $\overline{\mathrm{AVIX}})$ and the average SVIX of stocks ( $\overline{\mathrm{SVIX}})$ is 97 percent, where the same coefficient between $\overline{\text { SKEW }}$ and $\overline{\text { SVIX }}$ is -79 percent. These findings suggest AVIX is a different measure from SKEW, and the risk-neutral skewness measure cannot replace AVIX for measuring volatility-asymmetry.

[Insert Table 1 Here]

\subsubsection{Causality between AVIX and SVIX}

The near-perfect correlation between AVIX and SVIX indicates increasing volatility must associate with increasing volatility-asymmetry. The question then arises: which one causes the other to change? If the asymmetry in volatility drives the volatility, then the attribution of AVIX to equity premium should increase as the market becomes more volatile and vice versa. 
We provide evidence in Table 2. The attribution based on the AVIX/IEP ratio gets larger as VIX soars, ranging from 6.64 percent in the first decile of the VIX level to 12.05 percent in the last decile. Notably, the AVIX enlarges three times from 0.67 percent in the $9^{\text {th }}$ decile of VIX to 2.12 percent in the $10^{\text {th }}$ decile, where SVIX jumps a little more than two times from 6.52 to 14.03 percent. Although the scope of AVIX is relatively insignificant to the SVIX, intuitively, the dynamic of AVIX spurs the index value movement of SVIX.

[Insert Table 2 Here]

Furthermore, we examine the change of AVIX attribution to equity premium corresponding to various market conditions. We calculate the daily put/call ratio from the price of the volume-weighted options portfolio on the SPX as a proxy to determine investor anticipated equity market conditions. The categorization breakpoints of the put/call ratio for market conditions are at the 1/16 (extreme-bull), 2/16 (bull), 14/16 (bear), and 15/16 (extremebear) quantiles. It leaves the remaining put/call ratios as the neutral market condition.

[Insert Table 3 Here]

As shown in Table 3, the average AVIX/IEP ratio is 7.51 percent in the neutral market. Its value changes upward to 9.38 percent in extreme-bull and 9.94 percent in extreme-bear markets. It indicates that AVIX is not just a downside volatility measure; it reflects the volatilityasymmetry for both sides of the market gain/loss. Table 3 illustrates that the implied volatility enlarges asymptotically between bull and bear markets, highlighting the importance of AVIX in determining the equity risk premium. Specifically, the implied equity premium under the neutral, 
bull, and bear condition is $4.11,5.42$, and 7.88 percent, respectively. The percentage change of AVIX (SVIX) from the bear to extreme-bear state is 35.6 (25.21) percent, where the shift from the bull to extreme-bull market is 10.3 (5.52) percent. Intuitively, the asymmetry in return variation (measured by AVIX) causes the upward shift of the volatility toward either upside gains or downside losses. The magnitude of the downside shift is more significant than that of the upside movement.

\subsubsection{Mimicking Portfolio of Implied Market Index, MKT*}

A beta coefficient of a stock is its loading to a common risk factor. Since (excess) returns are compensation for bearing systematic risk, if the beta correctly predicts the risk, stocks that possess high beta should earn high return on average and vice versa. We document in Table 4 that stocks with high implied market beta yield relatively higher average (next-period) returns than those having low implied market beta. We compute the implied market beta, a composite of the SVIX- and AVIX-beta, using options prices on the third Friday of the month. The excess returns are calculated as the compounding daily excess returns in the next horizons that match the options' maturities of one, three, six and twelve months. We adjust all holding period returns to monthly returns.

Accordingly, the same pattern of return/beta crosses the four holding periods of one, three, six, and twelve months. The mean return monotonically increases as the average beta rises, except a return jump appears at the top decile portfolio. The large volatility-asymmetry in the tail 
of return distribution could cause this jump in returns. The monthly premium between the top and bottom decile portfolios of beta-sorted stocks is statistically significant across the board of all periods and both value- and equal-weighted portfolios. Generally, the equal-weighted funds have a relatively higher premium than the value-weighted funds indicating the impact of size effect on asset pricing with asymmetry is noteworthy.

\section{[Insert Table 4 Here]}

Recall (10.2), the optimal market return under expected utility maximization is the return on the market factor portfolio plus the impact of volatility-asymmetry on market return. Thus, the capital-weighted market index may not be a proxy of the market portfolio if risk-averse investors are concerned about asymmetries in market returns. Based on our theory of implied beta and the out-of-sample analysis in Table 4, we develop an investment strategy that mimics the return on the market factor with adjustment for volatility-asymmetry. The strategy is to invest 100 percent of capital in a risk-free asset and a fraction $\mathrm{X}$ of the capital in a zero-cost long-short fund with implied betas.

Corresponding to Table 4, one sells the first (bottom) decile portfolio short and simultaneously buys the last (top) decile group of stocks with the same amount of capital as the short-sell proceeds to form the zero-cost fund. The fraction X equals the reciprocal of the implied beta difference between the top and the bottom decile portfolios. The investment is rebalanced monthly on the third Friday of the month to match the monthly options' exercise date. We denote $R_{T o p}^{\mathrm{MKT}}$ and $R_{\text {Bottom }}^{\mathrm{MKT}}$ as returns on the top and bottom decile portfolios of implied market beta 
sorted stocks for convenience. Given that all assets on the security market line have the same slope in equilibrium and the market beta is one, the return on the mimicking portfolio of the asymmetry-adjusted market-factor (abbreviated $\mathrm{MKT}^{*}$ ), corresponding to the implied market betas, is as follows:

$$
R_{\mathrm{MKT}^{*}, t}=X_{t-1}\left(R_{\text {Top }, t}^{\mathrm{MKT}}-R_{B o t t o m, t}^{\mathrm{MKT}}\right)+R_{f, t}
$$

where $X_{t-1}=\frac{1}{\mathbb{B}_{\text {Top }, t-1}^{\mathrm{MKT}}-\mathbb{B}_{\text {Bottom }, t-1}^{\mathrm{MKT}}}$.

We note that Roll's Critique (1977) suggests it is impossible to observe a genuinely diversified market portfolio directly. Post (2003) also finds that the value-weighted market index, commonly used as a proxy for the market factor in asset pricing, is inefficient in second-degree stochastic dominance relative to benchmark portfolios formed on market capitalization and book-to-market equity ratio. Nevertheless, our (indirectly observed) mimicking market portfolio MKT*, accessing the expected return on assets from the ex-ante implied betas, reflects the expectation of the market risk/return tradeoff and could serve as an appropriate proxy for the actual market factor index.

\section{[Insert Figure 3.3 Here]}

To visualize our mimicking market portfolio, Figure 3 presents the daily index value of $\mathrm{MKT}^{*}$ comparing to that of the SPX, the implied market equity premium plus the risk-free rate (IEP+RF) according to (7), and the CBOE volatility index (VIX). We apply (29) to compute the $\mathrm{MKT}^{*}$ index, where the returns on the top and bottom decile portfolios and their associated 
implied market betas are log-value weighted. ${ }^{38}$ For matching the value of the SPX on January 19, 1996, the beginning index value of SPX, MKT*, and IEP+RF is set equally at 612 . The ending value in our sample period for SPX, MKT*, and IEP+RF is 3707, 2830, and 2324 on December 18, 2020, respectively. The index movement of MKT* and SPX follows a similar pattern over time with a correlation of 66.22 percent; however, SPX appears to be more volatile than MKT*.

Since the implied equity market premium is non-negative in value, the index IEP+RF monotonically increases over time. It characterizes the expected growth value of the equity markets, where the investible index MKT* mimics the price dynamic of the market growth. With the volatility-asymmetry adjustment embedded in the index calculation, MKT* is significantly less volatile than SPX, resulting in a relatively higher Sharpe ratio (62 vs. 37 percent) despite a lower mean-return. Importantly, the outperformance of MKT* over SPX results from the hedging ability of MKT* against downside losses. The return distribution statistics in Figure 3 show that MKT* generates approximately one-third of losses on the left trail of the SPX return distribution, making the Sortino ratio of $\mathrm{MKT}^{*}$ (75 percent) to be significantly higher than that of SPX (47 percent). MKT* follows the same pattern of index movement as SPX over time. However, the index of IEP, on the other hand, has a more stable change in value compared to SPX and MKT*. Because IEP is a risk-neutral ( $\mathbb{Q}$-space) estimate of market premium implied by options price, it may not capture the dynamic of the realized (P-space) market price movement.

\footnotetext{
${ }^{38}$ Since the $\mathrm{MKT}^{*}$ strategy selects one-fifth of stocks in the population, we employ the log-weighted approach to prevent concentrated portfolio bias toward large-cap equity.
} 
The mimicking market factor portfolio MKT* overcomes the problem of IEP in assessing a realized price dynamic by implementing a tradeable investment strategy that connects the current (previous) $\mathbb{Q}$-space estimates to the next period (current) $\mathbb{P}$-space outcomes. From the results in Table 4 and (29), the current implied market beta is a predictor of a stock's following period equity premium ratio with the mimicking market factor portfolio.

$$
\frac{R_{i, t+1}-R_{f, t+1}}{R_{\mathrm{MKT}^{*}, t+1}-R_{f, t+1}}=\mathbb{B}_{i, t}^{\mathrm{MKT}}+\varepsilon_{i, t+1}
$$

Equivalently, let $R X_{i}\left(=R_{i}-R_{f}\right)$ be the excess return on a stock, then we have the following implied market model:

$$
R X_{i, t}=\mathbb{B}_{i, t-1}^{\mathrm{MKT}} \cdot R X_{\mathrm{MKT}^{*}, t}+z_{i, t}
$$

where $z_{i, t}=\bar{z}_{i}+e_{i, t}$, and where $\bar{z}_{i}$ is the mean of $z_{i, t}$, and $e_{i, t}$ is zero on average. An important implication of (30.2) is that the payoffs from a periodically (e.g., monthly) rebalanced investment strategy by allocating $x \%\left(=\mathbb{B}_{i, t}^{\mathrm{MKT}}\right)$ of capital to $\mathrm{MKT}^{*}$ and $(1-x \%)$ to a risk-free bond fund replicates the returns on an equity investment.

\subsubsection{Pricing effectiveness of the implied market model}

Since (30.1) is equivalent to (30.2), we examine the predictability of the implied market beta by inspecting the effectiveness of the market model in pricing risky assets. If our implied market model is effective, then the residual returns on an asset $z_{i}$ should be unique to the asset 
and independent of other systematic risk factors. We employ the following multifactor regression and develop an index of pricing error to test for modeling effectiveness.

$$
z_{i, t}=\alpha_{i}+\sum_{F} b_{F} R_{F, t}+\epsilon_{i . t}
$$

where $b_{F}$ estimates the factor loading of $z_{i, t}$ corresponding to returns on a mimicking portfolio of a common risk-factor $R_{F}$ other than the market factor, and $\alpha_{i}$ is the regression alpha assuming that $E\left(\epsilon_{i . t}\right)=0$. Since $\bar{z}_{i}=\alpha_{i}+\sum_{F} b_{F} \bar{R}_{F, t}$, we have the following pricing error (PE) index:

$$
\mathrm{PE}_{i}=\bar{z}_{i}-\alpha_{i}
$$

If $\mathrm{PE}$ is zero, then the second term on the right-hand side of equation (31.1) is zero on average, indicating no systematic risk factors other than the market factor explaining the dynamic of $z_{i}$.

\section{[Insert Table 5 Here]}

We apply (30) and (31) to monthly returns on implied market beta sorted stocks, MKT*, and various pricing factors in Kenneth R. French's Data Library. Table 5 presents the PE and adjusted $\mathrm{R}^{2}$ of (31.1) corresponding to four alternative models, including (1) FF2 of SMB and HML; (2) FF2+MOM; (3) FF4 adds two more factors, RMW and CMA, to the FF2; and (4) FF4 + MOM, respectively. Applying to all decile portfolios of implied beta sorted, we find statistically that all PE indexes are insignificantly different from zero. The low value of the adjusted $\mathrm{R}^{2}$ of the in-sample regression according to (31.1), ranging from 0.35 to 14.63 percent, 
indicates the above alternative models have almost no power to explain the variability of the residual returns from the implied model of (30.2).

The drawbacks of the PE analysis in (31) are twofold. First, it is an in-sample estimation over the entire sample period that provides no information about the predictability of estimates over different periods. Second, the PE index based on the alpha of the multifactor regression ignores the impact of individual factors on the pricing effects of the model. To address this issue and further examine the robustness of the implied market model, we analyze the return predictability of non-market beta coefficients after controlling implied market beta with MKT* individually. On each rebalance date of the month, we estimate the non-market beta coefficients from a multifactor (including SMB, HML, RMW, CMA, and MOM) regression based on the daily residual returns $z_{i}$ of stocks, according to (30.2), in the previous 12-month horizon. Our purpose is to examine whether stocks with a high non-market beta generate a higher average return in the next period than the low beta stocks and vice versa.

\section{[Insert Table 6 Here]}

We form ten decile beta-sorted portfolios for each non-market beta estimate. The monthly excess returns are calculated as the compounding daily excess returns in a monthly horizon starting and ending on the third Friday of each month. We compute both the equal- and value-weighted excess returns in the subsequent month for each equity group. As shown in Table 6, except for the size (SMB) beta of equally-weighted portfolios, all other non-market (ex-post) betas appear to have no predictability of return on stocks. In summary, from our analysis shown 
in Tables IV, V, and VI, we conclude that there is no clear risk-return tradeoff from non-market factors other than the size factor once the implied market model controls the systematic risk.

\subsubsection{Hedging ability of MKT* beta against bear/crashing markets}

Levi and Welch (2020), hereafter LW, empirically find that the symmetric plain market (CAPM) beta is the better hedging measure than the asymmetric DOWN-beta of Ang, Chen, and Xing (2006) even in crashing markets. There is no evidence that the hedge provided by portfolios of stocks with low betas tend to collapse in bear markets. Also, the prevailing CAPM beta predicts the subsequent DOWN-beta (i.e., beta measured only on days when the stock market has declined) better than the DOWN-beta does itself.

Options premium reflects investors' expectations of future price movements. The returns on the mimicking portfolio MKT* thus mirror investors' expected market movements. With the adjustment of volatility-asymmetry, as shown in Figure 3, we predict the (plain) beta coefficient

of stocks with $\mathrm{MKT}^{*}$ (denoted $\beta_{i}^{\mathrm{MKT} *}$ ) is a superior hedging measure to alternative betas. Following the investment strategies in LW, we form annually rebalanced decile portfolios of stocks based on a sorted beta on the third Friday of December in each year. The beta coefficients are calculated using daily returns in the past year. After forming the portfolios, we hold the position for one year and compute investment returns on them daily to examine their performance on days with significant market losses. For comparison, we also form portfolios with implied betas of MKT and SKEW based on prices of twelve-month options contracts. 
[Insert Table 7 Here]

Table 7 focuses on the bear/extreme-bear market conditions in that most stocks experience losses (negative returns) under these conditions. ${ }^{39}$ Our testing results support LW's findings of the superiority of the CAPM beta. Although both DOWN and implied market betas appear to be hedging measures (the lower the beta the less the loss), they underperform the CAPM beta. However, we show that stocks with our low MKT* beta make portfolios "safer" than those with low CAPM and other alternative betas.

The decile portfolios of stocks with the lowest $\mathrm{MKT}^{*}$ beta generate approximately ten bps less average loss per day than those with the lowest CAPM beta in both extreme and bear markets. The mimicking market portfolio $\mathrm{MKT}^{*}$ has a strong hedging ability. It reduces threequarters of loss on MKT and SPX, from around -2.7 (-2.0) percent to -0.64 (-0.45) in the extreme bear (bear) condition. As a result, the portfolios with $\mathrm{MKT}^{*}$ beta yield fewer losses than those with alternative beta in almost every decile level. Consequently, investors can reduce downside risk exposure without short-selling or using derivatives by holding low MKT* beta stocks in their investment. From our findings, neither the implied nor the realized skewness beta is a good hedging measure to form safer portfolios against downside risk.

\subsubsection{Fama-Macbeth Regressions}

\footnotetext{
${ }^{39}$ We use the unconditional breakpoints at $1 / 16$ (1/8) quantiles of the daily market return in the sample period to determine the extreme bear and bear markets.
} 
To further test the robustness of the implied betas in pricing systematic risk-premium, we employ a series of cross-sectional Fama-MacBeth regressions with control for unsystematic variables that could explain excess returns on the firm's level. Again, we use a fixed horizon starting and ending on the third Friday of each month as a base for all cross-sectional regressions.

$$
X R_{i, t}=\lambda_{0}+\lambda_{1} \mathbb{B}_{i, t-1}+\lambda_{2}\left(X R_{i, t-1}\right)+\lambda_{2}\left(X R_{i, t-12}\right)+\Lambda^{\prime} C_{i, t-1}+\varepsilon_{i, t}
$$

where $C_{i, t-1}$ denotes a vector of the idiosyncratic parameters to the firm, and $\Lambda$ is a vector of corresponding coefficients of the regressors. We use past one-month excess returns to account for the short-term return reversal effect and the lagged twelve-month returns to account for the momentum effect. ${ }^{40}$ The control variables include log-size, B/M, standard deviation, skewness, kurtosis, maximum (minimum) monthly return in the past twelve months, and the natural logarithm of the monthly trading volume. ${ }^{41}$ The implied beta is a robust predictor of riskpremium on stocks if $\lambda_{1}$ is statistically significant.

\section{[Insert Table 8 Here]}

The testing results in Table 8 show that the cross-sectional return predictability of the implied betas of MKT, SVIX, and AVIX is statistically significant, according to regressions II, III, and IV. However, from regressions I and V, the significance of predictability vanishes if we replace the beta with that of CAPM and SKEW. No control variables affect the predictability of

\footnotetext{
${ }^{40}$ See Jegadeesh (1990) and Lehmann (1990) for the short-term reversal effect and Jegadeesh and Titman (1993) for the momentum effect.

${ }^{41}$ Size is computed as stock price times the number of shares outstanding. B/M stands for book-to-market ratio in Fama and French (1992). Following Bali, Cakici, and Whitelaw (2011), we control the maximum (minimum) monthly return for each stock.
} 
the implied market beta and the SVIX-beta. Interestingly, regression IV in Table 8 indicates that the short-term reversal on returns is associated with the AVIX-beta. That means, intuitively, the current price of stocks with high AVIX-beta (highly sensitive to market asymmetry) could be under or overvalued, maybe due to investors' overreactions. Then, the short-term reversal occurs in the next period with a positive (negative) return on the under (over) valued stocks.

\subsubsection{Comparative analysis of AVIX-Beta vs. alternative implied and realized betas}

As shown in Table 3, we find the dynamic of AVIX spurs the index value movement of SVIX. It suggests that the change of asymmetry in price movements intangibly drives that of the market volatility. Implicitly, the predictability of the implied market beta could root in that of the AVIX-beta. We employ a comparative analysis with a double sort of betas to examine the crosssection return predictability of the AVIX-beta vs. other beta measures.

\section{[Insert Table 9 Here]}

Table 9 shows the average monthly excess returns for twenty-five different equity groups double-sorted by the AVIX-beta vs. one of the four implied betas of SVIX, SKEW, USK, and LSK based on (24) and (26). Under a double sorting procedure, we first sort stocks into quintiles (in rows) based on a controlling beta, and then in each quintile row, we sort stocks into five

columns based on an alternative beta. For example, the first $5 \times 5\left(\mathbb{B}_{i, t-1}^{\mathrm{AVIX}} / \mathbb{B}_{i, t-1}^{\mathrm{SVIX}}\right)$ sort in Table 9 shows the average returns of SVIX-beta sorted portfolios controlled by the AVIX-beta sorting. The notation " $5-1$ " refers to the excess returns of portfolio 5 over portfolio 1 . It appears that 
four of five SVIX-beta sorted portfolios lose their return predictability after controlling by the AVIX-beta. On the other hand, according to the reverse $\mathbb{B}_{i, t-1}^{\operatorname{SVIX}} / \mathbb{B}_{i, t-1}^{\mathrm{AVIX}}$ sorting, the "5 - 1" premium on three of five AVIX-beta quintile portfolios is statistically significant even with the control of SVIX-beta. This evidence indicates that the risk-return tradeoff of SVIX is driven by that of AVIX.

The second pair of double sorts in Table 9 compares AVIX-beta with the implied skewness beta $\left(\mathbb{B}_{i, t-1}^{\mathrm{SKEW}}\right)$. The pattern of average returns on the SKEW-beta sorted portfolios appears to be in a V-shape. From the $\mathbb{B}_{i, t-1}^{\text {SKEW }} / \mathbb{B}_{i, t-1}^{\text {AVIX }}$ sorting, we find stocks having high or low SKEW-beta have higher average return than stocks with the average SKEW-beta. However, the V-shape structure disappears from the $\mathbb{B}_{i, t-1}^{\mathrm{AVIX}} / \mathbb{B}_{i, t-1}^{S \mathrm{SEW}}$ ranking, and the excess returns on SKEWbeta sorted portfolios are negative even though some of them are statistically significant. The return predictability of AVIX-beta is still strong with control of the SKEW-beta. Therefore, for analyzing ex-ante risk/return tradeoff with asymmetry, AVIX is superior to SKEW.

The comparative analysis between betas of AVIX and SKEW indicates that investors require excess returns to compensate risk generated from both left- and right-tail asymmetries in market returns. Referring to Figure 1, although positively skewed returns seem to reward investment, they do not reduce volatility in returns. Consequently, risk-averse investors demand higher returns for increasing right-tail asymmetries in return. We find evidence from the double sort of betas between upper SKEW (USK) and AVIX. Stocks with high USK-beta generate higher average returns than those with low USK-beta. Nevertheless, this effect generally 
vanishes on the AVIX-beta sorted portfolios. Outcomes similar to the USK/AVIX analysis appear to compare the lower SKEW-beta $\left(\mathbb{B}_{i, t-1}^{\mathrm{LSK}}\right)$ with the AVIX-beta. In short, our analysis reveals that AVIX can capture risk generated from both the upper and the lower skewness of market return distribution.

We further compare AVIX-beta with various realized betas calculated from daily returns in the previous 12-month horizon on the third Friday of the month. We then compute monthly excess returns of the beta sorted portfolio by compounding daily returns in a monthly horizon starting and ending on the third Friday of each month. Our analysis focuses on three market betas, including CAPM, Skew, and DOWN associated with returns on the market portfolio MKT in Kenneth R. French's Data Library. We also include the size beta corresponding to returns on the SMB index. Its impact on the risk/return prediction is significant compared to betas associated with other pricing factors (as shown in Table 6).

\section{[Insert Table 10 Here]}

Table 10 reveals that except for stocks with high AVIX-beta (in the fifth quintile group) in each quintile portfolio sorted by the CAPM-beta, the predictability of the CAPM-beta on the risk-return relationship is statistically insignificant. Nevertheless, AVIX-beta retains its significant predictability for all portfolios with the CAPM-beta ranked stocks. From the second and third pairs of double sort analysis in Table 10, we find no evidence to show the risk-return predictability on the realized betas of Skew and DOWN. Consistent with the implication from the testing results in Table 6, Table 10 shows that the ex-ante return and size-beta relationship is 
relatively significant indicating the SMB factor is essential for assessing equity risk-premium. From the SMB/AVIX beta-sorting, the average return on stocks with high SMB-beta significantly exceeds that on stocks with low SMB-beta for all levels of the AVIX-beta. However, only two of the five quintile portfolios have a significant size-premium once the ranking is controlled by the AVIX-beta.

\subsection{Conclusion}

This study makes several contributions to the literature on capital asset pricing and portfolio management. First, by defending the AVIX measure, we extend the SVIX models of Martin (2017) and Martin and Wagner (2019) to incorporate the higher moment and co-moment risk for measuring the ex-ante equity premium, free from functional form assumption of utility and return distribution.

Second, we formulate the (options) implied market beta of equity, as a composite of SVIX- and AVIX-beta, in an ex-ante asset pricing model. Superior to the CAPM beta, the implied market beta possesses robust predictability of risk-premium on stocks.

Third, based on the systematic risk/return equilibrium from the implied betas, we develop a novel mimicking portfolio $\mathrm{MKT}^{*}$ that tracks the realized returns on the implicit market pricing factor implied by options prices, free from parameter estimation. As shown in Figure 3, with the adjustment for volatility-asymmetry, $\mathrm{MKT}^{*}$ implicitly mimics the fundamental long-term growth of the equity markets. The market index SPX moves reversely along MKT* over time. 
MKT* outperforms SPX and significantly reduces losses in bear/crashing markets. Following Levi and Welch (2020), we show that the plain beta coefficient with MKT* is a superior hedging measure to all alternative betas against downside risk. That is, stocks with low $\mathrm{MKT}^{*}$ beta make investment portfolios much safer.

Lastly, our comparative analysis reveals that with the control of AVIX-beta, the return predictability of SVIX and other alternative betas generally vanishes. We conclude that one fundamental effect driving the increasing ex-ante risk premium of volatility in the risk-return tradeoff is the increased asymmetry in return distribution. In short, the coasymmetry risk spurs the covariance risk. 


\section{Appendix}

\section{Appendix A: a proof to show that $\delta_{t} \leq 0$}

We show that if $U^{\prime \prime \prime}(W)>0$, then $\delta_{t}<0$. For convenience, let $R_{t+1}=\frac{W_{t+1}-W_{t}}{W_{t}}=\frac{\Delta W}{W}$, and $r_{t+1}=$ $\ln \left(1+R_{t+1}\right)$ we rewrite $\delta_{t}$ as:

$$
\delta_{t}\left(R_{t+1}-r_{t+1}\right)=-\sum_{k=2}^{K \rightarrow \infty} \frac{W^{k} U^{(k+1)}\left(W_{t}\right)}{k ! U^{\prime}\left(W_{t}\right)} R_{t+1}^{k}
$$

We apply the Taylor series expansion to $U^{\prime \prime \prime}\left(W_{t+1}\right)$ around $W_{t}$ such that:

$$
U^{\prime \prime \prime}\left(W_{t+1}\right)=U^{\prime \prime \prime}\left(W_{t}\right)+W_{t} \cdot U^{(4)}\left(W_{t}\right) R+\sum_{k=5}^{K \rightarrow \infty} \frac{W_{t}^{k-3} U^{(k)}\left(W_{t}\right)}{(k-3) !} R^{k-3}
$$

Now, define $q\left(W_{t+1}\right)=\int_{W_{t}}^{W_{t+1}} U^{\prime \prime \prime}(s) d s$, we have

$q\left(W_{t+1}\right)=U^{\prime \prime \prime}\left(W_{t}\right)\left(W_{t+1}-W_{t}\right)+\frac{U^{(4)}\left(W_{t}\right)}{2}\left(W_{t+1}-W_{t}\right)^{2}+\sum_{k=5}^{K \rightarrow \infty} \frac{U^{(k)}\left(W_{t}\right)}{(k-2) !}\left(W_{t+1}-W_{t}\right)^{k-2}$

Since $U^{\prime \prime \prime}>0, q\left(W_{t+1}\right)>0$ as $W_{t+1}>W_{t}$ while $q\left(W_{t+1}\right)<0$ if $W_{t+1}<W_{t}$. Next, consider $G\left(W_{t+1}\right)=\int_{W_{t}}^{W_{t+1}} q(s) d s$. Then,

$$
G\left(W_{t+1}\right)=\frac{U^{\prime \prime \prime}\left(W_{t}\right)}{2}\left(W_{t+1}-W_{t}\right)^{2}+\frac{U^{(4)}\left(W_{t}\right)}{3 !}\left(W_{t+1}-W_{t}\right)^{3}+\sum_{k=5}^{K \rightarrow \infty} \frac{U^{(k)}\left(W_{t}\right)}{(k-1) !}\left(W_{t+1}-W_{t}\right)^{k-1}
$$

Because of the property of $q\left(W_{t+1}\right), G\left(W_{t+1}\right)$ reaches its minimum as $W_{t+1}=W_{t}$. Thus, $G\left(W_{t+1}\right) \geq 0$. Further, let $H\left(W_{t+1}\right)=\int_{W_{t}}^{W_{t+1}} G(s) d s$. Then, 
$H\left(W_{t+1}\right)=\frac{U^{\prime \prime \prime}\left(W_{t}\right)}{3 !}\left(W_{t+1}-W_{t}\right)^{3}+\frac{U^{(4)}\left(W_{t}\right)}{4 !}\left(W_{t+1}-W_{t}\right)^{4}+\sum_{k=5}^{K \rightarrow \infty} \frac{U^{(k)}\left(W_{t}\right)}{k !}\left(W_{t+1}-W_{t}\right)^{k}$.

Since $G\left(W_{t+1}\right) \geq 0$ for all $W_{t+1} . H\left(W_{t+1}\right)$ is a monotonic increasing function with $H\left(W_{t}\right)=0$, and thus $H\left(W_{t+1}\right)>0$ as $W_{t+1}>W_{t}$ while $H\left(W_{t+1}\right)<0$ as $W_{t+1}<W_{t}$. Compared to equation (A1),

$\delta_{t}(R-r)=-\sum_{k=2}^{\infty} \frac{W_{t}^{k} U^{(k+1)}\left(W_{t}\right)}{k ! U^{\prime}\left(W_{t}\right)} R^{k}=-\frac{1}{U^{\prime}\left(W_{t}\right)} \sum_{k=3}^{K \rightarrow \infty} k \frac{U^{(k+1)}\left(W_{t}\right)}{k ! U^{\prime}\left(W_{t}\right)}\left(W_{t+1}-W_{t}\right)^{k}=$ $-\frac{k^{*}}{U^{\prime}\left(W_{t}\right)} \sum_{k=3}^{K \rightarrow \infty} \frac{U^{(k+1)}\left(W_{t}\right)}{k ! U^{\prime}\left(W_{t}\right)}\left(W_{t+1}-W_{t}\right)^{k} \leq 0$.

Since $(R-r) \geq 0$, we have $\delta_{t} \leq 0$.

Appendix B: the sufficient condition for $\mathrm{VIX}^{2}$ serves as a lower bound on the equity premium

We show the condition to have the following inequality, according to Equation (4).

$$
\mathbb{E}_{t}\left[R_{M, t+1}-R_{f, t}\right]-\left(\frac{\mathrm{VIX}_{t}^{2}}{1+R_{f, t}}-\frac{R_{f, t}^{2}}{1+R_{f, t}}\right)=-\left(\mathrm{NCC}_{t}+\frac{A s y_{t}^{\mathbb{Q}}\left[R_{M, t+1}\right]}{1+R_{f, t}}\right) \geq 0
$$

From (3.2) and (12),

$$
\begin{aligned}
-\left(\mathrm{NCC}_{t}+\frac{A s y_{t}^{\mathbb{Q}}\left[R_{M, t+1}\right]}{1+R_{f, t}}\right) & =\frac{\frac{\delta_{t}}{\gamma_{t}} \sum_{k=3}^{K \rightarrow \infty}(-1)^{k-1} \frac{\mathbb{E}_{t}^{\mathbb{Q}}\left[R_{M, t+1}^{k}\right]}{k-1}}{1+R_{f, t}}-\frac{\sum_{k=3}^{K \rightarrow \infty}(-1)^{k} \frac{\mathbb{E}_{t}^{\mathbb{Q}}\left[R_{M, t+1}^{k}\right]}{k}}{1+R_{f, t}} \\
& =\frac{1}{1+R_{f, t}} \sum_{k=3}^{K \rightarrow \infty}(-1)^{k-1} \mathbb{E}_{t}^{\mathbb{Q}}\left[R_{M, t+1}^{k}\right]\left\{\frac{\frac{\delta_{t}}{\gamma_{t}}}{k-1}+\frac{1}{k}\right\} .
\end{aligned}
$$

So that

$\mathrm{NCC}_{t}+\frac{A s y_{t}^{\mathbb{Q}}\left[R_{M, t+1}\right]}{1+R_{f, t}}$ 
$=\frac{-1}{1+R_{f, t}}\left\{\left[\mathbb{E}_{t}^{\mathbb{Q}}\left[R_{M, t+1}^{3}\right]\left(\frac{\frac{\delta_{t}}{\gamma_{t}}}{2}+\frac{1}{3}\right)-\mathbb{E}_{t}^{\mathbb{Q}}\left[R_{M, t+1}^{4}\right]\left(\frac{\frac{\delta_{t}}{\gamma_{t}}}{3}+\frac{1}{4}\right)\right]+[\cdot]+\cdots\right\}$

Now, for each square bracket in the right-hand site of (B3), we have the following transformation. Let $k=2 n+1$, where $n=1,2,3, \ldots, N \rightarrow \infty$,

$\mathbb{E}_{t}^{\mathbb{Q}}\left[R_{M, t+1}^{k}\right]\left(\frac{\frac{\delta_{t}}{\gamma_{t}}}{k-1}+\frac{1}{k}\right)-\mathbb{E}_{t}^{\mathbb{Q}}\left[R_{M, t+1}^{k+1}\right]\left(\frac{\frac{\delta_{t}}{\gamma_{t}}}{k}+\frac{1}{k+1}\right) \geq \mathbb{E}_{t}^{\mathbb{Q}}\left[R_{M, t+1}^{k+1}\right]\left(-\frac{\frac{\delta_{t}}{\gamma_{t}}}{k-1}-\frac{1}{k}-\frac{\frac{\delta_{t}}{\gamma_{t}}}{k}-\frac{1}{k+1}\right)$

The inequality (B4) is true, if $A s y_{t}^{\mathbb{Q}}\left[R_{M, t+1}\right] \geq 0$. Note that the non-negative value of $A s y_{t}^{\mathbb{Q}}\left[R_{M, t+1}\right]$ implies that $-\mathbb{E}_{t}^{\mathbb{Q}}\left[R_{M, t+1}^{k}\right] \geq \mathbb{E}_{t}^{\mathbb{Q}}\left[R_{M, t+1}^{k+1}\right]$. We then have

$$
\mathbb{E}_{t}^{\mathbb{Q}}\left[R_{M, t+1}^{k+1}\right]\left(-\frac{\frac{\delta_{t}}{\gamma_{t}}}{k-1}-\frac{1}{k}-\frac{\frac{\delta_{t}}{\gamma_{t}}}{k}-\frac{1}{k+1}\right) \geq 0
$$

if the following inequation holds:

$$
-\frac{\frac{\delta_{t}}{\gamma_{t}}}{k-1}-\frac{1}{k}-\frac{\frac{\delta_{t}}{\gamma_{t}}}{k}-\frac{1}{k+1} \geq\left(-\frac{\delta_{t}}{\gamma_{t}}-1\right)\left(\frac{1}{k}+\frac{1}{k+1}\right) \geq 0
$$

Finally, from (B3) and the non-equality relationship of (B4), (B5), and (B6), we have this sufficient condition that if $\frac{\delta_{t}}{\gamma_{t}} \leq-1$, then $-\left(\mathrm{NCC}_{t}+\frac{A s y_{t}^{\mathbb{Q}}\left[R_{M, t+1}\right]}{1+R_{f, t}}\right) \geq 0$. According to (B1) and given that $\mathrm{VIX}_{t}^{2}>R_{f, t}^{2}$ in general, we conclude that the sufficient condition to ensure that $\frac{\operatorname{VIX}_{t}^{2}}{1+R_{f, t}}$ serves a lower bound on the equity premium is $\frac{\delta_{t}}{\gamma_{t}} \leq-1$. 
Figures and Tables
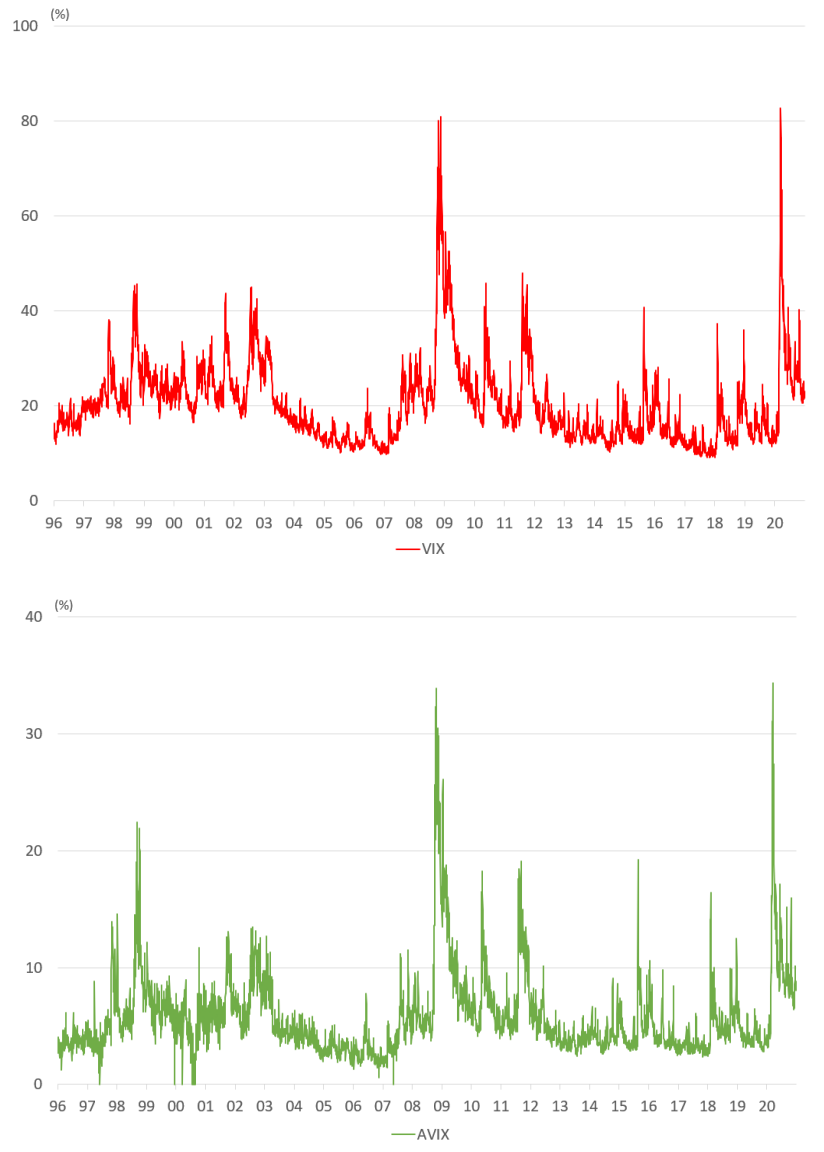

$100^{1 \% 6}$

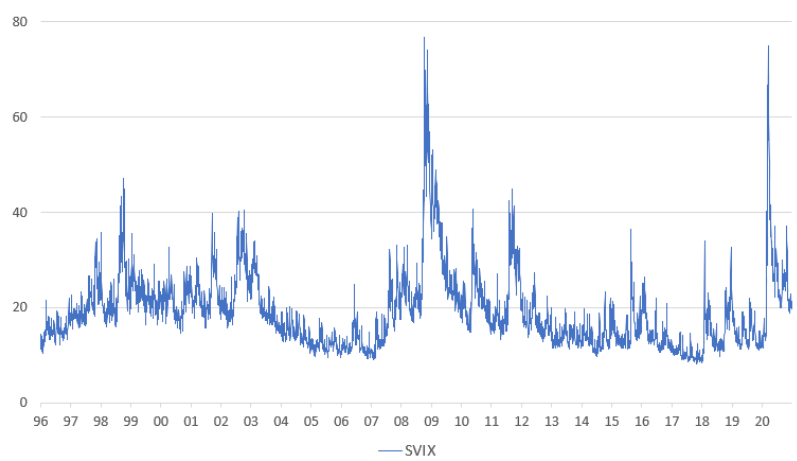

Figure 3.2

VIX, AVIX, and SVIX (1996 - 2020) 
Table 1

\section{Summary Statistics}

Panel A presents the summary statistics of annualized IEP, SVIX, AVIX, and SKEW at the one-month horizon (measured in percentage value). We follow the CBOE VIX calculation procedures using near- and next-term put and call options with maturities between 23 and 37 days. For data dated before October 6, 2014, we employ near- and next-term options with maturities of more than seven days. We exclude options with zero bid price. Panel B reports the implied betas based on (24) and (26.1). We calculate 3,133,256 daily implied betas using the Volatility Surface options database of individual stocks for a period from January 4, 1996, to December 31, 2020. All implied betas are winsorized at one and 99 percent levels. Panels C and D report the correlation between implied volatility measures and implied betas.

\begin{tabular}{lrrrrrrrrrrrrr}
\hline \multicolumn{10}{l}{ Panel A. Implied equity premium, variance, volatility-asymmetry, and skewness } \\
\hline \multicolumn{1}{c}{} & Mean & Std. Dev & Skew & Kurt & Min & P1 & P10 & P25 & Median & P75 & P90 & P99 & Max \\
\hline IEP & 4.74 & 5.31 & 4.94 & 35.60 & 0.73 & 0.94 & 1.43 & 1.96 & 3.33 & 5.44 & 8.84 & 30.10 & 68.07 \\
\hline$\left(1+R_{f}\right)$ SVIX $^{2}$ & 4.29 & 4.51 & 4.68 & 32.79 & 0.68 & 0.87 & 1.33 & 1.83 & 3.10 & 5.00 & 7.98 & 25.06 & 58.94 \\
AVIX $^{2}$ & 0.45 & 0.84 & 6.49 & 56.11 & 0.00 & 0.03 & 0.08 & 0.13 & 0.23 & 0.44 & 0.92 & 4.62 & 11.80 \\
SKEW & -0.76 & 1.53 & -6.86 & 61.31 & -21.76 & -8.46 & -1.52 & -0.69 & -0.35 & -0.20 & -0.13 & -0.06 & 0.61 \\
\hline$\left(1+R_{f}\right) \overline{\text { SVIX }}^{2}$ & 11.04 & 7.80 & 2.81 & 12.35 & 3.58 & 4.12 & 5.16 & 6.15 & 8.23 & 13.44 & 20.41 & 41.79 & 84.98 \\
$\overline{A V I X}^{2}$ & 1.55 & 2.00 & 5.02 & 38.73 & 0.26 & 0.33 & 0.45 & 0.59 & 0.86 & 1.75 & 3.21 & 10.61 & 29.14 \\
$\overline{S K E W}$ & -0.56 & 1.15 & -6.30 & 58.66 & -19.51 & -6.17 & -1.10 & -0.51 & -0.26 & -0.15 & -0.08 & 0.09 & 8.51 \\
\hline Panel B. Implied betas & & & & & & & & & & & & \\
\hline $\mathbb{B}_{i}^{\text {MKT }}$ & 1.67 & 1.80 & 2.39 & 7.09 & -0.55 & -0.55 & 0.24 & 0.62 & 1.14 & 2.07 & 3.71 & 10.29 & 10.29 \\
$\mathbb{B}_{i}^{\text {SVIX }}$ & 1.61 & 1.59 & 2.23 & 6.13 & -0.41 & -0.41 & 0.30 & 0.65 & 1.15 & 2.00 & 3.47 & 8.94 & 8.94 \\
$\mathbb{B}_{i}^{\text {AVIX }}$ & 2.65 & 5.60 & 3.54 & 15.25 & -4.77 & -4.77 & -0.66 & 0.21 & 1.04 & 2.86 & 7.17 & 35.38 & 35.38 \\
$\mathbb{B}_{i}^{\text {SKEW }}$ & 1.14 & 1.43 & 1.88 & 10.64 & -3.66 & -3.66 & 0.24 & 0.70 & 0.95 & 1.32 & 2.20 & 8.62 & 8.62 \\
\hline
\end{tabular}


Table 1 (Continued)

\begin{tabular}{|c|c|c|c|c|c|}
\hline \multicolumn{6}{|c|}{ Panel C. Correlations between implied variance, volatility-asymmetry, and skewness } \\
\hline & SVIX $^{2}$ & $\mathrm{AVIX}^{2}$ & SKEW & $\overline{\text { SVIX }}_{i}^{2}$ & $\overline{\mathrm{AVIX}}_{i}^{2}$ \\
\hline AVIX $^{2}$ & 0.94 & & & & \\
\hline SKEW & -0.93 & -0.99 & & & \\
\hline$\overline{\mathrm{SVIX}}_{i}^{2}$ & 0.86 & 0.75 & -0.73 & & \\
\hline$\overline{\mathrm{AVIX}}_{i}^{2}$ & 0.88 & 0.80 & -0.79 & 0.97 & \\
\hline$\overline{\text { SKEW }}_{i}$ & -0.88 & -0.86 & 0.86 & -0.79 & -0.87 \\
\hline \multicolumn{6}{|c|}{ Panel D. Correlations between implied betas } \\
\hline & $\mathbb{B}_{i}^{\mathrm{MKT}}$ & $\mathbb{B}_{i}^{\text {SVIX }}$ & $\mathbb{B}_{i}^{\mathrm{AVIX}}$ & & \\
\hline $\mathbb{B}_{i}^{S V I X}$ & 0.99 & & & & \\
\hline $\mathbb{B}_{i}^{A}$ AVIX & 0.92 & 0.90 & & & \\
\hline $\mathbb{B}_{i}^{\text {SKEW }}$ & 0.27 & 0.26 & 0.28 & & \\
\hline
\end{tabular}


Table 2

Implied equity premium and betas on VIX decile levels

This table presents the average annual IEP, SVIX, and AVIX corresponding to different decile levels of VIX sorted from our sample data within a period from January 4, 1996, to December 31, 2020. The last row of the table reports the percentage attribution of AVIX to the IEP on average. We depict the relationship between IEP, SVIX, and AVIX in the diagram below the table for a graphical illustration. All numbers reported in the table are in percentage value.

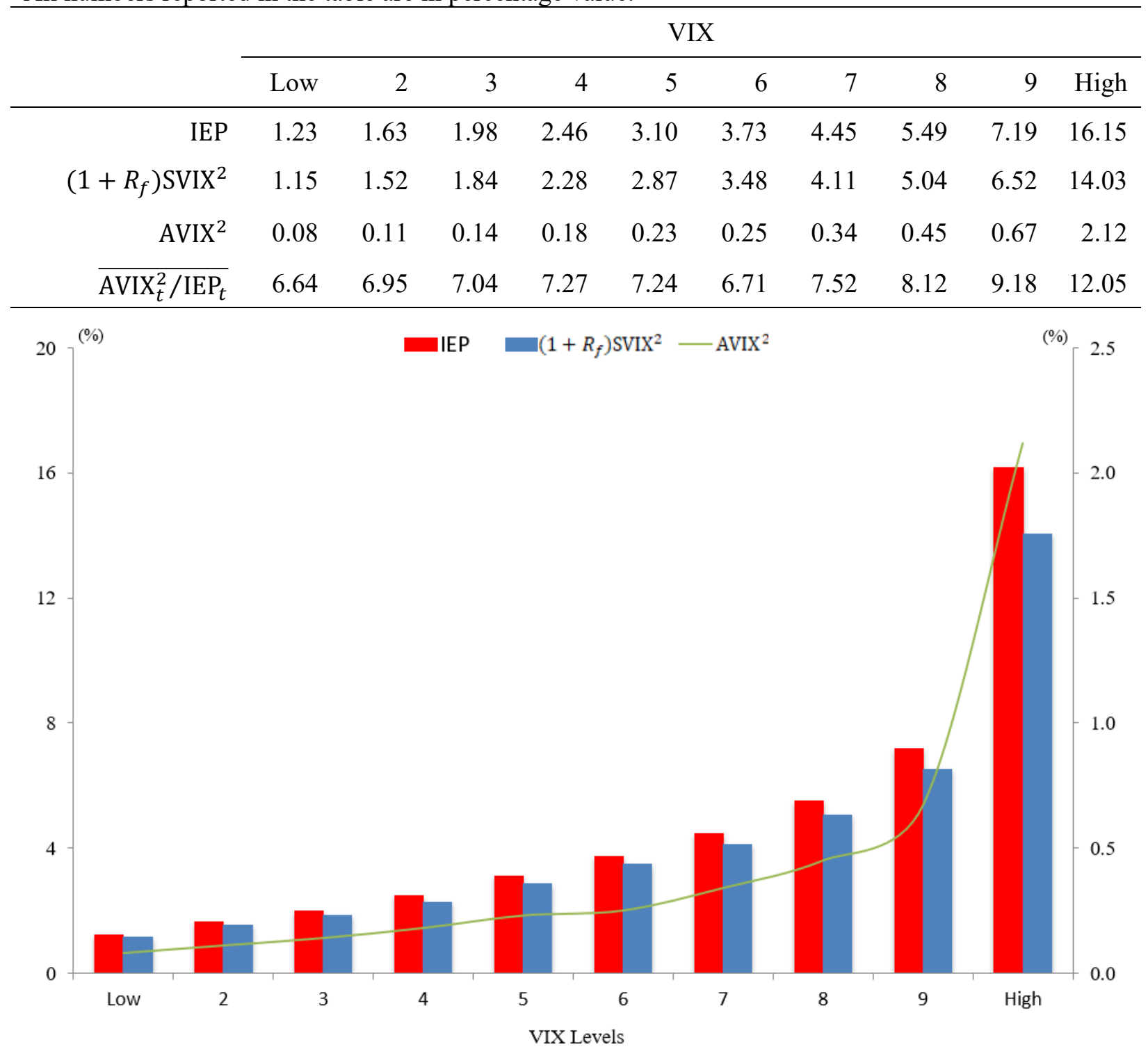


Table 3

Implied Equity Premium and Betas under Various Ex-ante Market Conditions

This table presents the average annual IEP, SVIX, and AVIX corresponding to different market conditions. We employ the put/call ratio calculated from the price of volume-weighted options portfolios on the S\&P 500 index as a proxy to determine ex-ante equity market conditions. The categorization breakpoints of the put/call ratio for market conditions are at the 1/16 (extreme bull), 2/16 (bull), 14/16 (bear), and 15/16 (extreme bear) quantiles. The last row of the table reports the percentage attribution of AVIX to the IEP on average. We depict the relationship between IEP, SVIX, and AVIX in the diagram below the table for a graphical illustration. All numbers reported in the table are in percentage value.

\begin{tabular}{rccccccc}
\hline & \multicolumn{7}{c}{ Market Condition } \\
\cline { 2 - 8 } & $(1)-(2)$ & Extreme & Bear & Bear & Neutral & Bull & Extreme \\
& \multicolumn{1}{c}{$(2)$} & $(1)$ & $(2)$ & $(3)$ & $(4)$ & $(5)$ & $\frac{(5)-(4)}{(4)}$ \\
\hline IEP & 26.40 & 9.96 & 7.88 & 4.11 & 5.42 & 5.76 & 6.27 \\
$\left(1+R_{f}\right) \mathrm{SVIX}^{2}$ & 25.21 & 8.74 & 6.98 & 3.74 & 4.86 & 5.13 & 5.56 \\
$\mathrm{AVIX}^{2}$ & 35.60 & 1.22 & 0.90 & 0.37 & 0.57 & 0.63 & 10.53 \\
$\mathrm{AVIX}_{t}^{2} / \mathrm{IEP}_{t}$ & 9.60 & 9.94 & 9.07 & 7.51 & 8.84 & 9.38 & 6.11 \\
\hline
\end{tabular}

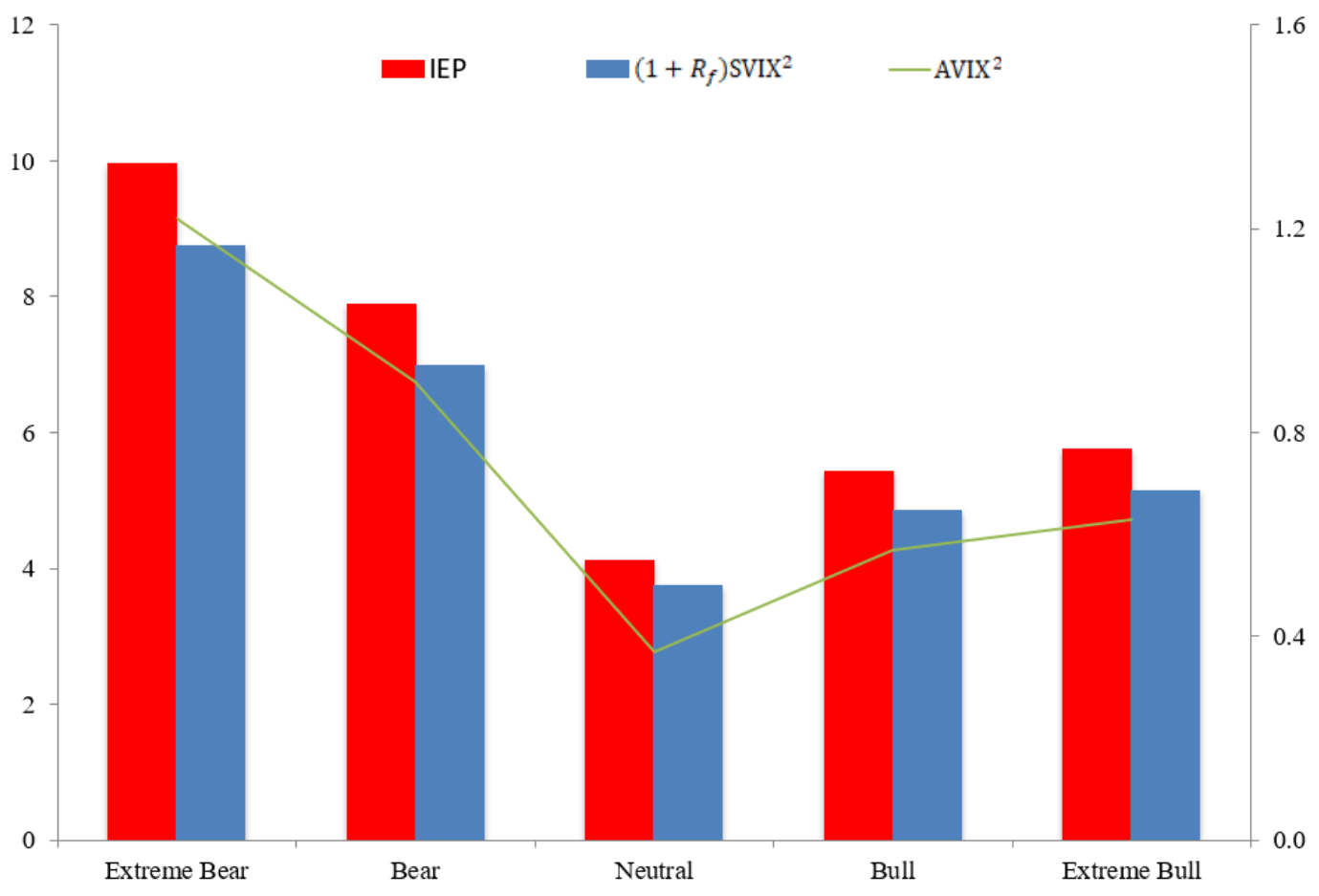

Ex ante Market State 


\section{Table 4}

\section{Implied Market Beta and Cross-sectional Average Return}

This table presents the average monthly excess returns (in percentage value) corresponding to ten different equity groups sorted by the implied market beta of equity calculated at the beginning of the period. We compute implied market betas, based on (24.1), using options prices on the third Friday of the month. The excess returns are calculated as the compounding daily excess returns in the next horizons that match the options' maturities. For comparison, we report both the equal- and valueweighted monthly excess returns for each equity group. The sample consists of all S\&P 500 constituents from January 4, 1996, to December 31, 2020. The notation "Top - Bottom" refers to the difference in returns between the top and bottom decile portfolios. The t-statistics are reported in square brackets where those in bold stand for statistical significance at the five percent level.

\begin{tabular}{|c|c|c|c|c|c|}
\hline $\begin{array}{l}\text { (A) Equal } \\
\text { Weighted }\end{array}$ & $\mathbb{B}_{p, t-1}^{\mathrm{MKT}}$ & One-Month & Three-Month & Six-Month & Twelve Month \\
\hline Bottom & 0.10 & 0.83 & 0.95 & 0.96 & 1.02 \\
\hline 2 & 0.35 & 1.01 & 1.04 & 1.10 & 1.15 \\
\hline 3 & 0.56 & 1.14 & 1.25 & 1.26 & 1.28 \\
\hline 4 & 0.78 & 1.44 & 1.30 & 1.38 & 1.43 \\
\hline 5 & 1.02 & 1.50 & 1.53 & 1.51 & 1.48 \\
\hline 6 & 1.31 & 1.49 & 1.65 & 1.64 & 1.60 \\
\hline 7 & 1.67 & 1.70 & 1.68 & 1.76 & 1.69 \\
\hline 8 & 2.18 & 2.01 & 1.93 & 1.87 & 1.96 \\
\hline 9 & 3.04 & 2.29 & 2.21 & 2.28 & 2.21 \\
\hline Top & 5.54 & 3.26 & 2.87 & 2.98 & 3.20 \\
\hline Top - Bottom & & $\begin{array}{r}2.43 \\
{[3.13]} \\
\end{array}$ & $\begin{array}{r}1.92 \\
{[4.21]} \\
\end{array}$ & $\begin{array}{r}2.02 \\
{[5.70]} \\
\end{array}$ & $\begin{array}{r}2.18 \\
{[7.81]} \\
\end{array}$ \\
\hline \multicolumn{6}{|l|}{$\begin{array}{l}\text { (B) Value } \\
\text { Weighted }\end{array}$} \\
\hline Bottom & 0.09 & 0.65 & 0.69 & 0.72 & 0.78 \\
\hline 2 & 0.35 & 0.89 & 0.92 & 0.85 & 0.80 \\
\hline 3 & 0.56 & 1.04 & 1.11 & 1.07 & 1.08 \\
\hline 4 & 0.78 & 1.13 & 1.22 & 1.26 & 1.32 \\
\hline 5 & 1.02 & 1.43 & 1.23 & 1.29 & 1.32 \\
\hline 6 & 1.31 & 1.34 & 1.39 & 1.34 & 1.42 \\
\hline 7 & 1.67 & 1.45 & 1.55 & 1.57 & 1.34 \\
\hline 8 & 2.18 & 1.53 & 1.38 & 1.42 & 1.50 \\
\hline 9 & 3.02 & 1.15 & 1.41 & 1.62 & 1.67 \\
\hline Top & 5.30 & 2.36 & 2.29 & 2.35 & 2.45 \\
\hline Top - Bottom & & $\begin{array}{r}1.71 \\
{[2.20]}\end{array}$ & $\begin{array}{r}1.60 \\
{[3.38]}\end{array}$ & $\begin{array}{r}1.63 \\
{[4.50]}\end{array}$ & $\begin{array}{r}1.67 \\
{[6.11]}\end{array}$ \\
\hline
\end{tabular}




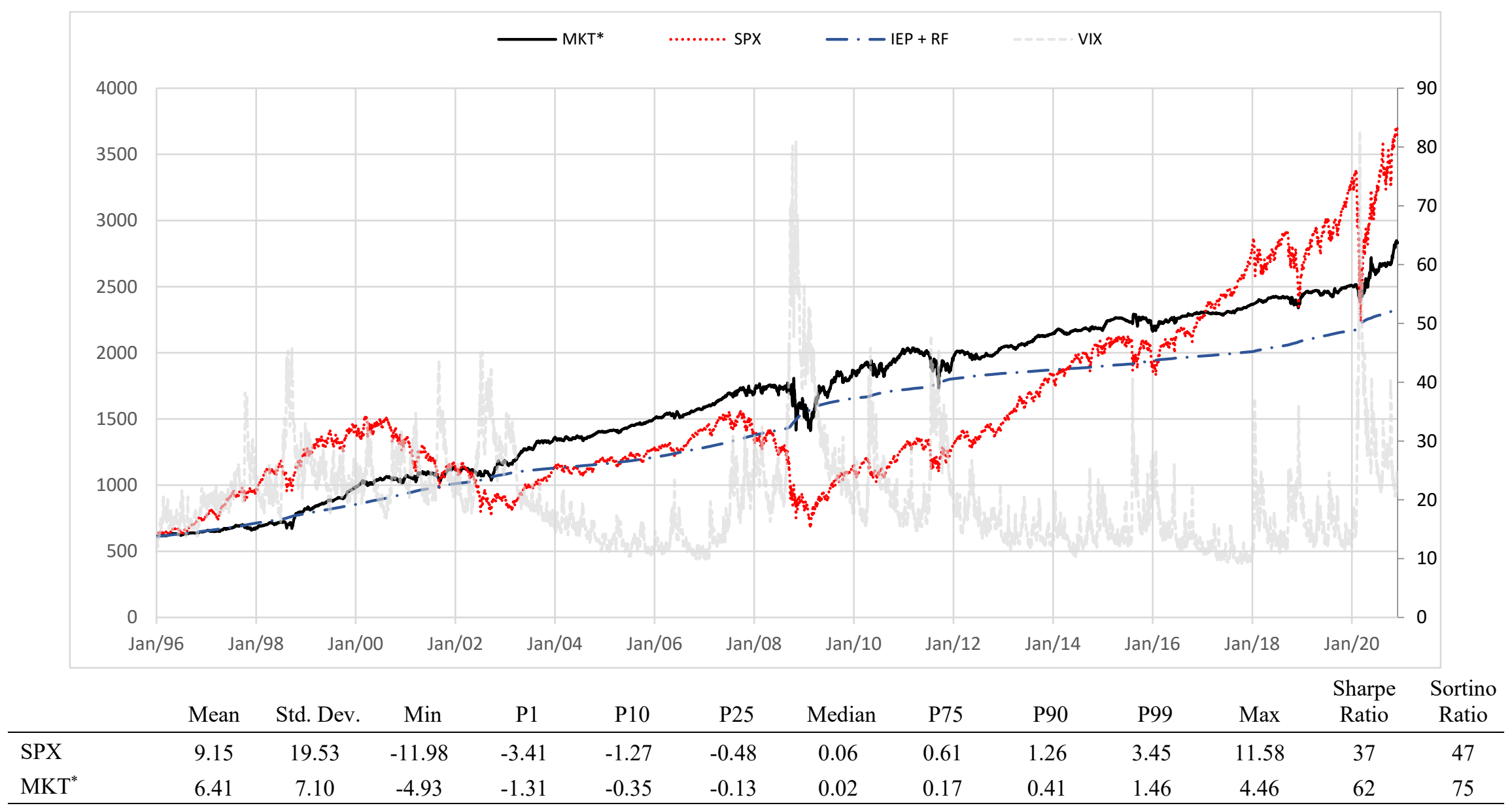

\section{Figure 3}

SPX, MKT*, IEP+RF, and VIX (1996 - 2020)

This figure depicts the daily index value of the S\&P 500 (SPX), the mimicking portfolio of the implied (asymmetry-adjusted) market factor (MKT*), the implied market equity premium plus the risk-free rate (IEP+RF), and the CBOE volatility index (VIX). We set the beginning index value of SPX, MKT*, and IEP+RF at 612 to match the value of the SPX on January 19, 1996. The number on the left y-axis represents the index value, where the right y-axis shows the VIX value. For comparison, the table below the graph provides summary statistics of monthly returns on SPX and MKT*, where the mean and standard deviation are annualized. All numbers in the table are in percentage value. We find the correlation between MKT*, and SPX is 62.22 percent during the sample period. 


\section{Table 5}

\section{Pricing Errors of Implied Market Model}

The table presents the pricing errors of the implied market model (28) corresponding to the implied market beta sorted portfolios. We calculate the index of pricing error (PE) based on the in-sample regression model (29) using the various factor (monthly) returns downloaded from Kenneth R. French's Data Library. Excluding the market factor, our analysis focuses on four conventional models, including (1) FF2 of SMB and HML, (2) FF2+MOM, (3) FF4 adds two more factors RMW and CMA to the FF2, and (4) FF4 + MOM, respectively. We report the PE in basis points (bps) and the adjusted $\mathrm{R}^{2}$ in percentage value. The associated t-statistics of PE are in square brackets.

\begin{tabular}{|c|c|c|c|c|c|c|c|c|}
\hline \multirow[b]{2}{*}{$\begin{array}{l}\text { Implied } \\
\text { Beta }\end{array}$} & \multicolumn{2}{|c|}{ FF2 } & \multicolumn{2}{|c|}{$\mathrm{FF} 2+\mathrm{MOM}$} & \multicolumn{2}{|c|}{ FF4 } & \multicolumn{2}{|c|}{ FF4 + MOM } \\
\hline & $\begin{array}{c}\mathrm{PE} \\
(\mathrm{bps})\end{array}$ & $\begin{array}{r}\text { Adj. } \mathrm{R}^{2} \\
(\%)\end{array}$ & $\begin{array}{c}\mathrm{PE} \\
(\mathrm{bps})\end{array}$ & $\begin{array}{r}\text { Adj. } R^{2} \\
(\%) \\
\end{array}$ & $\begin{array}{c}\mathrm{PE} \\
\text { (bps) }\end{array}$ & $\begin{array}{r}\text { Adj. } \mathrm{R}^{2} \\
(\%)\end{array}$ & $\begin{array}{c}\mathrm{PE} \\
\text { (bps) }\end{array}$ & $\begin{array}{r}\text { Adj. } \mathrm{R}^{2} \\
(\%)\end{array}$ \\
\hline Bottom & $\begin{array}{c}0.46 \\
{[0.02]}\end{array}$ & 0.75 & $\begin{array}{c}-0.75 \\
{[-0.03]}\end{array}$ & 0.44 & $\begin{array}{c}10.66 \\
{[0.47]}\end{array}$ & 3.93 & $\begin{array}{c}9.35 \\
{[0.41]}\end{array}$ & 3.73 \\
\hline 2 & $\begin{array}{c}2.19 \\
{[0.09]}\end{array}$ & 1.81 & $\begin{array}{c}-2.78 \\
{[-0.11]}\end{array}$ & 2.21 & $\begin{array}{c}8.12 \\
{[0.33]}\end{array}$ & 5.36 & $\begin{array}{c}5.62 \\
{[0.23]}\end{array}$ & 5.48 \\
\hline 3 & $\begin{array}{c}4.06 \\
{[0.15]}\end{array}$ & 4.04 & $\begin{array}{c}-3.36 \\
{[-0.13]}\end{array}$ & 5.11 & $\begin{array}{c}6.85 \\
{[0.26]}\end{array}$ & 7.35 & $\begin{array}{c}3.42 \\
{[0.13]}\end{array}$ & 7.75 \\
\hline 4 & $\begin{array}{c}4.95 \\
{[0.18]}\end{array}$ & 5.46 & $\begin{array}{c}-4.17 \\
{[-0.15]}\end{array}$ & 7.14 & $\begin{array}{c}8.79 \\
{[0.32]}\end{array}$ & 9.49 & $\begin{array}{c}4.23 \\
{[0.15]}\end{array}$ & 10.39 \\
\hline 5 & $\begin{array}{c}4.90 \\
{[0.16]}\end{array}$ & 5.64 & $\begin{array}{c}-6.08 \\
{[-0.20]}\end{array}$ & 7.81 & $\begin{array}{c}5.82 \\
{[0.20]}\end{array}$ & 10.85 & $\begin{array}{c}1.05 \\
{[0.04]}\end{array}$ & 11.69 \\
\hline 6 & $\begin{array}{c}5.94 \\
{[0.20]}\end{array}$ & 6.75 & $\begin{array}{c}-3.63 \\
{[-0.13]}\end{array}$ & 8.42 & $\begin{array}{c}7.79 \\
{[0.27]}\end{array}$ & 11.32 & $\begin{array}{c}3.58 \\
{[0.12]}\end{array}$ & 11.94 \\
\hline 7 & $\begin{array}{c}5.79 \\
{[0.20]}\end{array}$ & 7.18 & $\begin{array}{c}-6.01 \\
{[-0.21]}\end{array}$ & 9.91 & $\begin{array}{c}6.30 \\
{[0.22]}\end{array}$ & 13.56 & $\begin{array}{c}1.22 \\
{[0.04]}\end{array}$ & 14.63 \\
\hline 8 & $\begin{array}{c}5.37 \\
{[0.19]}\end{array}$ & 6.03 & $\begin{array}{c}-5.37 \\
{[-0.19]}\end{array}$ & 8.27 & $\begin{array}{c}9.27 \\
{[0.32]}\end{array}$ & 10.74 & $\begin{array}{c}3.87 \\
{[0.13]}\end{array}$ & 12.01 \\
\hline 9 & $\begin{array}{c}6.68 \\
{[0.22]}\end{array}$ & 7.34 & $\begin{array}{c}-4.33 \\
{[-0.14]}\end{array}$ & 9.45 & $\begin{array}{l}11.27 \\
{[0.37]}\end{array}$ & 11.05 & $\begin{array}{c}5.38 \\
{[0.18]}\end{array}$ & 12.43 \\
\hline Top & $\begin{array}{c}1.60 \\
{[0.07]}\end{array}$ & 0.59 & $\begin{array}{c}-2.54 \\
{[-0.01]}\end{array}$ & 0.35 & $\begin{array}{c}9.79 \\
{[0.43]}\end{array}$ & 1.85 & $\begin{array}{c}7.86 \\
{[0.34]}\end{array}$ & 1.81 \\
\hline
\end{tabular}




\section{Table 6}

\section{Return Predictability of Non-market Betas after Controlling Implied Market Beta with MKT*}

This table presents the average monthly excess returns (in percentage value) corresponding to ten different equity groups sorted by an estimated (ex-post) beta coefficient at the beginning of the period, according to the multifactor regression of (31.1). The monthly excess returns are calculated as the compounding daily excess returns in a monthly horizon starting $(t-1)$ and ending $(t)$ on the third Friday of each month. We use daily residual returns $z_{i}$ of the implied market model in (30.2) in the previous 12month horizon to estimate the realized betas, including SMB, HML, RMW, CMA, and MOM, respectively. We compute both the equal- and value-weighted excess returns in the subsequent month for each equity group. The sample consists of all S\&P 500 constituents from January 4, 1996, to December 31, 2020. The notation "Top - Bottom" refers to the difference in returns between the top and bottom decile portfolios. The t-statistics are reported in square brackets where those in bold stand for statistical significance at the five percent level.

\begin{tabular}{|c|c|c|c|c|c|}
\hline $\begin{array}{l}\text { (A) Equal } \\
\text { Weighted }\end{array}$ & $\hat{b}_{i, t-1}^{\mathrm{SMB}}$ & $\hat{b}_{i, t-1}^{\mathrm{HML}}$ & $\hat{b}_{i, t-1}^{\mathrm{RMW}}$ & $\hat{b}_{i, t-1}^{\mathrm{CMA}}$ & $\hat{b}_{i, t-1}^{\mathrm{MOM}}$ \\
\hline Bottom & 1.38 & 1.90 & 1.42 & 1.63 & 1.63 \\
\hline 2 & 1.33 & 1.51 & 1.08 & 1.75 & 1.46 \\
\hline 3 & 1.25 & 1.44 & 1.45 & 1.39 & 1.44 \\
\hline 4 & 1.30 & 1.37 & 1.28 & 1.37 & 1.32 \\
\hline 5 & 1.45 & 1.40 & 1.28 & 1.48 & 1.42 \\
\hline 6 & 1.32 & 1.39 & 1.63 & 1.60 & 1.64 \\
\hline 7 & 1.33 & 1.21 & 1.55 & 1.44 & 1.59 \\
\hline 8 & 1.47 & 1.55 & 1.55 & 1.15 & 1.40 \\
\hline 9 & 1.82 & 1.65 & 1.65 & 1.50 & 1.33 \\
\hline Top & 2.31 & 1.55 & 2.07 & 1.65 & 1.73 \\
\hline \multirow{2}{*}{ Top - Bottom } & 0.93 & -0.35 & 0.65 & 0.02 & 0.10 \\
\hline & [2.26] & {$[-0.65]$} & [1.37] & {$[0.04]$} & {$[0.17]$} \\
\hline \multicolumn{6}{|l|}{$\begin{array}{l}\text { (B) Value } \\
\text { Weighted }\end{array}$} \\
\hline Bottom & 0.76 & 1.03 & 0.50 & 1.06 & 1.24 \\
\hline 2 & 0.89 & 0.88 & 0.73 & 0.76 & 0.78 \\
\hline 3 & 0.79 & 1.06 & 1.24 & 0.87 & 0.92 \\
\hline 4 & 1.08 & 1.07 & 0.69 & 0.70 & 0.84 \\
\hline 5 & 0.97 & 0.93 & 0.85 & 0.94 & 0.89 \\
\hline 6 & 0.81 & 1.17 & 1.25 & 1.31 & 1.23 \\
\hline 7 & 0.96 & 0.93 & 0.84 & 1.20 & 0.86 \\
\hline 8 & 1.09 & 0.96 & 0.73 & 0.58 & 0.92 \\
\hline 9 & 1.16 & 0.87 & 1.12 & 0.95 & 0.94 \\
\hline Top & 1.58 & 0.81 & 1.49 & 0.88 & 1.17 \\
\hline \multirow{2}{*}{ Top - Bottom } & 0.82 & -0.22 & 0.99 & -0.18 & -0.07 \\
\hline & {$[1.59]$} & {$[-0.38]$} & {$[1.83]$} & {$[-0.32]$} & {$[-0.10]$} \\
\hline
\end{tabular}




\section{Table 7}

\section{Downside Loss on Stocks with Sorted Betas}

This table presents the average daily excess returns on stocks with sorted betas in extreme bear/bear market conditions. On the third Friday of December in each year, we form quintile portfolios based on sorted betas. The ex-ante beta coefficients of CAPM, DOWN, and Skew are computed based daily returns on stocks and the MKT index in the past twelve months. The ex-ante MKT* beta (denoted $\beta_{i, t-1}^{\text {MKT }^{*}}$ ) is a plain beta coefficient with our mimicking market portfolio MKT*. We use the twelvemonth option prices to calculate the implied betas. We calculate the average daily excess returns in subsequent extreme bear/bear markets for each group. We use unconditional 1/16 (1/8) quantiles of the market (MKT) return to determine the extreme bear (bear) market. The sample consists of all stocks in S\&P 500 from January 4, 1996 to December 31, 2020.

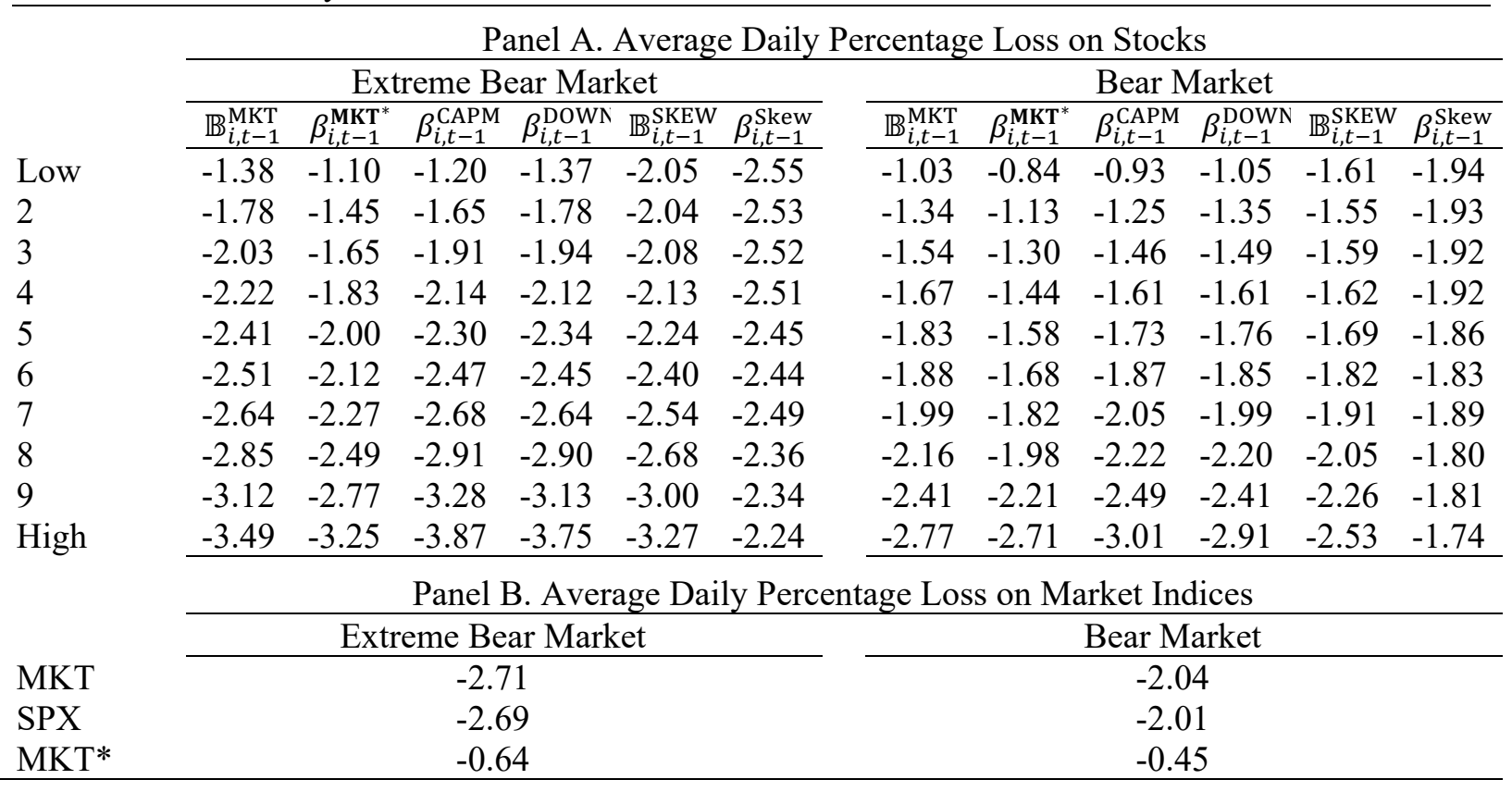


Table 8

\section{Fama-Macbeth Regressions}

This table presents the results from the Fama-MacBeth (1973) cross-sectional regressions of stocks' excess returns on the implied market beta with control for idiosyncratic factors that could explain excess returns on a firm's level. All cross-sectional regressions in (32) are based on a fixed horizon starting and ending on the third Friday of each month. The sample consists of all S\&P 500 stocks from January 4, 1996, to December 31, 2020. The Newey-West (1987) $t$-statistics are reported in square brackets, where those in bold stand for statistical significance at the five percent level.

\begin{tabular}{|c|c|c|c|c|c|}
\hline & $\mathrm{I}$ & II & III & IV & $\mathrm{V}$ \\
\hline Intercept & $\begin{array}{c}0.01 \\
{[1.12]}\end{array}$ & $\begin{array}{c}0.02 \\
{[1.74]}\end{array}$ & $\begin{array}{c}0.02 \\
{[1.77]}\end{array}$ & $\begin{array}{c}0.01 \\
{[1.48]}\end{array}$ & $\begin{array}{c}0.01 \\
{[0.92]}\end{array}$ \\
\hline$\beta_{i, t-1}^{\mathrm{CAPM}}$ & $\begin{array}{c}-0.11 \\
{[-0.32]}\end{array}$ & & & & \\
\hline $\mathbb{B}_{i, t-1}^{\mathrm{MKT}}$ & & $\begin{array}{c}0.20 \\
{[3.09]}\end{array}$ & & & \\
\hline $\mathbb{B}_{i, t-1}^{S V I X}$ & & & $\begin{array}{c}\mathbf{0 . 2 7} \\
{[3.02]}\end{array}$ & & \\
\hline $\mathbb{B}_{i, t-1}^{\mathrm{AVIX}}$ & & & & $\begin{array}{c}0.05 \\
{[2.38]}\end{array}$ & \\
\hline $\mathbb{B}_{i, t-1}^{\text {SKEW }}$ & & & & & $\begin{array}{c}-0.05 \\
{[-0.78]}\end{array}$ \\
\hline Past 1-month XR & $\begin{array}{c}-0.01 \\
{[-2.17]}\end{array}$ & $\begin{array}{c}-0.01 \\
{[-1.89]}\end{array}$ & $\begin{array}{c}-0.01 \\
{[-1.81]}\end{array}$ & $\begin{array}{c}-0.01 \\
{[-2.05]}\end{array}$ & $\begin{array}{c}-0.02 \\
{[-2.38]}\end{array}$ \\
\hline Past 12-month XR & $\begin{array}{c}-0.04 \\
{[-0.55]}\end{array}$ & $\begin{array}{c}-0.01 \\
{[-0.08]}\end{array}$ & $\begin{array}{c}-0.01 \\
{[-0.09]}\end{array}$ & $\begin{array}{c}-0.01 \\
{[-0.10]}\end{array}$ & $\begin{array}{c}-0.01 \\
{[-0.11]}\end{array}$ \\
\hline Log (Size) & $\begin{array}{c}-0.57 \\
{[-2.18]}\end{array}$ & $\begin{array}{c}-0.34 \\
{[-1.35]}\end{array}$ & $\begin{array}{c}-0.32 \\
{[-1.27]}\end{array}$ & $\begin{array}{c}-0.31 \\
{[-1.60]}\end{array}$ & $\begin{array}{c}-0.56 \\
{[-2.13]}\end{array}$ \\
\hline $\mathrm{B} / \mathrm{M}$ & $\begin{array}{c}0.17 \\
{[1.74]}\end{array}$ & $\begin{array}{c}0.17 \\
{[1.66]}\end{array}$ & $\begin{array}{c}0.17 \\
{[1.68]}\end{array}$ & $\begin{array}{c}0.17 \\
{[1.61]}\end{array}$ & $\begin{array}{c}0.16 \\
{[1.59]}\end{array}$ \\
\hline Standard deviation & $\begin{array}{c}0.57 \\
{[3.14]}\end{array}$ & $\begin{array}{c}0.25 \\
{[1.25]}\end{array}$ & $\begin{array}{c}0.22 \\
{[1.10]}\end{array}$ & $\begin{array}{c}0.24 \\
{[1.64]}\end{array}$ & $\begin{array}{c}0.47 \\
{[2.37]}\end{array}$ \\
\hline Skewness & $\begin{array}{c}0.04 \\
{[1.07]}\end{array}$ & $\begin{array}{c}0.03 \\
{[0.71]}\end{array}$ & $\begin{array}{c}0.03 \\
{[0.71]}\end{array}$ & $\begin{array}{c}0.03 \\
{[0.71]}\end{array}$ & $\begin{array}{c}0.03 \\
{[0.70]}\end{array}$ \\
\hline Kurtosis & $\begin{array}{c}-0.12 \\
{[-2.09]}\end{array}$ & $\begin{array}{c}-0.09 \\
{[-1.27]}\end{array}$ & $\begin{array}{c}-0.08 \\
{[-1.19]}\end{array}$ & $\begin{array}{c}-0.08 \\
{[-1.46]}\end{array}$ & $\begin{array}{c}-0.10 \\
{[-1.48]}\end{array}$ \\
\hline Maximum Monthly XR & $\begin{array}{c}0.01 \\
{[0.15]}\end{array}$ & $\begin{array}{c}0.03 \\
{[0.48]}\end{array}$ & $\begin{array}{c}0.03 \\
{[0.47]}\end{array}$ & $\begin{array}{c}0.04 \\
{[0.56]}\end{array}$ & $\begin{array}{c}0.04 \\
{[0.64]}\end{array}$ \\
\hline Minimum Monthly XR & $\begin{array}{c}0.09 \\
{[0.78]}\end{array}$ & $\begin{array}{c}0.13 \\
{[1.06]}\end{array}$ & $\begin{array}{c}0.13 \\
{[1.07]}\end{array}$ & $\begin{array}{c}0.12 \\
{[1.02]}\end{array}$ & $\begin{array}{c}0.10 \\
{[0.80]}\end{array}$ \\
\hline Log (Trading volume) & $\begin{array}{c}0.13 \\
{[0.50]}\end{array}$ & $\begin{array}{c}-0.02 \\
{[-0.12]}\end{array}$ & $\begin{array}{c}-0.04 \\
{[-0.20]}\end{array}$ & $\begin{array}{c}0.04 \\
{[0.18]}\end{array}$ & $\begin{array}{c}0.15 \\
{[0.63]}\end{array}$ \\
\hline
\end{tabular}




\section{Table 9}

\section{Comparative Analysis of Return Predictability: AVIX-Beta vs. Alternative Implied Betas}

This table presents the average monthly excess returns (in percentage value) for twenty-five different equity groups double-sorted by the AVIX-beta vs. an alternative implied beta. The monthly excess returns are calculated as the compounding daily excess returns in a monthly horizon starting $(t-1)$ and ending $(t)$ on the third Friday of each month. We compute the implied betas, including AVIX, SVIX, SKEW, USK, and LSK, using option prices on the third Friday of the month. In each section, we first sort stocks into quintiles based on betas on the left, and then in each quintile, we sort stocks based on betas on the top. We compute the equal-weighted excess returns in the subsequent horizon for each equity group. The sample consists of all S\&P 500 constituents from January 4, 1996, to December 31, 2020. The notation " $5-1$ " refers to the difference in the excess returns between portfolio five and portfolio one. The numbers in bold stand for statistical significance at the five percent level.

\begin{tabular}{|c|c|c|c|c|c|c|c|c|c|c|c|c|c|}
\hline \multirow[b]{2}{*}{$\mathbb{B}_{t-1}^{\mathrm{AVIX}}$} & \multicolumn{6}{|c|}{$\mathbb{B}_{t-1}^{\text {SVIX }}$} & \multicolumn{7}{|c|}{$\mathbb{B}_{t-1}^{\mathrm{AVIX}}$} \\
\hline & 1 & 2 & 3 & 4 & 5 & $5-1$ & $\mathbb{B}_{t-1}^{\text {SVIX }}$ & 1 & 2 & 3 & 4 & 5 & $5-1$ \\
\hline 1 & 0.61 & 0.59 & 0.63 & 0.68 & 0.84 & 0.23 & 1 & 0.58 & 0.57 & 0.67 & 0.71 & 0.83 & 0.24 \\
\hline 2 & 0.83 & 0.87 & 0.97 & 1.00 & 0.96 & 0.13 & 2 & 0.73 & 0.82 & 1.04 & 0.99 & 1.17 & 0.44 \\
\hline 3 & 1.19 & 1.00 & 0.99 & 1.09 & 1.19 & 0.00 & 3 & 1.02 & 1.06 & 0.99 & 1.09 & 1.17 & 0.15 \\
\hline 4 & 1.24 & 1.11 & 1.36 & 1.49 & 1.38 & 0.14 & 4 & 1.11 & 1.13 & 1.48 & 1.36 & 1.66 & 0.55 \\
\hline 5 & 1.78 & 1.39 & 1.65 & 1.97 & 2.93 & 1.15 & 5 & 1.56 & 1.60 & 1.41 & 1.95 & 2.99 & 1.43 \\
\hline $5-1$ & 1.17 & 0.80 & 1.02 & 1.29 & 2.09 & & $5-1$ & 0.98 & 1.03 & 0.73 & 1.24 & 2.17 & \\
\hline \multicolumn{7}{|c|}{$\mathbb{B}_{t-1}^{\text {SKEW }}$} & \multicolumn{7}{|c|}{$\mathbb{B}_{t-1}^{\mathrm{AVIX}}$} \\
\hline $\mathbb{B}_{t-1}^{\mathrm{AVIX}}$ & 1 & 2 & 3 & 4 & 5 & $5-1$ & $\mathbb{B}_{t-1}^{\text {SKEW }}$ & 1 & 2 & 3 & 4 & 5 & $5-1$ \\
\hline 1 & 0.80 & 0.74 & 0.61 & 0.64 & 0.57 & -0.23 & 1 & 0.82 & 1.14 & 1.28 & 1.63 & 2.32 & 1.51 \\
\hline 2 & 1.21 & 0.98 & 0.95 & 0.88 & 0.76 & -0.45 & 2 & 0.56 & 0.73 & 0.86 & 1.09 & 1.26 & 0.70 \\
\hline 3 & 1.38 & 0.98 & 1.02 & 1.13 & 0.85 & -0.53 & 3 & 0.62 & 0.81 & 0.88 & 1.07 & 1.68 & 1.06 \\
\hline 4 & 1.57 & 1.47 & 1.43 & 1.24 & 1.07 & -0.50 & 4 & 0.77 & 0.96 & 1.11 & 1.31 & 1.48 & 0.71 \\
\hline 5 & 2.28 & 1.69 & 1.67 & 1.98 & 1.92 & -0.36 & 5 & 0.81 & 1.16 & 1.12 & 1.61 & 2.59 & 1.78 \\
\hline $5-1$ & 1.48 & 0.95 & 1.06 & 1.34 & 1.35 & & $5-1$ & -0.01 & 0.02 & -0.17 & -0.03 & 0.26 & \\
\hline \multicolumn{7}{|c|}{$\mathbb{B}_{t-1}^{\mathrm{USK}}$} & \multicolumn{7}{|c|}{$\mathbb{B}_{t-1}^{A V I X}$} \\
\hline $\mathbb{B}_{t-1}^{\mathrm{AVIX}}$ & 1 & 2 & 3 & 4 & 5 & $5-1$ & $\mathbb{B}_{t-1}^{\mathrm{USK}}$ & 1 & 2 & 3 & 4 & 5 & $5-1$ \\
\hline 1 & 0.60 & 0.59 & 0.64 & 0.67 & 0.65 & 0.05 & 1 & 0.60 & 0.52 & 0.66 & 0.73 & 0.83 & 0.23 \\
\hline 2 & 0.89 & 0.92 & 0.88 & 1.13 & 0.91 & 0.02 & 2 & 0.69 & 0.79 & 0.97 & 1.17 & 1.11 & 0.41 \\
\hline 3 & 1.12 & 1.01 & 1.02 & 1.17 & 0.96 & -0.16 & 3 & 0.92 & 0.90 & 1.05 & 1.18 & 1.29 & 0.37 \\
\hline 4 & 1.31 & 1.24 & 1.37 & 1.50 & 1.44 & 0.13 & 4 & 0.95 & 1.23 & 1.30 & 1.51 & 1.76 & 0.81 \\
\hline 5 & 1.64 & 1.58 & 1.63 & 1.88 & 2.97 & 1.33 & 5 & 1.29 & 1.58 & 1.87 & 1.74 & 3.03 & 1.74 \\
\hline $5-1$ & 1.04 & 0.98 & 0.99 & 1.21 & 2.32 & & $5-1$ & 0.70 & 1.06 & 1.22 & 1.01 & 2.20 & \\
\hline \multicolumn{7}{|c|}{$\mathbb{B}_{t-1}^{\text {LSK }}$} & \multicolumn{7}{|c|}{$\mathbb{B}_{t-1}^{\mathrm{AVIX}}$} \\
\hline $\mathbb{B}_{t-1}^{\mathrm{AVIX}}$ & 1 & 2 & 3 & 4 & 5 & $5-1$ & $\mathbb{B}_{t-1}^{\mathrm{LSK}}$ & 1 & 2 & 3 & 4 & 5 & $5-1$ \\
\hline 1 & 0.62 & 0.67 & 0.68 & 0.69 & 0.67 & 0.05 & 1 & 0.60 & 0.60 & 0.65 & 0.73 & 1.02 & 0.41 \\
\hline 2 & 1.07 & 0.99 & 0.94 & 0.91 & 0.82 & -0.25 & 2 & 0.74 & 0.91 & 0.81 & 1.19 & 1.06 & 0.32 \\
\hline 3 & 1.23 & 1.12 & 1.11 & 0.95 & 0.94 & -0.29 & 3 & 0.93 & 1.00 & 1.00 & 1.19 & 1.35 & 0.41 \\
\hline 4 & 1.37 & 1.38 & 1.41 & 1.37 & 1.24 & -0.13 & 4 & 1.00 & 1.21 & 1.22 & 1.51 & 1.79 & 0.79 \\
\hline 5 & 1.59 & 1.49 & 1.86 & 1.76 & 2.83 & 1.25 & 5 & 1.13 & 1.50 & 1.65 & 1.94 & 2.95 & 1.82 \\
\hline $5-1$ & 0.96 & 0.82 & 1.18 & 1.07 & 2.16 & & $5-1$ & 0.52 & 0.90 & 1.00 & 1.21 & 1.93 & \\
\hline
\end{tabular}


Table 10

\section{Comparative Analysis of Return Predictability:}

AVIX-Beta vs. Realized Betas

This table presents the average monthly excess returns (in percentage value) for twenty-five different equity groups double-sorted by the AVIX-beta vs. one of the realized betas. The monthly excess returns are calculated as the compounding daily excess returns in a monthly horizon starting $(t-1)$ and ending $(t)$ on the third Friday of each month. We compute the AVIX beta using option prices on the third Friday of the month. To calculate the (ex-post) realized betas, including CAPM, Skew, DOWN, and SMB, we use daily returns in the previous 12-momth horizon. In each section, we first sort stocks into quintiles based on betas on the left, and then in each quintile, we sort stocks based on betas on the top. We compute the equal-weighted excess returns in the subsequent horizon for each equity group. The sample consists of all S\&P 500 constituents from January 4, 1996, to December 31, 2020. The notation "5 - 1" refers to the difference in the excess returns between portfolio five and portfolio one. The numbers in bold stand for statistical significance at the five percent level.

\begin{tabular}{|c|c|c|c|c|c|c|c|c|c|c|c|c|c|}
\hline \multirow[b]{2}{*}{$\mathbb{B}_{t-1}^{A V I X}$} & \multicolumn{5}{|c|}{$\beta_{t-1}^{\text {CAPM }}$} & & \multicolumn{7}{|c|}{$\mathbb{B}_{t-1}^{\mathrm{AVIX}}$} \\
\hline & 1 & 2 & 3 & 4 & 5 & $5-1$ & $\beta_{t-1}^{\text {CAPM }}$ & 1 & 2 & 3 & 4 & 5 & $5-1$ \\
\hline 1 & 0.63 & 0.71 & 0.66 & 0.54 & 0.80 & 0.18 & 1 & 0.69 & 0.69 & 0.83 & 0.84 & 1.23 & 0.54 \\
\hline 2 & 0.94 & 0.87 & 0.92 & 1.11 & 0.91 & -0.03 & 2 & 0.55 & 0.86 & 1.11 & 1.10 & 1.55 & 1.00 \\
\hline 3 & 0.97 & 1.13 & 1.22 & 1.01 & 1.02 & 0.05 & 3 & 0.63 & 0.98 & 1.19 & 1.27 & 1.53 & 0.90 \\
\hline 4 & 1.16 & 1.44 & 1.45 & 1.40 & 1.31 & 0.15 & 4 & 0.81 & 1.09 & 1.19 & 1.69 & 2.01 & 1.20 \\
\hline 5 & 1.80 & 1.86 & 1.86 & 1.87 & 2.16 & 0.35 & 5 & 1.09 & 1.02 & 1.47 & 1.47 & 2.76 & 1.67 \\
\hline $5-1$ & 1.18 & 1.15 & 1.20 & 1.33 & 1.35 & & $5-1$ & 0.39 & 0.34 & 0.63 & 0.63 & 1.53 & \\
\hline \multicolumn{7}{|c|}{$\beta_{t-1}^{\text {Skew }}$} & \multicolumn{7}{|c|}{$\mathbb{B}_{t-1}^{\mathrm{AVIX}}$} \\
\hline $\mathbb{B}_{t-1}^{A V I X}$ & 1 & 2 & 3 & 4 & 5 & $5-1$ & $\beta_{t-1}^{\text {Skew }}$ & 1 & 2 & 3 & 4 & 5 & $5-1$ \\
\hline 1 & 0.71 & 0.75 & 0.71 & 0.59 & 0.59 & -0.12 & 1 & 0.83 & 1.12 & 1.11 & 1.36 & 2.15 & 1.32 \\
\hline 2 & 0.97 & 0.96 & 0.99 & 1.07 & 0.77 & -0.20 & 2 & 0.67 & 0.93 & 1.18 & 1.47 & 2.22 & 1.56 \\
\hline 3 & 1.04 & 1.03 & 1.16 & 1.12 & 1.00 & -0.04 & 3 & 0.73 & 1.09 & 1.31 & 1.38 & 2.22 & 1.48 \\
\hline 4 & 1.29 & 1.36 & 1.67 & 1.30 & 1.16 & -0.13 & 4 & 0.79 & 0.94 & 1.07 & 1.19 & 1.65 & 0.86 \\
\hline 5 & 2.11 & 2.17 & 1.86 & 1.81 & 1.64 & -0.47 & 5 & 0.53 & 0.77 & 0.75 & 0.87 & 1.32 & 0.79 \\
\hline $5-1$ & 1.40 & 1.42 & 1.15 & 1.22 & 1.05 & & $5-1$ & -0.31 & -0.35 & -0.36 & -0.49 & -0.83 & \\
\hline \multicolumn{7}{|c|}{$\beta_{t-1}^{\text {DOWN }}$} & \multicolumn{7}{|c|}{$\mathbb{B}_{t-1}^{A V I X}$} \\
\hline $\mathbb{B}_{t-1}^{A V I X}$ & 1 & 2 & 3 & 4 & 5 & $5-1$ & $\beta_{t-1}^{\text {DOWN }}$ & 1 & 2 & 3 & 4 & 5 & $5-1$ \\
\hline 1 & 0.68 & 0.66 & 0.56 & 0.70 & 0.73 & 0.05 & 1 & 0.64 & 0.66 & 0.78 & 0.90 & 1.52 & 0.88 \\
\hline 2 & 0.86 & 0.91 & 1.04 & 1.08 & 0.86 & 0.00 & 2 & 0.67 & 0.81 & 1.20 & 1.09 & 1.24 & 0.57 \\
\hline 3 & 0.89 & 1.27 & 1.06 & 1.00 & 1.12 & 0.23 & 3 & 0.73 & 1.02 & 1.02 & 1.26 & 1.96 & 1.23 \\
\hline 4 & 1.30 & 1.29 & 1.64 & 1.30 & 1.24 & -0.06 & 4 & 0.85 & 1.17 & 1.34 & 1.28 & 1.74 & 0.89 \\
\hline 5 & 1.93 & 1.73 & 1.65 & 2.02 & 2.20 & 0.27 & 5 & 0.94 & 1.00 & 1.52 & 1.70 & 2.59 & 1.65 \\
\hline $5-1$ & 1.25 & 1.08 & 1.09 & 1.32 & 1.47 & & $5-1$ & 0.30 & 0.34 & 0.75 & 0.80 & 1.08 & \\
\hline \multicolumn{7}{|c|}{$\beta_{t-1}^{\text {SMB }}$} & \multicolumn{7}{|c|}{$\mathbb{B}_{t-1}^{\mathrm{AVIX}}$} \\
\hline $\mathbb{B}_{t-1}^{A V I X}$ & 1 & 2 & 3 & 4 & 5 & $5-1$ & $\beta_{t-1}^{S M B}$ & 1 & 2 & 3 & 4 & 5 & $5-1$ \\
\hline 1 & 0.61 & 0.57 & 0.68 & 0.68 & 0.80 & 0.19 & 1 & 0.52 & 0.65 & 1.02 & 0.92 & 1.71 & 1.19 \\
\hline 2 & 0.80 & 0.91 & 1.02 & 1.00 & 1.01 & 0.21 & 2 & 0.69 & 0.80 & 0.85 & 0.95 & 1.46 & 0.77 \\
\hline 3 & 0.88 & 1.07 & 0.91 & 1.11 & 1.37 & 0.49 & 3 & 0.75 & 1.07 & 1.08 & 1.09 & 1.30 & 0.55 \\
\hline 4 & 1.26 & 1.26 & 1.27 & 1.48 & 1.51 & 0.25 & 4 & 0.86 & 1.04 & 1.08 & 1.40 & 1.79 & 0.93 \\
\hline 5 & 1.63 & 1.64 & 1.79 & 1.80 & 2.67 & 1.04 & 5 & 1.02 & 1.44 & 1.65 & 1.84 & 2.70 & 1.69 \\
\hline $5-1$ & 1.02 & 1.07 & 1.11 & 1.12 & 1.87 & & $5-1$ & $\mathbf{0 . 5 0}$ & $\mathbf{0 . 8 0}$ & 0.63 & 0.92 & 0.99 & \\
\hline
\end{tabular}




\section{References}

Ang, A., Chen, J., \& Xing, Y. (2006). Downside risk. The Review of Financial Studies, 19(4), 1191-1239.

Bali, T. G., Cakici, N., \& Whitelaw, R. F. (2011). Maxing out: Stocks as lotteries and the crosssection of expected returns. Journal of Financial Economics, 99(2), 427-446.

Carhart, M. M. (1997). On persistence in mutual fund performance. The Journal of Finance, 52(1), 57-82.

Chabi-Yo, F., Leisen, D. P., \& Renault, E. (2014). Aggregation of preferences for skewed asset returns. Journal of Economic Theory, 154, 453-489.

Chabi-Yo, F., \& Loudis, J. (2020). The conditional expected market return. Journal of Financial Economics, 137, 752-786.

Dittmar, R. F. (2002). Nonlinear pricing kernels, kurtosis preference, and evidence from the cross section of equity returns. The Journal of Finance, 57(1), 369-403.

Fama, E. F., \& French, K. R. (1992). The cross-section of expected stock returns. The Journal of Finance, 47(2), 427-465.

Fama, E. F., \& French, K. R. (2015). A five-factor asset pricing model. Journal of Financial Economics, 116(1), 1-22.

Fama, E. F., \& MacBeth, J. D. (1973). Risk, return, and equilibrium: Empirical tests. Journal of Political Economy, 81(3), 607-636.

Harvey, C. R., \& Siddique, A. (2000). Conditional skewness in asset pricing tests. The Journal of finance, 55(3), 1263-1295.

Jegadeesh, N. (1990). Evidence of predictable behavior of security returns. The Journal of Finance, 45(3), 881-898.

Jegadeesh, N., \& Titman, S. (1993). Returns to buying winners and selling losers: Implications for stock market efficiency. The Journal of Finance, 48(1), 65-91.

Kadan, O., \& Tang, X. (2020). A bound on expected stock returns. The Review of Financial Studies, 33(4), 1565-1617. 
Knez, P. J., \& Ready, M. J. (1997). On the robustness of size and book-to-market in crosssectional regressions. The Journal of Finance, 52(4), 1355-1382.

Kremens, L., and Martin, I., (2019). The quanto theory of exchange rates, American Economic Review, 109, 810-843.

Lehmann, B. N. (1990). Fads, martingales, and market efficiency. The Quarterly Journal of Economics, 105(1), 1-28.

Levi, Y., \& Welch, I. (2020). Symmetric and asymmetric market betas and downside risk. The Review of Financial Studies, 33(6), 2772-2795.

Liu, Y. (2021). "Index option returns and generalized entropy bounds." Journal of Financial Economics, 139 (3), 1015-1036.

Martin, I. (2017). What is the expected return on the market? The Quarterly Journal of Economics, 132(1), 367-433.

Martin, I. W., \& Wagner, C. (2019). What is the Expected Return on a Stock? The Journal of Finance, 74(4), 1887-1929.

Newey, W., \& West, K. (1987), A simple positive semi-definite, heteroskedasticity and autocorrelation consistent covariance matrix, Econometrica, 55, 703-708.

Post, T. (2003). Empirical tests for stochastic dominance efficiency. The Journal of Finance, 58(5), 1905-1931.

Pulley, L. B. (1983). "Mean-variance approximations to expected logarithmic utility." Operations Research, 31(4), 685-696.

Roll, R. (1977), "A critique of the asset pricing theory's tests Part I: On past and potential testability of the theory", Journal of Financial Economics, 4 (2): 129-176.

Schneider, P., Wagner, C., and Zechner, J. (2020). Low-risk anomalies? The Journal of Finance, 75(5), 2673-2718.

Schneider, P., \& Trojani, F. (2015). Fear trading. Swiss Finance Institute Research Paper, (1503 ). 